\title{
Infection prevention in intensive care patients: probiotics compared to antibiotics
}

Citation for published version (APA):

Oudhuis, G. J. A. P. M. (2012). Infection prevention in intensive care patients: probiotics compared to antibiotics. [Doctoral Thesis, Maastricht University]. Datawyse / Universitaire Pers Maastricht. https://doi.org/10.26481/dis.20120217go

Document status and date:

Published: 01/01/2012

DOI:

10.26481/dis.20120217go

Document Version:

Publisher's PDF, also known as Version of record

\section{Please check the document version of this publication:}

- A submitted manuscript is the version of the article upon submission and before peer-review. There can be important differences between the submitted version and the official published version of record.

People interested in the research are advised to contact the author for the final version of the publication, or visit the DOI to the publisher's website.

- The final author version and the galley proof are versions of the publication after peer review.

- The final published version features the final layout of the paper including the volume, issue and page numbers.

Link to publication

\footnotetext{
General rights rights.

- You may freely distribute the URL identifying the publication in the public portal. please follow below link for the End User Agreement:

www.umlib.nl/taverne-license

Take down policy

If you believe that this document breaches copyright please contact us at:

repository@maastrichtuniversity.nl

providing details and we will investigate your claim.
}

Copyright and moral rights for the publications made accessible in the public portal are retained by the authors and/or other copyright owners and it is a condition of accessing publications that users recognise and abide by the legal requirements associated with these

- Users may download and print one copy of any publication from the public portal for the purpose of private study or research.

- You may not further distribute the material or use it for any profit-making activity or commercial gain

If the publication is distributed under the terms of Article $25 \mathrm{fa}$ of the Dutch Copyright Act, indicated by the "Taverne" license above, 


\section{Infection prevention in Intensive Care patients: probiotics compared to antibiotics}


(C) Guy J Oudhuis, Maastricht 2012

Layout: Tiny Wouters

Cover design: Roger Haan, ontwerpstudiohaan.nl

Production: Datawyse | Universitaire Pers Maastricht

ISBN: 9789461591128

The research in this thesis was financially supported by ZonMw (The Netherlands organisation for health research and development), grant no. 6100.0007 .

Printing of this thesis was financially supported by Maastricht University Medical Centre ${ }^{+}$. 


\title{
Infection prevention in Intensive Care
}

\author{
patients: probiotics compared to
}

\author{
antibiotics
}

\author{
PROEFSCHRIFT \\ Ter verkrijging van de graad van doctor \\ aan de Universiteit Maastricht, \\ op gezag van de Rector Magnificus, \\ Prof. mr. G.P.M.F. Mols, \\ volgens het besluit van het College van Decanen, \\ in het openbaar te verdedigen \\ op vrijdag 17 februari 2012 om 14.00 uur \\ door \\ Guy Joseph Alphonse Pierre Marie Oudhuis \\ geboren op 11 april 1981 te Roosendaal
}

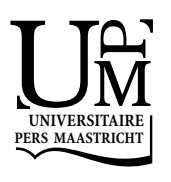


Promotor

Prof. dr. C.A. Bruggeman

\section{Copromotores}

Dr. E.E. Stobberingh

Dr. A. Verbon (Erasmus MC, Rotterdam)

\section{Beoordelingscommissie}

Prof. dr. C.H.C. Dejong (voorzitter)

Prof. dr. A.A.M. Masclee

Prof. dr. F. van Schooten

Prof. dr. E.F.M. Wouters 
For the ones I love 



\section{Contents}

Chapter 1 General introduction and outline of the thesis 9

Chapter 2 Antimicrobial resistance in Escherichia coli and Pseudomonas aeruginosa from Intensive Care Units in The Netherlands, 1998-2005

Chapter 3 Soluble Triggering Receptor Expressed on Myeloid cells-1 in bronchoalveolar lavage fluid is not predictive for ventilatorassociated pneumonia

Chapter 4 Probiotics versus antibiotic decontamination of the digestive tract: infection and mortality

Chapter 5 Antibiotic resistance among E. coli isolates of Intensive Care patients receiving selective digestive tract decontamination or probiotics

Chapter 6 Infection prevention in Intensive Care patients using the probiotic Lactobacillus plantarum 299/299v

Chapter $7 \quad$ General discussion and future perspectives

Summary

Samenvatting

Dankwoord

Curriculum vitae

List of publications

List of abbreviations 



\section{Chapter 1}

General introduction and outline of the thesis

Partially published in:

Curr Opin Crit Care 2011;17:487-492 
| Chapter 1 


\section{Setting: the Intensive Care}

Patients admitted to an Intensive Care Unit (ICU) of a hospital are, due to their underlying illness or exogenous factors such as trauma, prone to develop a nosocomial (i.e. hospital-acquired) infection. Several patient-related factors contribute to the increased morbidity such as, amongst others, breaches in natural barrier function through the use of intravascular devices and mechanical ventilation (MV) support ${ }^{1}$. Due to the severe underlying condition(s), mortality among ICU patients is already high, i.e. $11-17 \%^{2,3}$. Infections, as the most common complications associated with hospitalisation ${ }^{4}$, with an estimated prevalence of $17-51 \%^{2,3,5}$, lead to an even further increased mortality, length of stay and healthcare costs ${ }^{6}$. Excess mortality depends on the patient's age, underlying condition, severity of the illness, type of infection, causative pathogen and adequacy of therapy ${ }^{7}$. Mortality rates range from around $20 \%{ }^{8,9}$ to as high as $40 \%^{10,11}$. Excess length of hospitalisation and extra hospital costs also depend on the type and site of infection ${ }^{12-15}$. In case of ventilatorassociated pneumonia (VAP) the average length of ICU stay increased with a mean of six days, against an additional cost of $\$ 10,000^{10}$. Effective infection prevention can lead to substantial savings of patients' lives and healthcare resources, when employed as soon as possible after admission ${ }^{16}$. The same could hold true for rapid diagnostic biomarkers for VAP. Therefore, a number of biomarkers as well as methods aimed at infection prevention have been developed and evaluated. Not all with the same amount of success, as will be shortly discussed here.

\section{Biomarkers for the diagnosis of ventilator-associated pneumonia}

The past fifteen years, a number of potential biomarkers have been proposed for use in determining the diagnosis for patients with VAP in a rapid fashion, with contradictory results ${ }^{17}$. Difficulties for diagnosing VAP lead to potential over- or underprescription of antibiotics and misguided treatment ${ }^{17}$. The negative association between delayed diagnosis, delayed initiation of treatment and outcome or between inappropriate initial antibiotic therapy and outcome are well documented ${ }^{18}$. Although initial studies showed promising results ${ }^{19,20}$, recent studies suggest that measurement of biomarkers, like procalcitonin ${ }^{21}$, soluble Triggering Receptor Expressed on Myeloid cells-1 (sTREM-1) $)^{22}$ or Clara cell protein $10^{23}$, have poor diagnostic value for VAP. 


\section{Preventive strategies}

Evaluation of the semirecumbent position (of $45^{\circ}$ ) as preventive measure against VAP yielded conflicting results. One research group concluded that it reduced the risk of nosocomial pneumonia ${ }^{24}$, whereas others reported that the targeted elevation was not reached. The achieved difference in treatment position (compared to standard care) did not prevent development of $\mathrm{VAP}^{25}$. Although clinical results looked promising in reducing the risk of $\mathrm{VAP}^{26-29}$, concerns were raised about the safety of (continuous) subglottic secretion drainage, since injuries to tracheal (sub)mucosa, caused by the use of the special tube, have been reported ${ }^{30-32}$.

Oral or oropharyngeal application of chlorhexidine, another preventive strategy, was effective in reducing the incidence of lower respiratory tract infections including VAP in some studies ${ }^{33,34}$, although not in others ${ }^{35}$. In a recent meta-analysis, antiseptic oral decontamination prophylaxis reduced the incidence of VAP, although it did not affect mortality $^{36}$.

The above-mentioned measures mainly focus on prevention of pneumonia in the aero-digestive region, and do not take into account the (lower) gastrointestinal (GI) tract. However, there is accumulating evidence that the $\mathrm{Gl}$ tract serves as an important reservoir for bacteria that cause all kinds of nosocomial infections, including pneumonia ${ }^{37-40}$.

\section{The changed gastrointestinal tract of ICU patients}

The normal human GI tract harbours over 500 bacterial species, in an amount of $10^{14}$ bacteria, the indigenous gut microbiota ${ }^{41}$. Potentially pathogenic microorganisms (PPMs) like Enterobacteriaceae, Pseudomonadaceae, Staphylococcus aureus and yeasts normally constitute a small part of the gut microbiota in healthy individuals. The mainly anaerobic flora limits colonisation with these PPMs through a mechanism called colonisation resistance, together with other mechanisms like salivary flow, gastric acidity, bile acids, secretory $\operatorname{lgA}$, and peristalsis ${ }^{42}$. Other functions of the microbiota are modulation of local and systemic immunity, feeding of enterocytes, and maintenance of intestinal motility and mucus secretion ${ }^{43-45}$.

However, PPMs can become dominant and subsequently cause infection in (critically) ill patients. The majority of nosocomial infections are caused by PPMs via the so-called endogenous route ${ }^{46,47}$, possibly through the process of microbial translocation. Translocation is the passage of viable bacteria through the epithelial mucosa of the GI tract ${ }^{48,49}$. It is promoted by decreased intestinal motility, jaundice and antibiotic use leading to bacterial overgrowth ${ }^{50}$. Increased mucosal permeability due to malnutrition, manipulation of the bowel and parenteral nutrition ${ }^{51}$ and (local) immune system deficiencies of the host have also been described ${ }^{52,53}$. Bacterial translocation is 
associated with a significant increase in (postoperative) bacterial infections and sepsis in patients undergoing surgery ${ }^{54,55}$.

The two most extensively studied prophylactic methods targeting the Gl tract for infection prevention, i.e. selective decontamination of the digestive tract (SDD) and probiotics, will be presented in more detail in the following paragraphs.

\section{Selective decontamination of the digestive tract}

\section{Background}

SDD aims at elimination of PPMs from the upper and lower GI tract and oropharynx using antibiotics to prevent primary and secondary endogenous infections, while leaving the indigenous anaerobic flora intact. SDD was first described by Van der Waaij et al. in the 1970s and introduced in an ICU setting (i.e. multi-trauma patients) by Stoutenbeek and colleagues in $1984^{56,57}$. Antibiotics of the SDD regimen should fulfil the following criteria: 1 ) their spectrum should cover (facultative) aerobic Gramnegative bacteria, including $P$. aeruginosa; 2 ) they should be non-absorbable to achieve constantly high intraluminal antibiotic levels; 3) they should have minimal inactivation by faecal material; and 4) acquired resistance should be rare $^{58}$. The most often administered combination consists of polymyxin $E$ (colistin), tobramycin and amphotericin B (PTA), topically applied to the oropharynx as a paste, and through a nasogastric tube to stomach and intestine to prevent secondary endogenous infections. Polymyxin E is active against most aerobic Gram-negative bacteria with the exception of Proteus spp., Morganella spp., and Serratia spp.. There is considerable inactivation by faeces ${ }^{59}$, so administration of relatively high doses is mandatory to achieve effective concentrations. Acquired resistance against this compound is rarely seen. Tobramycin is active against most aerobic Gram-negative bacteria as well as S. aureus. Compared to other aminoglycosides (e.g. gentamicin), there is almost no inactivation by faeces. Amphotericin B is active against most yeasts. Acquired resistance is rare ${ }^{58}$.

Topical application is combined with a four-day course of systemic antibiotic therapy with a third generation cephalosporin, usually cefotaxime. The systemic component is used for pre-emptive treatment of primary endogenous infections, i.e. infections with commensal respiratory tract flora, incubating at the time of ICU admission, that are not covered by the non-absorbable agents ${ }^{60}$. The application of antibiotics is combined with taking surveillance cultures (throat, faeces) regularly to assess the compliance with and effectiveness of SDD, to distinguish exogenous from endogenous infections and to detect antimicrobial resistance ${ }^{61}$. Moreover, the institution of optimal hygiene to prevent (exogenous) cross-infection is mandatory. 


\section{The efficacy of SDD in preventing infections and mortality}

During the past 25-30 years there has been continuous debate about the efficacy of SDD with regard to morbidity and mortality. Scepticism about emerging antimicrobial resistance and increasing antibiotic use dominated the discussion, as well as costeffectiveness, which is beyond the scope of this thesis. Different studies yielded conflicting results, owing to differences in study design, study power, patient population and applied SDD regimen. The developments with regard to these issues will be presented chronologically in the next paragraphs.

\section{The early years}

During the 1980s, nearly 20 clinical trials on SDD have been performed. Infectionrelated morbidity served as the major endpoint in all studies during that decade, and was significantly reduced in almost all trials ${ }^{60}$.

Table 1.1 summarises the indications for SDD that had been identified by the end of the decade ${ }^{60}$, as well as important issues requiring clarification ${ }^{60,62}$.

\section{SDD: fifteen years on}

By the end of the 1990s, two meta-analyses reported effect of SDD on mortality (Table 1.1), whereas five previous meta-analyses failed to do so. Debate focused on whether different patient groups, i.e. medical and surgical patients, derived the same amount of benefit from topical and systemic SDD with regard to outcome. The first meta-analysis showed a reduction in overall mortality among unselected critically ill patients, whereas the second reported a reduction among surgical patients only (Table 1.1$)^{42,62}$. Both reported significant reductions in respiratory tract infections (Table 1.1). However, the number of included trials was greater in the 1998 metaanalysis, i.e. 33 vs. 21 trials in the 1999 meta-analysis; 19 trials were incorporated in both analyses. Moreover, different statistical methods were used to calculate (pooled) odds ratios.

After publication of these meta-analyses, Silvestri et al., as SDD advocate, stated that it was unfortunate that many patients were deprived from SDD, given the welldocumented effects on morbidity and mortality. They mentioned three reasons why certain randomised clinical trials (RCTs) did not show the expected reduction in infections or mortality: 1) the original full SDD protocol was not properly applied, hence efficacy was reduced; 2) the protocol intrinsically does not cover methicillinresistant Staphylococcus aureus (MRSA), so additional measures need to be taken when MRSA is endemic; 3 ) there was a substantial exogenous infection problem due to MRSA, Pseudomonas and Acinetobacter spp. in the involved trials (Table 1.1) ${ }^{63}$. 
Table 1.1 The effects of and remaining issues regarding SDD through the years

\begin{tabular}{|c|c|c|c|}
\hline Period & Positive findings & Unsolved issues & Secondary issues \\
\hline $1984-1990$ & $\begin{array}{l}\text { - reduction infections in } \\
\text { 1. trauma patients } \\
\text { 2. liver transplant } \\
\text { - outbreak control of MDR }\end{array}$ & $\begin{array}{l}\text { - effects on mortality? } \\
\text { - emergence of (long-term) } \\
\text { resistance? }{ }^{60} \\
\text { - cost-effectiveness? }\end{array}$ & $\begin{array}{l}\text { - no standard definitions of } \\
\text { infections } \\
\text { - need for more rigorously } \\
\text { designed and uniform trials } \\
\text { - sample sizes } \\
\text { - different SDD regimens }\end{array}$ \\
\hline $1991-2000$ & $\begin{array}{l}\text { meta-analyses: } \\
\text { - reduction RTIs with full } \\
\text { SDD }^{42,62} \\
\text { - reduction mortality with } \\
\text { full SDD }{ }^{42,62}\end{array}$ & $\begin{array}{l}\text { - } \text { mortality reduction in } \\
\text { unselected or surgical } \\
\text { patients? } \\
\text { - mortality reduction in } \\
\text { trials? } \\
\text { - } \text { (Gram-positive) antibiotic }^{63} \\
\text { resistance? }{ }^{64} \\
\text { - SDD in MDR endemic } \\
\text { settings? }^{65} \\
\text { - costs? }\end{array}$ & $\begin{array}{l}\text { - sample sizes } \\
\text { - different SDD regimens } \\
\text { - diagnostic criteria of } \\
\text { infection } \\
\text { - effect on secondary } \\
\text { endpoints MV and LOS } \\
\text { - study design } \\
\text { - parenteral antibiotics only? }\end{array}$ \\
\hline 2001-2002 & $\begin{array}{l}\text { - reduction VAP incidence } \\
\text { with } \text { SOD }^{66} \\
\text { - reduction infections with } \\
\text { full SDD in surgical/trauma } \\
\text { patients } \\
\text { - reduction hospital mortality } \\
\text { in patients with moderate } \\
\text { APACHE II scores }\end{array}$ & $\begin{array}{l}\text { - } \text { mortality reduction with } \\
\text { SOD? } \\
\text { - reduction (Gram-positive) } \\
\text { infections with topical } \\
\text { SDD? } \text { ? }^{67} \\
\text { - } \text { risk of emerging } \\
\text { resistance? }{ }^{67} \\
\text { - increased costs? }\end{array}$ & $\begin{array}{l}\text { - SDD vs. SOD } \\
\text { - effect of SOD on MV } \\
\text { duration/LOS }\end{array}$ \\
\hline $2003-2008$ & $\begin{array}{l}\text { - } \text { reduction mortality with } \\
\text { full SDD in unselected } \\
\text { patients } \\
\text { - } \text { reduction colonisation with } \\
\text { resistant Gram-negative } \\
\text { bacteria }^{69} \\
\text { - decreased costs and LOS } \\
\text { - } \text { reduction ICU mortality and }^{69} \\
\text { pneumonia in burn } \\
\text { patients } \\
\text { - } \text { reduction mortality and }^{\text {(Gram-negative) BSI in }} \\
\text { meta-analysis }^{75}\end{array}$ & $\begin{array}{l}\text { - effects only in settings with } \\
\text { low VRE/MRSA } \\
\text { prevalence? } \\
\text { - risk of resistance in settings } \\
\text { with high VRE/MRSA } \\
\text { prevalence? } \\
\text { - SDD effect not higher in } \\
\text { trauma patients compared }^{73} \\
\text { to other groups }^{76}\end{array}$ & $\begin{array}{l}\text { - study design } \\
\text { - effect of additional SDD } \\
\text { measures? } \\
\text { - addition of vancomycin to } \\
\text { SDD regimen? } \\
\text { - effect on MV duration/LOS/ } \\
\text { antibiotic use? } \\
\text { - SDD vs. SOD } \\
\text { - reduction in primary } \\
\text { endogenous vs. secondary } \\
\text { endogenous infections } \\
\text { - full SDD vs. systemic } \\
\text { prophylaxis? }\end{array}$ \\
\hline 2009-present & $\begin{array}{l}\text { - reduction RTIs and overall } \\
\text { mortality with full SDD } \\
\text { - reduction RTIs with topical } \\
\text { SDD } \\
\text { - SDD and SOD equal in } \\
\text { mortality reduction } \\
\text { }{ }^{80}\end{array}$ & $\begin{array}{l}\text { - antibiotic resistance? }{ }^{80} \\
\text { - equal effect in settings with } \\
\text { low and high resistance } \\
\text { levels? } \\
\text { - cost-effectiveness? }\end{array}$ & $\begin{array}{l}\text { - tendency towards shorter } \\
\text { MV duration and LOS } \\
\text { - lower antibiotic use with } \\
\text { SDD/SOD? } \\
\text { - full SDD vs. systemic } \\
\text { prophylaxis? }\end{array}$ \\
\hline
\end{tabular}

$\mathrm{SDD}$, selective decontamination of the digestive tract; $M D R$, multi-drug resistance; RTI, respiratory tract infection; MV, mechanical ventilation; LOS, length of stay; VAP, ventilator-associated pneumonia; SOD, selective oropharyngeal decontamination; VRE, vancomycin-resistant enterococci; MRSA, methicillinresistant S. aureus; ICU, intensive care unit; BSI, bloodstream infection. 
Others drew somewhat different conclusions from the 1998/1999 meta-analyses. The mortality benefit of SDD appeared to be primarily due to administration of parenteral antibiotics, instead of topical antibiotics. However, prophylactic parenteral antibiotics during the perioperative period were already accepted practice ${ }^{64}$. Moreover, the use of SDD was associated with increased colonisation and infection with, mainly Grampositive, antibiotic-resistant bacteria (Table 1.1) ${ }^{64}$.

Bonten and colleagues agreed that SDD in any form, except Gl tract decontamination alone, resulted in a reduced incidence of "pneumonia" (despite differences in diagnostic criteria), provided that there is no endemic colonisation with multiresistant bacteria ${ }^{65}$. However, the authors advocated a critical attitude towards the results of meta-analyses. Reasons for this critical attitude were: 1) an effect of SDD on (attributable) ICU mortality had only been demonstrated in the two meta-analyses (Table 1.1) ${ }^{42,62}$. Additional mortality caused by VAP is probably low, so the authors stated that many patients died with pneumonia, but not because of pneumonia ${ }^{65}$; 2 ) a significant reduction in costs was not confirmed in most studies, so SDD could not be cost-effective (Table 1.1$)^{65}$; 3) the topical regimen selects for colonisation and infection with Gram-positive, intrinsically resistant, bacteria (e.g. E. faecalis, MRSA) and for increased (multi-)resistance of Gram-negative bacteria. The application of SDD in ICUs where colonisation with multi-resistant pathogens is endemic is potentially dangerous (Table 1.1) ${ }^{65}$.

After 15 years of research on the topic, there was no unequivocal answer to the issue of efficacy of SDD with regard to mortality. Heterogeneity in studied patients, applied protocols and study quality hampered consensus. Concerns about applicability in multi-resistance endemic settings were quite rightly and could not be ignored (Table 1.1). An adequately powered, double blind, placebo-controlled RCT in a homogeneous patient population is warranted to determine the effect of SDD on ICU mortality.

\section{Moving on}

In the first three years after publication of the meta-analyses, some clinical trials have been published. Again with conflicting results (Table 1.1).

A placebo-controlled trial on prevention of late-onset VAP, occurring after at least four days of MV, was performed in ICU patients $(n=226)$ with selective oral decontamination (SOD, gentamicin, colistin, vancomycin) only. A significantly lower VAP incidence was shown in the study group (10\%) compared to two placebo groups ( $31 \%$ and $23 \%$, respectively). This was neither associated with a shorter duration of MV or ICU stay, nor better survival ${ }^{66}$, which was in line with conclusions of the metaanalysis by D'Amico et al. ${ }^{62}$. No cases of acquired resistance to antibiotics used in the regimen had been observed, including vancomycin-resistant enterococci (VRE) ${ }^{66}$. 
However, Zwaveling et al. showed that "topical only" (oropharyngeal + gastrointestinal) SDD did only prevent postoperative infections with Gram-negative bacteria and yeasts in patients undergoing elective liver transplantation. There was no overall benefit of SDD, since the total number of postoperative infections and infectionrelated morbidity was not affected. Total costs were higher in the SDD group, as well as the risk of antimicrobial resistance. Mortality was not evaluated ${ }^{67}$.

Confirming the meta-analysis by Nathens ${ }^{42}$, Krueger and co-workers reported that prophylaxis with systemic ciprofloxacin and topical gentamicin + polymyxin B significantly reduced the incidence of infections in critically ill surgical and trauma patients compared to placebo (Table 1.1) ${ }^{68}$. However, hospital mortality was significantly reduced only in patients with moderate APACHE II scores on admission (Table 1.1), which was contradictory to the meta-analysis by D'Amico ${ }^{62}$. No evidence for an increase in antibiotic resistance was found, but costs for antibiotics were higher in the prophylaxis group (Table 1.1) ${ }^{68}$.

So, nearly 20 years after the first publication, recent trials did not contribute to consensus about the application of SDD in different patient groups. Reports yielded conflicting results on effects of different decontamination regimens (SDD vs. SOD) and different SDD protocols on infectious morbidity and attributable mortality (with only one trial showing a positive effect). Also the issues of cost-effectiveness and risk of emergence of antibiotic resistance have not been elucidated (Table 1.1).

\section{A breakthrough?}

In 2003, De Jonge et al. demonstrated, in a well-powered single-centre randomised controlled trial with 934 surgical/medical ICU patients, that the original SDD protocol significantly decreased ICU and in-hospital mortality, compared to patients receiving standard treatment (Table 1.1 $)^{69}$. A decrease in colonisation with resistant Gramnegative bacteria was found. Moreover, length of stay in the ICU and total costs of antibiotic treatment were reduced in the SDD group (Table 1.1). Infections were not assessed $^{69}$.

There were some concerns however, about the study design of the above-mentioned trial. It was not blinded and randomisation raised questions ${ }^{70,71}$. No cross-over of units design was incorporated in the trial. Therefore, pre-existing differences in care between the two participating units, as well as different (nursing) staff, might have introduced (performance) bias (Table 1.1) ${ }^{71,72}$. Moreover, additional measures were taken in the SDD regimen to prevent colonisation: aerosolised polymyxin $E$ for persistent tracheal colonisation and SDD by suppository in patients with blind bowel loops. These measures may have augmented the beneficial effect of SDD, compared to results of an earlier meta-analysis (Table 1.1) ${ }^{62}$. 
Although there was the beginning of evidence that SDD reduced mortality, the risk of emergence of bacterial resistance remained. The decision to use SDD should depend on both the risk of (emergence of) resistant organisms in a certain environment and the patient population ${ }^{73}$. So, in ICUs with a high incidence of VRE or MRSA, SDD may not be applicable (Table 1.1) ${ }^{73}$. Surveillance samples should be taken to monitor longterm microbiological effects of $\mathrm{SDD}^{73}$. A large, randomised, double blind, placebocontrolled trial was still needed.

In support of a positive effect of SDD on patient survival, a Spanish research group showed that classic SDD $(n=53)$, compared to placebo $(n=54)$, significantly reduced mortality (ICU mortality $10 \%$ vs. $28 \%$ ) and overall pneumonia incidence $(17 / 1000$ ventilator-days vs. 31) among critically ill burn patients ${ }^{74}$. However, it was mainly a reduction in primary endogenous infections; there was no difference in incidence of secondary endogenous infections. Moreover, a trend towards an increase in MRSA infections was observed as MRSA was endemic in the involved ICU during the trial period $^{74}$. After conclusion of the trial, topical vancomycin was added to the SDD regimen given to patients in the former study ICU (Table 1.1) ${ }^{74}$.

A new meta-analysis (51 included trials), focusing on the effect of SDD on bloodstream infection (BSI) and mortality, showed that SDD significantly reduced overall BSIs (odds ratio (OR) $0.73,95 \%$ confidence interval $(\mathrm{Cl})$ 0.59-0.90, $P=0.004)$, Gram-negative BSIs (OR 0.39, 95\% Cl 0.24-0.63, $P<0.001$ ) and overall mortality (OR $0.80,95 \% \mathrm{Cl} 0.69-0.94$, $P=0.006$ ), without affecting Gram-positive BSIs (Table 1.1). A subgroup analysis of combined parenteral and enteral SDD showed an even larger impact on the three mentioned endpoints (Table 1.1) ${ }^{75}$.

A trial among multiple trauma patients $(n=401)$ showed a significant reduction in infection rate in the SDD group (49\%) compared to standard care (61\%). However, the trial appeared to be underpowered to detect a reduction in the primary endpoint, i.e. late mortality $(\mathrm{OR} \quad 0.75,95 \% \mathrm{Cl} 0.40-1.37, P=0.35)^{76}$. Mortality results were nevertheless in line with earlier meta-analyses among unselected patients. SDD was not more beneficial to trauma patients than to surgical and medical patients (Table $1.1)^{76}$.

Only three prospective randomised trials ${ }^{68,69,74}$ had been able to show that SDD improved outcome in ICU patients ${ }^{77}$. Therefore, the conduct of a large, well-powered multi-centre SDD/SOD cluster-randomised cross-over study with patient outcome as primary endpoint was announced, aiming to confirm this effect ${ }^{77}$. Furthermore, remaining questions were whether oral decontamination is as effective as the full SDD protocol and whether SDD could successfully be applied in settings with high levels of antibiotic resistance (MRSA, VRE, extended-spectrum beta-lactamase (ESBL), Table $1.1)^{77}$. Repeated meta-analyses with huge overlap of included studies, reporting the 
same outcome, should not be considered as cumulating evidence of a positive effect $^{77}$.

However, in 2009 an updated version of a Cochrane review (36 trials included) on antibiotic prophylaxis to reduce respiratory tract infections and mortality in adult ICU patients was issued. Conclusions did not change compared to the 2004 version ${ }^{78}$. So, topical plus systemic antibiotic prophylaxis reduced RTIs and overall mortality in adult ICU patients. Topical prophylaxis alone reduced RTIs but not mortality (Table 1.1) ${ }^{79}$.

So, only two additional trials showed a mortality reduction in this period, given the additions to the SDD protocol and methodological flaws. The applicability of different protocols in settings with high levels of antimicrobial resistance still had to be determined.

\section{Answers at last, or...?}

The effectiveness of the full original SDD regimen and SOD (PTA in oropharynx alone), both with protocol modifications if deemed necessary, was shown compared to standard care, in a large cross-over, cluster-randomised trial $(n=5939)$ in 13 ICUs in The Netherlands. Mortality at day 28 served as the primary endpoint. An OR for death at day 28 (compared to standard care) of 0.86 (95\% Cl 0.74-0.99) for SOD, and 0.83 $(95 \% \mathrm{Cl} 0.72-0.97)$ for SDD were shown. The estimated absolute mortality reduction was $2.9 \%$ for SOD and $3.5 \%$ for SDD, respectively (Table 1.1$)^{80}$. No significant effects on antibiotic use, length of stay and duration of MV could be established (Table 1.1) ${ }^{80}$. Some criticism has been postulated about the methodological issues of the trial, like $\mathrm{Cls}$ of the odds ratio for mortality just below one; change of the primary endpoint during the trial; and statistical adjustments that had to be made to correct for differences in baseline characteristics ${ }^{81}$.

\section{Summary}

After nearly 30 years of research in the field, a small, but clinically relevant effect of both SDD and SOD on (28-day) mortality of critically ill patients has now been determined, next to positive effects on incidence of nosocomial pneumonia and BSI. SOD could be preferable in terms of less systemic antibiotic use, and thus less antibiotic pressure. Advocates find it unethical to withhold SDD or SOD, while adversaries still find the positive effects questionable. Studies were heterogeneous in many aspects: type of applied antibiotics, concentrations, dosing frequencies, patient populations, and diagnostic criteria for VAP. Moreover, no sufficient evidence exists about the cost-effectiveness of both prophylactic regimens. Investigators should now focus on the most debated possible disadvantage of SDD, i.e. the long-term selection of antibiotic-resistant microorganisms. The major concern is that SDD might not be useful in settings with high (baseline) resistance levels (e.g. VRE or MRSA endemicity). 
Future studies are needed to determine if SDD and SOD are safe with regard to development of antibiotic resistance, since the majority of currently available trials still did not exhaustively address this issue ${ }^{82}$.

\section{Antimicrobial resistance}

While SDD advocates claim that there is no link between SDD and antibiotic resistance and that problems due to resistant aerobic Gram-negative bacilli should be separated from those due to MRSA and $\mathrm{VRE}^{76}$, a number of trials, focusing on the (long-term) effects of SDD on antimicrobial resistance, have been published over time.

Early reports already showed that shifts in bacterial ecology towards Gram-positive pathogens ${ }^{83,84}$ or non-fermenters ${ }^{85}$, as well as antimicrobial (multi-drug) resistance ${ }^{83,84}$ emerged. This was dependent on the applied regimen, especially those that incorporated a quinolone ${ }^{83,84}$, and the level of colonisation and infection (with antibiotic-resistant microorganisms) at ICU admission.

Comparable results were also presented in later studies. However, some trials reported a decrease in antimicrobial resistance with SDD ${ }^{69}$. The chosen SDD protocol, the setting, as well as study design ${ }^{86,87}$ determined whether ecological shifts, mainly towards Gram-positive bacteria ${ }^{68,86,88}$, and antibiotic resistance occurred. MRSA was not a major issue. Even in low-level resistance settings, prudence and proper surveillance seems to be warranted, also with regard to emergence of ESBL-producing bacteria $^{89}$.

Recently, microbiological results of the same clinical trial ${ }^{80}$ led to different conclusions, depending on the applied perspective and analysed samples. In one study, proportions of patients with intestinal Gram-negative bacteria resistant to ceftazidime, tobramycin and ciprofloxacin were significantly increased postintervention. Resistance levels in the respiratory tract increased gradually during intervention (ceftazidime: $P<0.05$ for trend) and to levels of $10 \%$ or more for all three antibiotics postintervention $(P<0.05)^{90}$. Two other analyses showed that antimicrobial resistance levels were lower compared to standard care ${ }^{80,91}$.

A recent 5-year prospective cohort study outside The Netherlands (i.e. Spain) reported a stable incidence density of antibiotic-resistant bacteria while using SDD. However, the authors showed both a significant increase in incidence of ceftazidimeresistant $P$. aeruginosa, not related to an increase in prevalence at admission, and an increase in incidence of imipenem-resistant $P$. aeruginos $a$ associated with an increase in imipenem consumption ${ }^{92}$.

Although the majority of studies did not report (significantly) increased resistance levels, there seemed to be a lack of effect of SDD/SOD on for instance enterococci and 
non-fermenters like Acinetobacter spp., even in a Dutch study setting, during a relatively short observation period ${ }^{93}$. Resistance among Gram-negative bacteria appeared to increase nonetheless during and after SDD/SOD use.

\section{Conclusion}

Contradictory results on antimicrobial resistance emerge from different trials conducted through the years. Antibiotic use results in antibiotic resistance eventually ${ }^{94}$, although the time that it takes differs. The paramount elements probably are the different pre-existing levels of (multi-drug) resistance in different countries ${ }^{95}$, and different components of SDD that have been applied. Addition of vancomycin and substitution of polymyxin $E$ and tobramycin by neomycin and paromomycin, as proposed earlier, might not be the answer.

At present, a multi-centre cross-over comparison of SDD and SOD as standard care in the ICU setting is running in The Netherlands (until February 2013). Results from clinical and surveillance cultures will be used to assess long-term development of antibiotic resistance in different pathogens from both patient groups ${ }^{82}$. Special attention needs to be paid to the emergence of ESBL and carbapenemases.

However, studies are also warranted in settings with higher baseline levels of resistance. Whether these will ever be executed, let alone satisfy all criticisers, is highly doubtful.

\section{Probiotics for prevention of nosocomial infections: efficacy and adverse events}

Due to the relatively short period of time that probiotics are being evaluated in critical care, and the fact that probiotics are currently in a different research phase compared to SDD, results will not be discussed chronologically, but by field of interest.

\section{Background}

The beneficial properties of probiotics had already been recognised by Metchnikoff at the beginning of the 1900s and were "rediscovered" 60 years later by Lilly and Stillwell $^{96}$. More recently, studies with critically ill patients and patients with abdominal diseases showed conflicting results regarding the effect of probiotics on infection rates, as did meta-analyses ${ }^{97-99}$. Furthermore, the safety of probiotics became a matter of intense debate after the publication of a clinical trial of probiotics in severe acute pancreatitis patients showing excess mortality ${ }^{100}$. Thereafter, only a few trials have been published in the field ${ }^{101-104}$. 
Here, we will assess the concept of prevention of infections by probiotics and summarise the current knowledge of the efficacy of probiotics in patients with abdominal diseases and patients in the Intensive Care. Moreover, safety issues regarding probiotics will be discussed.

\section{Definitions}

Probiotics, literally meaning "for life", are live microorganisms, which confer a health benefit on the host when administered in adequate amounts ${ }^{105}$. A product can be called a probiotic when the following requirements are met: 1) strains are designated individually (e.g. in case of a multi-species product); 2) strains are speciated appropriately; 3 ) strains retain a viable count at the end of their shelf life and 4) the designated product formulation confers a proven clinical endpoint ${ }^{106}$.

Probiotics are often administered in conjunction with prebiotics. Prebiotics are nondigestible food ingredients consisting mainly of plant fibres that are used by the gut microbiota as a substrate for fermentation. Prebiotics beneficially affect the host by selectively stimulating growth, activity, or both of a restricted number of bacteria in the colon ${ }^{107}$. Moreover, they could enhance survival of probiotic strains when administered in combination as a so-called synbiotic ${ }^{108}$.

Numerous bacterial species can serve as probiotic. An important group is that of lactic acid bacteria, which can be divided in two subgroups; the fibre-fermenting group, such as the fruit/vegetable-borne Lactobacillus plantarum, and the mainly milk-borne bacteria like Lactobacillus casei. The first occur more frequently and in larger amounts in the gut compared to the latter ${ }^{41}$.

\section{Possible mechanisms of action of probiotics}

In order to be effective, a probiotic or synbiotic should be able to survive the hostile environment of the stomach, colonise the gut mucosa and reduce colonisation and overgrowth of the intestine by PPMs ${ }^{109}$. Many probiotics exert their action in the colon. Klarin et al. demonstrated that $L$. plantarum 299v could survive the passage from stomach to rectum and adhere onto rectal mucosa even in critically ill patients that were treated with antibiotics ${ }^{110}$. The main goal of ingestion of probiotics is to create an unfavourable local environment for pathogen colonisation ${ }^{111}$, and thereby to reduce translocation: leakage of microbes and toxins from the gut into the body ${ }^{41}$.

Several molecular working mechanisms of probiotics have been described ${ }^{41,112}$. Some lactobacilli, e.g. L. plantarum, adhere to the intestinal wall via mannose receptors and compete for these receptors with Gram-negative bacteria such as E. coli and Pseudomonas spp. ${ }^{113}$, thereby preventing Gram-negative colonisation and presumably infection. Another way to interfere in pathogen adhesion is the production of mucins (MUC2 and MUC3). An increase in mucin messenger RNA expression was demonstrated in vitro when mucosal cells were incubated with L. plantarum 299v, which led to inhibition of adherence of $E$. coli to intestinal cells ${ }^{114}$. Certain 
Lactobacillus and Bifidobacterium strains bind and sequestrate aflatoxin $\mathrm{B}^{115,116}$, thus decreasing sufficient amount of free toxins that can contaminate food or serve as carcinogen. Probiotics compete for nutrients with potential pathogens ${ }^{117}$; alter local $\mathrm{pH}^{118}$; produce bacteriocins to inhibit pathogens ${ }^{119}$; enhance intestinal barrier function ${ }^{121}$, and scavenge superoxide radicals ${ }^{121}$.

In addition, probiotics have been shown to be immune modulating. Defects in macrophage function (an effect of antibiotic administration) are eliminated by suppletion of certain low-molecular-weight peptides obtained from indigenous gut microbiota such as Bacteroides spp. and Lactobacillus ${ }^{122}$. Furthermore, cell-free extracts (supernatant) of $B$. longum and L. acidophilus significantly enhanced phagocytosis of both inert particles and viable Salmonella ${ }^{123}$. Probiotics may activate macrophages to increase antigen presentation and secretory IgA production ${ }^{124,125}$; modulate cytokine profiles ${ }^{126}$; reduce pro-inflammatory cytokines ${ }^{127}$; induce antiinflammatory cytokines like IL-10 ${ }^{128}$; and modulate dendritic cell phenotype and function $^{129}$.

Although the exact working mechanism of probiotics is not yet clear, probiotics are increasingly being used.

\section{Use of probiotics in humans}

Due to concerns regarding development of antibiotic resistance in hospitals, rising healthcare costs and lack of new antimicrobial classes being developed, probiotics have been considered a good prophylactic or therapeutic alternative in numerous conditions. Probiotics do not have the risk of antimicrobial resistance and offer practical benefits like low-cost preparation, long shelf life, and ease of administration $^{111}$.

Most evidence is available on prevention and treatment of acute infectious diarrhoea, for instance rotavirus infection ${ }^{130}$ or antibiotic-associated diarrhoea ${ }^{131}$. Also reported are prevention of lactose malabsorption or intolerance ${ }^{132}$, the consolidation of remission of inflammatory bowel disease $e^{133}$ and reduction of the incidence of atopic eczema in infants ${ }^{134}$. Nearly a decade ago, the first clinical studies using $L$. plantarum 299 as probiotic showed promising reductions in surgical and ICU sepsis rates ${ }^{135-137}$. In the next paragraphs we will focus on prevention of acquired infections by probiotics, in patients with abdominal diseases and patients in the ICU.

\section{Prevention of infections in abdominal diseases}

An important population in which probiotics are investigated is the one with patients undergoing abdominal surgery or suffering from pancreatitis. 


\section{Abdominal surgery}

Rayes et al. investigated the incidence of bacterial infections in patients after major abdominal surgery $(n=90)$ in a prospective, randomised trial. The incidence of infections was significantly lower $(P=0.01)$ in the group with enteral fibre-containing nutrition with viable L. plantarum 299 (10\%) and heat-killed Lactobacillus (10\%) compared to the group on parenteral nutrition or fibre-free enteral nutrition $(30 \%)^{135}$. The same authors assessed the incidence of postoperative infections among liver transplant recipients $(n=95)$, comparing three groups; one group using standard formula of enteral nutrition with SDD; one group using fibre-containing formula and viable L. plantarum 299 and the third group using fibre-containing formula and heatkilled L. plantarum 299. Patients receiving viable L. plantarum 299 developed significantly less bacterial infections (13\%) compared to SDD $(48 \%)$ and heat-killed

L. plantarum $(34 \%, P=0.02)^{136}$. Two other clinical trials used Synbiotic $2000^{\circledR}$, containing four different strains: Pediococcus pentosaceus, Leuconostoc mesenteroides, L. paracasei and L. plantarum combined with fibres. Among liver transplant recipients $(n=66)$, the incidence of postoperative bacterial infections was significantly reduced when given Synbiotic $2000^{\circledR}$ (3\%) compared to fibres alone $(48 \%)^{138}$. Also patients undergoing pancreas resection $(n=80)$ had significantly fewer postoperative bacterial infections when given Synbiotic $2000^{\circledR}(12.5 \%)$ compared to fibres only $(40 \%, P=0.005)^{139}$.

Among biliary cancer patients undergoing hepatectomy, postoperative infections were significantly reduced by a synbiotic product containing $B$. breve Yakult and L. casei Shirota ${ }^{140}$. Postoperative infectious complications were significantly reduced by a combination of Enterococcus faecalis, Clostridium butyricum and Bacillus mesentericus among patients undergoing pancreaticoduodenectomy ${ }^{141}$. By contrast, three other studies, conducted by the same research group, applying different regimens of probiotics, did not show an influence of probiotics on septic morbidity after abdominal surgery, possibly due to a relatively short period of postoperative administration $^{142-144}$.

A meta-analysis, based on the above-mentioned trials ${ }^{97}$ and a review ${ }^{145}$, including six additional trauma and pancreatitis trials, concluded that the use of probiotics or synbiotics reduced postoperative infections after abdominal surgery (OR for any infection $0.26,95 \% \mathrm{Cl} 0.12-0.55, P<0.001)$. However, the results of the meta-analysis should be interpreted with caution due to the heterogeneity of the included studies. Very recently, Liu et al. reported that patients undergoing colorectal surgery for carcinoma $(n=100)$ who received probiotics (L. plantarum, L. acidophilus, B. longum) experienced significantly less infectious complications compared to placebo in a trial with bacterial translocation as primary endpoint ${ }^{104}$. 


\section{Pancreatitis}

Patients with acute pancreatitis $(n=45)$ were randomised to either viable $L$. plantarum 299 with oat fibre substrate by nasojejunal tube, or to an identical preparation with heat-killed Lactobacillus. Infected pancreatic necrosis and abscesses occurred in one of 22 patients receiving viable L. plantarum 299 compared to seven of 23 patients in the heat-killed group $(P=0.02)^{137}$. In another study, 62 patients with severe acute pancreatitis were either given Synbiotic $2000^{\circledR}$ with prebiotics or prebiotics only. The total incidence of systemic inflammatory response syndrome and multi-organ failure was significantly lower in the first group $(P<0.05)$, as was the number of patients recovering with complications. A lower rate of late organ failure was detected in the synbiotic group ${ }^{146}$. Besselink et al. conducted a randomised controlled trial with predicted severe acute pancreatitis patients that received a multi-species probiotic (six strains) as infection prophylaxis and compared them to placebo. In the probiotic group $16 \%$ of patients died, compared to $6 \%$ in the placebo group (relative risk (RR) 2.53). Nine patients in the probiotic group developed bowel ischemia, of which eight with fatal outcome, compared to none in the placebo group $(P=0.004)^{100}$. The conclusion of a recent meta-analysis with seven included studies on pre-, pro- and synbiotics for acute pancreatitis (the included studies being heterogeneous) was that no sufficient evidence to support the use of pro- or synbiotics for prevention of postoperative infections in pancreatitis could be demonstrated (OR $0.30,95 \% \mathrm{Cl} 0.09$ 1.02, $P=0.05)^{98}$.

\section{Prevention of ventilator-associated pneumonia and other ICU infections}

Since the prevalence of infections, e.g. VAP, and subsequent mortality is high in critically ill patients, probiotics have also been applied for infection prevention in ICU. The synbiotic formula Trevis ${ }^{\mathrm{TM}}$ (L. acidophilus La5, B. lactis Bb-12, S. thermophilus, L. bulgaricus with oligofructose) applied in ICU patients was not associated with measurable clinical benefit compared to placebo ${ }^{147}$. Another report by the same research group showed that enteral administration of L. plantarum $299 \mathrm{v}$ to critically ill patients did not significantly change septic morbidity compared to conventional ICU therapy ${ }^{148}$. Synbiotic 2000Forte ${ }^{\circledR}$ applied in critically ill, multi-trauma patients significantly reduced infection and sepsis rates compared to placebo ${ }^{149}$, as well as glutamine, fermentable fibre and peptide $\operatorname{diet}^{150}$. Oral administration of $L$. casei rhamnosus delayed respiratory tract colonisation and infection by $P$. aeruginosa in ICU patients. There was a trend towards reduced occurrence of VAP with $P$. aeruginosa ${ }^{151}$. Application of L. plantarum 299 to critically ill patients on MV led to a VAP rate of $4 \%$ compared to $14 \%$ in the chlorhexidine group (not significant) ${ }^{152}$. Similar findings were reported for Synbiotic 2000Forte ${ }^{{ }^{\circledR 101}}$. 
A recent meta-analysis showed that use of probiotics in mechanically ventilated patients was associated with a lower incidence of VAP compared to controls ${ }^{99}$. However, four other recent reviews/meta-analyses ${ }^{109,111,153,154}$, two of which with special focus on hospital-acquired pneumonia, failed to show a reduction in infections among critically ill patients or stated that there is insufficient evidence for reduction of nosocomial pneumonia by probiotics.

A possible explanation for the differences in outcome may be the inclusion of different clinical trials with low homogeneity among the populations ${ }^{99}$, varying from patients admitted to the ICU to patients after abdominal surgery or with pancreatitis. Other factors playing a role in the variation in outcome are 1) the application of different probiotic strains with varying properties and bioavailability; 2) the significantly different definitions of infectious endpoints like VAP in the different trials ${ }^{109}$; 3) considerable variation in dose, time of onset and duration of administration of probiotics or synbiotics. All these factors are known to be crucial entities in probiotic use ${ }^{155}$ and hamper proper comparison of trials with probiotics. Suboptimal trial design, inadequate blinding, and small study samples make it even more difficult to draw an appropriate conclusion from these data ${ }^{154}$.

After publication of these meta-analyses, two randomised controlled trials with ICU patients have been published. In a prematurely stopped trial, 167 patients were given Ergyphilus $^{\circledR}$ (mainly L. rhamnosus GG, among three other strains) or placebo for the duration of MV. The primary endpoint 28-day mortality was not significantly different between both groups. However, among a subgroup of patients with severe sepsis, 28day mortality was reduced in the probiotic group. By contrast, probiotics were associated with a higher mortality in patients with non-severe sepsis, but mortality was unexpectedly low in placebo-treated patients. Additionally, no reductions in nosocomial infections (especially VAP) were demonstrated. The authors concluded that prophylactic administration of probiotics to critically ill could not be encouraged $^{102}$.

In another trial, both oropharyngeal and gastric administration of L. rhamnosus GG was found to be well tolerated and efficacious in preventing (Gram-negative) VAP in a selected ICU population ( $n=146)$, with high APACHE II scores and prolonged duration of $\mathrm{MV}$, compared to placebo (incidence 19 vs. $40 \%, P=0.007)^{103}$. Mortality was not significantly different between both groups. The authors stated that their results could not be generalised to a broader ICU population and should be considered as preliminary observations $^{103}$.

\section{Adverse effects of probiotics}

Until recently, the use of probiotics was generally regarded as well tolerated. Only a few case reports had been published reporting adverse effects, e.g. Saccharomyces 
boulardii fungaemia ${ }^{156}$ and bacteraemia with lactobacilli ${ }^{157}$. These rare cases of bacteraemia or fungaemia were mostly polymicrobial ${ }^{158}$ and occurred in patients with severe comorbidities such as immune suppression ${ }^{156}$, short bowel syndrome ${ }^{159}$ or in patients with indwelling central venous catheters ${ }^{160}$. No increase in adverse effects could be demonstrated on a population level in Finland, after a nationwide increase in probiotic consumption ${ }^{161}$. So, the safety issue of probiotics was not considered to be of paramount importance. However, in 2008 Besselink et al. reported excess mortality among their group of patients with predicted severe acute pancreatitis receiving a multi-species probiotic, compared to placebo ${ }^{100}$. The authors hypothesised that the combination of severe pancreatitis, subsequent organ failure, intestinal hypoperfusion through reduction in mucosal blood flow and an increased bacterial load due to the probiotic strains could have led to increased local inflammation, further compromising mucosal blood supply, resulting in bowel ischemia ${ }^{162}$. They concluded that bacteraemia, infected pancreatic necrosis, organ failure and mortality were all associated with intestinal barrier dysfunction early in the course of acute pancreatitis. Prophylaxis with the specific combination of probiotic strains was associated with increased bacterial translocation and enterocyte damage in patients with organ failure specifically ${ }^{162}$. The authors stated that because of the results of their trial, probiotics should not be used in critically ill patients until more information became available about causes and underlying mechanism of the excess mortality.

However, type and number of strains, e.g. single strain vs. multi-species product, may influence outcome, including appearance of adverse events. Also, the investigated condition and route of administration, i.e. application via gastric versus duodenal or jejunal tube, may be crucial for adverse events like intestinal ischemia. Therefore, results of one trial may not be applicable to other probiotic studies in critically ill patients, although vigilance for adverse effects is warranted, especially in this patient population.

\section{Conclusion}

Despite the vast amount of clinical trials on probiotics, no unequivocal conclusion can be drawn regarding efficacy in infection prevention. Safety of probiotic use in critically ill patients is a matter of ongoing debate. It should be emphasised that every probiotic may consist of different strains (such as lactobacilli or bifidobacteria) which exert their own specific properties, which could lead to different results with regard to efficacy or adverse effects. Results of studies with certain probiotics in specific patient populations can therefore not be readily extrapolated to other studies using different probiotics in different patient populations.

Despite the ongoing debate, probiotics still seem to be a safe alternative for antibiotic prophylaxis in this era of increasing antibiotic resistance and deserve a well-monitored "second life". 


\section{Scope and outline of this thesis}

As discussed in the previous sections, infection prevention for intensive care unit (ICU) patients is needed. For this purpose different pharmacological and nonpharmacological modalities have been proposed, all with their benefits and drawbacks. This thesis focuses on the application of two well-described but controversial measures; selective decontamination of the digestive tract (SDD) versus the use of probiotics. Impact on infectious events and mortality, as well as antibiotic resistance and antibiotic use will be assessed.

Before antibiotic prophylaxis or therapy can be applied, knowledge of local antibiotic resistance levels among ICU isolates is crucial. Local antimicrobial guidelines and appropriate treatment, which is essential for a positive outcome, depend on this knowledge. Therefore, we describe in chapter $\mathbf{2}$ the developments in antibiotic resistance among Escherichia coli and Pseudomonas aeruginosa isolates from 14 ICUs in The Netherlands between 1998 and 2005.

Rapid non-conventional diagnostics could lead to an earlier diagnosis of ventilatorassociated pneumonia (VAP) and therefore earlier appropriate antibiotic treatment. Inappropriate initial empirical therapy is consistently associated with increased mortality, especially due to serious infections such as sepsis and VAP. Chapter 3 describes the evaluation of the usefulness of soluble Triggering Receptor Expressed on Myeloid cells-1 (sTREM-1) in bronchoalveolar lavage fluid from ICU patients as rapid diagnostic test for VAP.

A direct comparison of probiotics and antibiotic decontamination of the digestive tract has never been made before in ICU. In chapter 4 the results of a clinical trial comparing SDD to the probiotic Lactobacillus plantarum 299/299v plus fibre (LAB) are depicted. The hypothesis was that LAB is non-inferior to SDD in infection prevention. Secondary endpoints were mortality, additional antibiotic use and prevalence of (antibiotic-resistant) microorganisms in surveillance cultures.

In chapter 5, the prevalence of antibiotic-resistant Escherichia coli from clinical samples and surveillance samples of the distal digestive tract of ICU patients receiving either SDD or probiotics was determined. The influence of both modalities on the prevalence or selection of antibiotic-resistant bacteria in the distal digestive tract might disqualify their use as infection-preventive measure.

The presence of L. plantarum 299/299v in rectal swabs from ICU patients receiving this strain as probiotic, was evaluated by randomly amplified polymorphic DNA (RAPD) analysis, in association with potential pathogen-colonisation, and incidence of infection and mortality (chapter 6). It is unknown to what extent LAB is actually able to colonise the intestinal tract of the critically ill, since the function of their gastrointestinal tract is supposed to be different from that of healthy persons.

In chapter 7, a general overview of the topics presented in this thesis will be depicted. Moreover, future perspectives and recommendations for research will be discussed. 
General introduction 29

\section{References}

1. Gastmeier P, Schumacher M, Daschner F, Ruden H. An analysis of two prevalence surveys of nosocomial infection in German intensive care units. J Hosp Infect 1997;35:97-105.

2. Alberti C, Brun-Buisson C, Burchardi H, Martin C, Goodman S, Artigas A, Sicignano A, Palazzo M, Moreno R, Boulme R, Lepage E, Le Gall R. Epidemiology of sepsis and infection in ICU patients from an international multicentre cohort study. Intensive Care Med 2002;28:108-121.

3. Vincent JL, Rello J, Marshall J, Silva E, Anzueto A, Martin CD, Moreno R, Lipman J, Gomersall C, Sakr Y, Reinhart K. International study of the prevalence and outcomes of infection in intensive care units. JAMA 2009;302:2323-2329.

4. Burke JP. Infection control - a problem for patient safety. N Engl J Med 2003;348:651-656.

5. Inan D, Saba R, Gunseren F, Ongut G, Turhan O, Yalcin AN, Mamikoglu L. Daily antibiotic cost of nosocomial infections in a Turkish university hospital. BMC Infect Dis 2005;5:5.

6. Vincent JL. Nosocomial infections in adult intensive care units. Lancet 2003;361:2068-2077.

7. Blot S, Depuydt P, Vandewoude K, De Bacquer D. Measuring the impact of multidrug resistance in nosocomial infection. Curr Opin Infect Dis 2007;20:391-396.

8. Blot S, Vandewoude K, Hoste E, De Waele J, Kint K, Rosiers F, Vogelaers D, Colardyn F. Absence of excess mortality in critically ill patients with nosocomial Escherichia coli bacteremia. Infect Control Hosp Epidemiol 2003;24:912-915.

9. Rello J, Ochagavia A, Sabanes E, Roque M, Mariscal D, Reynaga E, Valles J. Evaluation of outcome of intravenous catheter-related infections in critically ill patients. Am J Respir Crit Care Med 2000;162: 1027-1030.

10. Safdar N, Dezfulian C, Collard HR, Saint S. Clinical and economic consequences of ventilatorassociated pneumonia: a systematic review. Crit Care Med 2005;33:2184-2193.

11. Vandewoude $\mathrm{KH}$, Blot SI, Benoit D, Colardyn F, Vogelaers D. Invasive aspergillosis in critically ill patients: attributable mortality and excesses in length of ICU stay and ventilator dependence. J Hosp Infect 2004;56:269-276.

12. Weber WP, Zwahlen M, Reck S, Feder-Mengus C, Misteli H, Rosenthal R, Brandenberger D, Oertli D, Widmer AF, Marti WR. Economic burden of surgical site infections at a European university hospital. Infect Control Hosp Epidemiol 2008;29:623-629.

13. Olsen MA, Chu-Ongsakul S, Brandt KE, Dietz JR, Mayfield J, Fraser VJ. Hospital-associated costs due to surgical site infection after breast surgery. Arch Surg 2008;143:53-60.

14. Blot SI, Depuydt P, Annemans L, Benoit D, Hoste E, De Waele JJ, Decruyenaere J, Vogelaers D, Colardyn F, Vandewoude $\mathrm{KH}$. Clinical and economic outcomes in critically ill patients with nosocomial catheter-related bloodstream infections. Clin Infect Dis 2005;41:1591-1598.

15. Digiovine B, Chenoweth C, Watts C, Higgins M. The attributable mortality and costs of primary nosocomial bloodstream infections in the intensive care unit. Am J Respir Crit Care Med 1999;160: 976-981.

16. Blot S. Limiting the attributable mortality of nosocomial infection and multidrug resistance in intensive care units. Clin Microbiol Infect 2008;14:5-13.

17. Fagon JY. Biological markers and diagnosis of ventilator-associated pneumonia. Crit Care 2011;15: 130.

18. Iregui M, Ward S, Sherman G, Fraser VJ, Kollef MH. Clinical importance of delays in the initiation of appropriate antibiotic treatment for ventilator-associated pneumonia. Chest 2002;122:262-268.

19. Oppert M, Reinicke A, Muller C, Barckow D, Frei U, Eckardt KU. Elevations in procalcitonin but not Creactive protein are associated with pneumonia after cardiopulmonary resuscitation. Resuscitation 2002;53:167-170.

20. Gibot S, Cravoisy A, Levy B, Bene MC, Faure G, Bollaert PE. Soluble Triggering Receptor Expressed on Myeloid cells and the diagnosis of pneumonia. N Engl J Med 2004;350:451-458.

21. Linssen $\mathrm{CF}$, Bekers $\mathrm{O}$, Drent $\mathrm{M}$, Jacobs JA. C-reactive protein and procalcitonin concentrations in bronchoalveolar lavage fluid as a predictor of ventilator-associated pneumonia. Ann Clin Biochem 2008;45:293-298. 
22. Anand NJ, Zuick S, Klesney-Tait J, Kollef MH. Diagnostic implications of soluble Triggering Receptor Expressed on Myeloid cells-1 in BAL fluid of patients with pulmonary infiltrates in the ICU. Chest 2009; 135:641-647.

23. Vanspauwen MJ, Linssen CF, Bruggeman CA, Jacobs JA, Drent M, Bergmans DC, Van Mook WN. Clara cell protein in bronchoalveolar lavage fluid: a predictor of ventilator-associated pneumonia? Crit Care 2011;15:R14.

24. Drakulovic MB, Torres A, Bauer TT, Nicolas JM, Nogue S, Ferrer M. Supine body position as a risk factor for nosocomial pneumonia in mechanically ventilated patients: a randomised trial. Lancet 1999;354:1851-1858.

25. Van Nieuwenhoven CA, Vandenbroucke-Grauls C, Van Tiel FH, Joore HC, Van Schijndel RJ, Van der Tweel I, Ramsay G, Bonten MJ. Feasibility and effects of the semirecumbent position to prevent ventilator-associated pneumonia: a randomized study. Crit Care Med 2006;34:396-402.

26. Bouza E, Perez MJ, Munoz P, Rincon C, Barrio JM, Hortal J. Continuous aspiration of subglottic secretions in the prevention of ventilator-associated pneumonia in the postoperative period of major heart surgery. Chest 2008;134:938-946.

27. Kollef $\mathrm{MH}$, Skubas NJ, Sundt TM. A randomized clinical trial of continuous aspiration of subglottic secretions in cardiac surgery patients. Chest 1999;116:1339-1346.

28. Dezfulian C, Shojania K, Collard HR, Kim HM, Matthay MA, Saint S. Subglottic secretion drainage for preventing ventilator-associated pneumonia: a meta-analysis. Am J Med 2005;118:11-18.

29. Smulders K, Van der Hoeven H, Weers-Pothoff I, Vandenbroucke-Grauls C. A randomized clinical trial of intermittent subglottic secretion drainage in patients receiving mechanical ventilation. Chest 2002; 121:858-862.

30. Berra L, De Marchi L, Panigada M, Yu ZX, Baccarelli A, Kolobow T. Evaluation of continuous aspiration of subglottic secretion in an in vivo study. Crit Care Med 2004;32:2071-2078.

31. Girou E, Buu-Hoi A, Stephan F, Novara A, Gutmann L, Safar M, Fagon JY. Airway colonisation in longterm mechanically ventilated patients. Effect of semi-recumbent position and continuous subglottic suctioning. Intensive Care Med 2004;30:225-233.

32. Harvey RC, Miller P, Lee JA, Bowton DL, MacGregor DA. Potential mucosal injury related to continuous aspiration of subglottic secretion device. Anesthesiology 2007;107:666-669.

33. Koeman M, Van der Ven AJ, Hak E, Joore HC, Kaasjager K, De Smet AG, Ramsay G, Dormans TP, Aarts LP, De Bel EE, Hustinx WN, Van der Tweel I, Hoepelman AM, Bonten MJ. Oral decontamination with chlorhexidine reduces the incidence of ventilator-associated pneumonia. Am J Respir Crit Care Med 2006;173:1348-1355.

34. Segers P, Speekenbrink RG, Ubbink DT, Van Ogtrop ML, De Mol BA. Prevention of nosocomial infection in cardiac surgery by decontamination of the nasopharynx and oropharynx with chlorhexidine gluconate: a randomized controlled trial. JAMA 2006;296:2460-2466.

35. Fourrier $F$, Dubois $D$, Pronnier $P$, Herbecq $P$, Leroy $O$, Desmettre $T$, Pottier-Cau E, Boutigny $H, D i$ Pompeo C, Durocher A, Roussel-Delvallez M. Effect of gingival and dental plaque antiseptic decontamination on nosocomial infections acquired in the intensive care unit: a double-blind placebo-controlled multicenter study. Crit Care Med 2005;33:1728-1735.

36. Chan EY, Ruest A, Meade MO, Cook DJ. Oral decontamination for prevention of pneumonia in mechanically ventilated adults: systematic review and meta-analysis. BMJ 2007;334:889.

37. Deitch EA. Bacterial translocation of the gut flora. J Trauma 1990;30:S184-189.

38. Berg RD. Bacterial translocation from the gastrointestinal tract. J Med 1992;23:217-244.

39. MacFie J, O'Boyle C, Mitchell CJ, Buckley PM, Johnstone D, Sudworth P. Gut origin of sepsis: a prospective study investigating associations between bacterial translocation, gastric microflora, and septic morbidity. Gut 1999;45:223-228.

40. Zandstra DF, Van Saene HK. Selective decontamination of the digestive tract as infection prevention in the critically ill. A level 1 evidence-based strategy. Minerva Anestesiol 2011;77:212-219.

41. Bengmark S. Pre-, pro- and synbiotics. Curr Opin Clin Nutr Metab Care 2001;4:571-579.

42. Nathens $A B$, Marshall JC. Selective decontamination of the digestive tract in surgical patients: a systematic review of the evidence. Arch Surg 1999;134:170-176.

43. Backhed F, Ley RE, Sonnenburg JL, Peterson DA, Gordon JI. Host-bacterial mutualism in the human intestine. Science 2005;307:1915-1920. 
General introduction $\mid 31$

44. Hooper LV, Gordon JI. Commensal host-bacterial relationships in the gut. Science 2001;292: 1115-1118.

45. Guarner F, Malagelada JR. Gut flora in health and disease. Lancet 2003;361:512-519.

46. Bergmann OJ, Kilian M, Ellegaard J. Potentially pathogenic microorganisms in the oral cavity during febrile episodes in immunocompromised patients with haematologic malignancies. Scand J Infect Dis 1989;21:43-51.

47. Van der Waaij D, Tieleman-Speltie TM, De Roeck-Houben AM. Relation between the faecal concentration of various potentially pathogenic microorganisms and infections in individuals (mice) with severely decreased resistance to infection. Antonie Van Leeuwenhoek 1978;44:395-405.

48. Van Leeuwen PA, Boermeester MA, Houdijk AP, Ferwerda CC, Cuesta MA, Meyer S, Wesdorp RI. Clinical significance of translocation. Gut 1994;35:S28-34.

49. MacFie J, Reddy BS, Gatt M, Jain PK, Sowdi R, Mitchell CJ. Bacterial translocation studied in 927 patients over 13 years. Br J Surg 2006;93:87-93.

50. Nieuwenhuijs VB, Verheem A, Van Duijvenbode-Beumer H, Visser MR, Verhoef J, Gooszen HG, Akkermans LM. The role of interdigestive small bowel motility in the regulation of gut microflora, bacterial overgrowth, and bacterial translocation in rats. Ann Surg 1998;228:188-193.

51. Deitch EA, Xu D, Naruhn MB, Deitch DC, Lu Q, Marino AA. Elemental diet and IV-TPN-induced bacterial translocation is associated with loss of intestinal mucosal barrier function against bacteria. Ann Surg 1995;221:299-307.

52. Berg RD. Bacterial translocation from the gastrointestinal tract. Adv Exp Med Biol 1999;473:11-30.

53. Bengmark S. Gut microenvironment and immune function. Curr Opin Clin Nutr Metab Care 1999;2: 83-85.

54. O'Boyle CJ, MacFie J, Mitchell CJ, Johnstone D, Sagar PM, Sedman PC. Microbiology of bacterial translocation in humans. Gut 1998;42:29-35.

55. Tran DD, Cuesta MA, Van Leeuwen PA, Nauta JJ, Wesdorp RI. Risk factors for multiple organ system failure and death in critically injured patients. Surgery 1993;114:21-30.

56. Van der Waaij D, Berghuis-de Vries JM, Lekkerkerk-van der Wees JEC. Colonization resistance of the digestive tract in conventional and antibiotic-treated mice. J Hyg (Lond) 1971;69:405-411.

57. Stoutenbeek CP, Van Saene HK, Miranda DR, Zandstra DF. The effect of selective decontamination of the digestive tract on colonisation and infection rate in multiple trauma patients. Intensive Care Med 1984;10:185-192.

58. De Jonge E. Effects of selective decontamination of digestive tract on mortality and antibiotic resistance in the intensive care unit. Curr Opin Crit Care 2005;11:144-149.

59. Van Saene JJ, Van Saene HK, Stoutenbeek CP, Lerk CF. Influence of faeces on the activity of antimicrobial agents used for decontamination of the alimentary canal. Scand J Infect Dis 1985;17: 295-300.

60. Van Saene HK, Stoutenbeek CP, Gilbertson AA. Review of available trials of selective decontamination of the digestive tract (SDD). Infection 1990;18 Suppl 1:S5-9.

61. Sanchez Garcia M, Cambronero Galache JA, Lopez Diaz J, Cerda Cerda E, Rubio Blasco J, Gomez Aguinaga MA, Nunez Reiz A, Rogero Marin S, Onoro Canaveral JJ, Sacristan del Castillo JA. Effectiveness and cost of selective decontamination of the digestive tract in critically ill intubated patients. A randomized, double-blind, placebo-controlled, multicenter trial. Am J Respir Crit Care Med 1998;158:908-916.

62. D'Amico R, Pifferi S, Leonetti C, Torri V, Tinazzi A, Liberati A. Effectiveness of antibiotic prophylaxis in critically ill adult patients: systematic review of randomised controlled trials. BMJ 1998;316: 1275-1285.

63. Silvestri L, Mannucci F, Van Saene HK. Selective decontamination of the digestive tract: a life saver. J Hosp Infect 2000;45:185-190.

64. Kollef $\mathrm{MH}$. Opinion: the clinical use of selective digestive decontamination. Crit Care 2000;4:327-332.

65. Bonten MJ, Kullberg BJ, Van Dalen R, Girbes AR, Hoepelman IM, Hustinx W, Van der Meer JW, Speelman P, Stobberingh EE, Verbrugh HA, Verhoef J, Zwaveling JH. Selective digestive decontamination in patients in intensive care. The Dutch Working Group on Antibiotic Policy. J Antimicrob Chemother 2000;46:351-362. 
66. Bergmans DC, Bonten MJ, Gaillard CA, Paling JC, Van der Geest S, Van Tiel FH, Beysens AJ, De Leeuw PW, Stobberingh EE. Prevention of ventilator-associated pneumonia by oral decontamination: a prospective, randomized, double-blind, placebo-controlled study. Am J Respir Crit Care Med 2001; 164:382-388.

67. Zwaveling JH, Maring JK, Klompmaker IJ, Haagsma EB, Bottema JT, Laseur M, Winter HL, Van Enckevort PJ, Ten Vergert EM, Metselaar HJ, Bruining HA, Slooff MJ. Selective decontamination of the digestive tract to prevent postoperative infection: a randomized placebo-controlled trial in liver transplant patients. Crit Care Med 2002;30:1204-1209.

68. Krueger WA, Lenhart FP, Neeser G, Ruckdeschel G, Schreckhase H, Eissner HJ, Forst H, Eckart J, Peter $\mathrm{K}$, Unertl KE. Influence of combined intravenous and topical antibiotic prophylaxis on the incidence of infections, organ dysfunctions, and mortality in critically ill surgical patients: a prospective, stratified, randomized, double-blind, placebo-controlled clinical trial. Am J Respir Crit Care Med 2002;166: 1029-1037.

69. De Jonge E, Schultz MJ, Spanjaard L, Bossuyt PM, Vroom MB, Dankert J, Kesecioglu J. Effects of selective decontamination of digestive tract on mortality and acquisition of resistant bacteria in intensive care: a randomised controlled trial. Lancet 2003;362:1011-1016.

70. Kim SW, Kami M, Kobayashi K, Takaue Y, Honda O. Selective decontamination of digestive tract in intensive care. Lancet 2003;362:2118; author reply 2119-2120.

71. Bonten MJ, Kluytmans J, De Smet AM, Bootsma M, Hoes A. Selective decontamination of digestive tract in intensive care. Lancet 2003;362:2118-2119; author reply 2119-2120.

72. Verbrugh HA. Selective decontamination of digestive tract in intensive care. Lancet 2003;362: 2117-2118.

73. Vincent JL. Selective digestive decontamination: for everyone, everywhere? Lancet 2003;362: 1006-1007.

74. De la Cal MA, Cerda E, Garcia-Hierro P, Van Saene HK, Gomez-Santos D, Negro E, Lorente JA. Survival benefit in critically ill burned patients receiving selective decontamination of the digestive tract: a randomized, placebo-controlled, double-blind trial. Ann Surg 2005;241:424-430.

75. Silvestri L, Van Saene HK, Milanese M, Gregori D, Gullo A. Selective decontamination of the digestive tract reduces bacterial bloodstream infection and mortality in critically ill patients. Systematic review of randomized, controlled trials. J Hosp Infect 2007;65:187-203.

76. Stoutenbeek CP, Van Saene HK, Little RA, Whitehead A. The effect of selective decontamination of the digestive tract on mortality in multiple trauma patients: a multicenter randomized controlled trial. Intensive Care Med 2007;33:261-270.

77. De Smet AM, Bonten MJ. Selective decontamination of the digestive tract. Curr Opin Infect Dis 2008; 21:179-183.

78. Liberati A, D'Amico R, Pifferi S, Torri V, Brazzi L. Antibiotic prophylaxis to reduce respiratory tract infections and mortality in adults receiving intensive care. Cochrane Database Syst Rev 2004; CD000022.

79. Liberati A, D'Amico R, Pifferi S, Torri V, Brazzi L, Parmelli E. Antibiotic prophylaxis to reduce respiratory tract infections and mortality in adults receiving intensive care. Cochrane Database Syst Rev 2009;CD000022.

80. De Smet AM, Kluytmans JA, Cooper BS, Mascini EM, Benus RF, Van der Werf TS, Van der Hoeven JG, Pickkers P, Bogaers-Hofman D, Van der Meer NJ, Bernards AT, Kuijper EJ, Joore JC, Leverstein-van Hall MA, Bindels AJ, Jansz AR, Wesselink RM, De Jongh BM, Dennesen PJ, Van Asselt GJ, Te Velde LF, Frenay IH, Kaasjager K, Bosch FH, Van Iterson M, Thijsen SF, Kluge GH, Pauw W, De Vries JW, Kaan JA, Arends JP, Aarts LP, Sturm PD, Harinck HI, Voss A, Uijtendaal EV, Blok HE, Thieme Groen ES, Pouw ME, Kalkman CJ, Bonten MJ. Decontamination of the digestive tract and oropharynx in ICU patients. N Engl J Med 2009;360:20-31.

81. Bergmans DC, Zwaveling JH. [Selective decontamination in the ICU: benefit of the doubt]. Ned Tijdschr Geneeskd 2009;153:A488.

82. Schultz MJ, Haas LE. Antibiotics or probiotics as preventive measures against ventilator-associated pneumonia: a literature review. Crit Care 2011;15:R18.

83. Verwaest $C$, Verhaegen J, Ferdinande $P$, Schetz $M$, Van den Berghe G, Verbist L, Lauwers $P$. Randomized, controlled trial of selective digestive decontamination in 600 mechanically ventilated patients in a multidisciplinary intensive care unit. Crit Care Med 1997;25:63-71. 
General introduction $\mid 33$

84. Lingnau W, Berger J, Javorsky F, Fille M, Allerberger F, Benzer H. Changing bacterial ecology during a five-year period of selective intestinal decontamination. J Hosp Infect 1998;39:195-206.

85. Hammond JM, Potgieter PD. Long-term effects of selective decontamination on antimicrobial resistance. Crit Care Med 1995;23:637-645.

86. Leone M, Albanese J, Antonini F, Nguyen-Michel A, Martin C. Long-term (6-year) effect of selective digestive decontamination on antimicrobial resistance in intensive care, multiple-trauma patients. Crit Care Med 2003;31:2090-2095.

87. Bonten MJ, Grundmann H. Selective digestive decontamination and antibiotic resistance: a balancing act. Crit Care Med 2003;31:2239-2240.

88. Heininger A, Meyer E, Schwab F, Marschal M, Unertl K, Krueger WA. Effects of long-term routine use of selective digestive decontamination on antimicrobial resistance. Intensive Care Med 2006;32: 1569-1576.

89. Al Naiemi N, Heddema ER, Bart A, De Jonge E, Vandenbroucke-Grauls CM, Savelkoul PH, Duim B. Emergence of multidrug-resistant Gram-negative bacteria during selective decontamination of the digestive tract on an intensive care unit. J Antimicrob Chemother 2006;58:853-856.

90. Oostdijk EA, De Smet AM, Blok HE, Thieme Groen ES, Van Asselt GJ, Benus RF, Bernards SA, Frenay IH, Jansz AR, De Jongh BM, Kaan JA, Leverstein-van Hall MA, Mascini EM, Pauw W, Sturm PD, Thijsen SF, Kluytmans JA, Bonten MJ. Ecological effects of selective decontamination on resistant Gram-negative bacterial colonization. Am J Respir Crit Care Med 2010;181:452-457.

91. De Smet AM, Kluytmans JA, Blok HE, Mascini EM, Benus RF, Bernards AT, Kuijper EJ, Leverstein-van Hall MA, Jansz AR, De Jongh BM, Van Asselt GJ, Frenay IH, Thijsen SF, Conijn SN, Kaan JA, Arends JP, Sturm PD, Bootsma MC, Bonten MJ. Selective digestive tract decontamination and selective oropharyngeal decontamination and antibiotic resistance in patients in intensive care units: an openlabel, clustered group-randomised, crossover study. Lancet Infect Dis 2011;11:372-380.

92. Ochoa-Ardila ME, Garcia-Canas A, Gomez-Mediavilla K, Gonzalez-Torralba A, Alia I, Garcia-Hierro P, Taylor N, Van Saene HK, De la Cal MA. Long-term use of selective decontamination of the digestive tract does not increase antibiotic resistance: a 5-year prospective cohort study. Intensive Care Med 2011;37:1458-1465.

93. Vincent JL, Jacobs F. Effect of selective decontamination on antibiotic resistance. Lancet Infect Dis 2011;11:337-338.

94. Neuhauser MM, Weinstein RA, Rydman R, Danziger LH, Karam G, Quinn JP. Antibiotic resistance among Gram-negative bacilli in US intensive care units: implications for fluoroquinolone use. JAMA 2003;289:885-888.

95. Shibli AB, Milbrandt EB, Baldisseri M. Dirty mouth? Should you clean it out? Decontamination for the prevention of pneumonia and mortality in the ICU. Crit Care 2010;14:314.

96. Lilly DM, Stillwell RH. Probiotics: growth-promoting factors produced by microorganisms. Science 1965;147:747-748.

97. Pitsouni E, Alexiou V, Saridakis V, Peppas G, Falagas ME. Does the use of probiotics/synbiotics prevent postoperative infections in patients undergoing abdominal surgery? A meta-analysis of randomized controlled trials. Eur J Clin Pharmacol 2009;65:561-570.

98. Zhang MM, Cheng JQ, Lu YR, Yi ZH, Yang P, Wu XT. Use of pre-, pro- and synbiotics in patients with acute pancreatitis: a meta-analysis. World J Gastroenterol 2010;16:3970-3978.

99. Siempos II, Ntaidou TK, Falagas ME. Impact of the administration of probiotics on the incidence of ventilator-associated pneumonia: a meta-analysis of randomized controlled trials. Crit Care Med 2010;38:954-962.

100. Besselink MG, Van Santvoort HC, Buskens E, Boermeester MA, Van Goor H, Timmerman HM, Nieuwenhuijs VB, Bollen TL, Van Ramshorst B, Witteman BJ, Rosman C, Ploeg RJ, Brink MA, Schaapherder AF, Dejong CH, Wahab PJ, Van Laarhoven CJ, Van der Harst E, Van Eijck CH, Cuesta MA, Akkermans LM, Gooszen HG. Probiotic prophylaxis in predicted severe acute pancreatitis: a randomised, double-blind, placebo-controlled trial. Lancet 2008;371:651-659.

101. Knight DJ, Gardiner D, Banks A, Snape SE, Weston VC, Bengmark S, Girling KJ. Effect of synbiotic therapy on the incidence of ventilator-associated pneumonia in critically ill patients: a randomised, double-blind, placebo-controlled trial. Intensive Care Med 2009;35:854-861. 
102. Barraud D, Blard C, Hein F, Marcon O, Cravoisy A, Nace L, Alla F, Bollaert PE, Gibot S. Probiotics in the critically ill patient: a double blind, randomized, placebo-controlled trial. Intensive Care Med 2010;36: 1540-1547.

103. Morrow LE, Kollef MH, Casale TB. Probiotic prophylaxis of ventilator-associated pneumonia: a blinded, randomized, controlled trial. Am J Respir Crit Care Med 2010;182:1058-1064.

104. Liu Z, Qin H, Yang Z, Xia Y, Liu W, Yang J, Jiang Y, Zhang H, Wang Y, Zheng Q. Randomised clinical trial: the effects of perioperative probiotic treatment on barrier function and postoperative infectious complications in colorectal cancer surgery - a double-blind study. Aliment Pharmacol Ther 2011;33: 50-63.

105. Joint FAO/WHO expert consultation. Health and nutritional properties of probiotics in food including powder milk with live lactic acid bacteria. FAO/WHO 2001. Accessed 24 April 2011. Available at http://www.who.int/foodsafety/publications/fs_management/probiotics/en/.

106. Joint FAO/WHO working group meeting. Guidelines for the evaluation of probiotics in food. FAO/WHO 2002. Accessed 24 April 2011. Available at http://www.who.int/foodsafety/publications/ fs_management/probiotics2/en/.

107. Gibson GR, Roberfroid MB. Dietary modulation of the human colonic microbiota: introducing the concept of prebiotics. J Nutr 1995;125:1401-1412.

108. Wang X, Brown IL, Evans AJ, Conway PL. The protective effects of high amylose maize (amylomaize) starch granules on the survival of Bifidobacterium spp. in the mouse intestinal tract. J Appl Microbiol 1999;87:631-639.

109. Watkinson PJ, Barber VS, Dark P, Young JD. The use of pre- pro- and synbiotics in adult intensive care unit patients: systematic review. Clin Nutr 2007;26:182-192.

110. Klarin B, Johansson ML, Molin G, Larsson A, Jeppsson B. Adhesion of the probiotic bacterium Lactobacillus plantarum $299 \mathrm{v}$ onto the gut mucosa in critically ill patients: a randomised open trial. Crit Care 2005;9:R285-293.

111. Isakow W, Morrow LE, Kollef MH. Probiotics for preventing and treating nosocomial infections: review of current evidence and recommendations. Chest 2007;132:286-294.

112. Madsen K. Probiotics in critically ill patients. J Clin Gastroenterol 2008;42 Suppl 3:S116-118.

113. Adlerberth I, Ahrne S, Johansson ML, Molin G, Hanson LA, Wold AE. A mannose-specific adherence mechanism in Lactobacillus plantarum conferring binding to the human colonic cell line HT-29. Appl Environ Microbiol 1996;62:2244-2251.

114. Mack DR, Michail S, Wei S, McDougall L, Hollingsworth MA. Probiotics inhibit enteropathogenic E. coli adherence in vitro by inducing intestinal mucin gene expression. Am J Physiol 1999;276:G941-950.

115. Haskard C, Binnion C, Ahokas J. Factors affecting the sequestration of aflatoxin by Lactobacillus rhamnosus strain GG. Chem Biol Interact 2000;128:39-49.

116. Oatley JT, Rarick MD, Ji GE, Linz JE. Binding of aflatoxin B1 to bifidobacteria in vitro. J Food Prot 2000; 63:1133-1136.

117. Dai D, Walker WA. Protective nutrients and bacterial colonization in the immature human gut. Adv Pediatr 1999;46:353-382.

118. Aiba Y, Suzuki N, Kabir AM, Takagi A, Koga Y. Lactic acid-mediated suppression of Helicobacter pylori by the oral administration of Lactobacillus salivarius as a probiotic in a gnotobiotic murine model. Am J Gastroenterol 1998;93:2097-2101.

119. Eckmann L. Innate immunity and mucosal bacterial interactions in the intestine. Curr Opin Gastroenterol 2004;20:82-88.

120. Gionchetti P, Lammers KM, Rizzello F, Campieri M. Probiotics and barrier function in colitis. Gut 2005; 54:898-900.

121. Akisu M, Baka M, Yalaz M, Huseyinov A, Kultursay N. Supplementation with Saccharomyces boulardii ameliorates hypoxia/reoxygenation-induced necrotizing enterocolitis in young mice. Eur J Pediatr Surg 2003;13:319-323.

122. Pulverer G, Ko HL, Roszkowski W, Beuth J, Yassin A, Jeljaszewicz J. Digestive tract microflora liberates low molecular weight peptides with immunotriggering activity. Zentralb/ Bakteriol 1990;272:318-327.

123. Hatcher GE, Lambrecht RS. Augmentation of macrophage phagocytic activity by cell-free extracts of selected lactic acid-producing bacteria. J Dairy Sci 1993;76:2485-2492. 
\begin{tabular}{l|l} 
& \\
General introduction & 35
\end{tabular}

124. Qamar A, Aboudola S, Warny M, Michetti P, Pothoulakis C, LaMont JT, Kelly CP. Saccharomyces boulardii stimulates intestinal immunoglobulin $\mathrm{A}$ immune response to Clostridium difficile toxin $\mathrm{A}$ in mice. Infect Immun 2001;69:2762-2765.

125. Macpherson AJ, Uhr T. Induction of protective IgA by intestinal dendritic cells carrying commensal bacteria. Science 2004;303:1662-1665.

126. Rachmilewitz D, Katakura K, Karmeli F, Hayashi T, Reinus C, Rudensky B, Akira S, Takeda K, Lee J, Takabayashi K, Raz E. Toll-like receptor 9 signaling mediates the anti-inflammatory effects of probiotics in murine experimental colitis. Gastroenterology 2004;126:520-528.

127. Sheih YH, Chiang BL, Wang LH, Liao CK, Gill HS. Systemic immunity-enhancing effects in healthy subjects following dietary consumption of the lactic acid bacterium Lactobacillus rhamnosus HNO01. J Am Coll Nutr 2001;20:149-156.

128. Niers LE, Timmerman HM, Rijkers GT, Van Bleek GM, Van Uden NO, Knol EF, Kapsenberg ML, Kimpen $\mathrm{JL}$, Hoekstra MO. Identification of strong interleukin-10 inducing lactic acid bacteria which downregulate T helper type 2 cytokines. Clin Exp Allergy 2005;35:1481-1489.

129. Hart AL, Lammers K, Brigidi P, Vitali B, Rizzello F, Gionchetti P, Campieri M, Kamm MA, Knight SC, Stagg AJ. Modulation of human dendritic cell phenotype and function by probiotic bacteria. Gut 2004; 53:1602-1609.

130. Majamaa H, Isolauri E, Saxelin M, Vesikari T. Lactic acid bacteria in the treatment of acute rotavirus gastroenteritis. J Pediatr Gastroenterol Nutr 1995;20:333-338.

131. McFarland LV. Meta-analysis of probiotics for the prevention of antibiotic associated diarrhea and the treatment of Clostridium difficile disease. Am J Gastroenterol 2006;101:812-822.

132. Masood MI, Qadir MI, Shirazi JH, Khan IU. Beneficial effects of lactic acid bacteria on human beings. Crit Rev Microbiol 2011;37:91-98.

133. Kruis W. Review article: antibiotics and probiotics in inflammatory bowel disease. Aliment Pharmacol Ther 2004;20 Suppl 4:75-78.

134. Viljanen M, Savilahti E, Haahtela T, Juntunen-Backman K, Korpela R, Poussa T, Tuure T, Kuitunen M. Probiotics in the treatment of atopic eczema/dermatitis syndrome in infants: a double-blind placebocontrolled trial. Allergy 2005;60:494-500.

135. Rayes N, Hansen S, Seehofer D, Muller AR, Serke S, Bengmark S, Neuhaus P. Early enteral supply of fiber and lactobacilli versus conventional nutrition: a controlled trial in patients with major abdominal surgery. Nutrition 2002;18:609-615.

136. Rayes N, Seehofer D, Hansen S, Boucsein K, Muller AR, Serke S, Bengmark S, Neuhaus P. Early enteral supply of Lactobacillus and fiber versus selective bowel decontamination: a controlled trial in liver transplant recipients. Transplantation 2002;74:123-127.

137. Olah A, Belagyi T, Issekutz A, Gamal ME, Bengmark S. Randomized clinical trial of specific Lactobacillus and fibre supplement to early enteral nutrition in patients with acute pancreatitis. Br J Surg 2002;89: 1103-1107.

138. Rayes N, Seehofer D, Theruvath T, Schiller RA, Langrehr JM, Jonas S, Bengmark S, Neuhaus P. Supply of pre- and probiotics reduces bacterial infection rates after liver transplantation--a randomized, double-blind trial. Am J Transplant 2005;5:125-130.

139. Rayes N, Seehofer D, Theruvath T, MogI M, Langrehr JM, Nussler NC, Bengmark S, Neuhaus P. Effect of enteral nutrition and synbiotics on bacterial infection rates after pylorus-preserving pancreatoduodenectomy: a randomized, double-blind trial. Ann Surg 2007;246:36-41.

140. Kanazawa H, Nagino M, Kamiya S, Komatsu S, Mayumi T, Takagi K, Asahara T, Nomoto K, Tanaka R, Nimura Y. Synbiotics reduce postoperative infectious complications: a randomized controlled trial in biliary cancer patients undergoing hepatectomy. Langenbecks Arch Surg 2005;390:104-113.

141. Nomura T, Tsuchiya Y, Nashimoto A, Yabusaki H, Takii Y, Nakagawa S, Sato N, Kanbayashi C, Tanaka O. Probiotics reduce infectious complications after pancreaticoduodenectomy. Hepatogastroenterology 2007;54:661-663.

142. McNaught CE, Woodcock NP, MacFie J, Mitchell CJ. A prospective randomised study of the probiotic Lactobacillus plantarum $299 \mathrm{v}$ on indices of gut barrier function in elective surgical patients. Gut 2002; 51:827-831.

143. Anderson $A D, M c N a u g h t ~ C E$, Jain PK, MacFie J. Randomised clinical trial of synbiotic therapy in elective surgical patients. Gut 2004;53:241-245. 
144. Reddy BS, Macfie J, Gatt M, Larsen CN, Jensen SS, Leser TD. Randomized clinical trial of effect of synbiotics, neomycin and mechanical bowel preparation on intestinal barrier function in patients undergoing colectomy. Br J Surg 2007;94:546-554.

145. Rayes N, Seehofer D, Neuhaus P. Prebiotics, probiotics, synbiotics in surgery--are they only trendy, truly effective or even dangerous? Langenbecks Arch Surg 2009;394:547-555.

146. Olah A, Belagyi T, Poto L, Romics L Jr., Bengmark S. Synbiotic control of inflammation and infection in severe acute pancreatitis: a prospective, randomized, double blind study. Hepatogastroenterology 2007;54:590-594.

147. Jain PK, McNaught CE, Anderson AD, MacFie J, Mitchell CJ. Influence of synbiotic containing Lactobacillus acidophilus La5, Bifidobacterium lactis $\mathrm{Bb} 12$, Streptococcus thermophilus, Lactobacillus bulgaricus and oligofructose on gut barrier function and sepsis in critically ill patients: a randomised controlled trial. Clin Nutr 2004;23:467-475.

148. McNaught C, Woodcock N, Anderson A, MacFie J. A prospective randomised trial of probiotics in critically ill patients. Clinical Nutrition 2005;24:211-219.

149. Kotzampassi K, Giamarellos-Bourboulis EJ, Voudouris A, Kazamias P, Eleftheriadis E. Benefits of a synbiotic formula (Synbiotic 2000Forte ${ }^{\circledR}$ ) in critically ill trauma patients: early results of a randomized controlled trial. World J Surg 2006;30:1848-1855.

150. Spindler-Vesel A, Bengmark S, Vovk I, Cerovic O, Kompan L. Synbiotics, prebiotics, glutamine, or peptide in early enteral nutrition: a randomized study in trauma patients. J Parenter Enteral Nutr 2007;31:119-126.

151. Forestier C, Guelon D, Cluytens V, Gillart T, Sirot J, De Champs C. Oral probiotic and prevention of Pseudomonas aeruginosa infections: a randomized, double-blind, placebo-controlled pilot study in intensive care unit patients. Crit Care 2008;12:R69.

152. Klarin B, Molin G, Jeppsson B, Larsson A. Use of the probiotic Lactobacillus plantarum 299 to reduce pathogenic bacteria in the oropharynx of intubated patients: a randomised controlled open pilot study. Crit Care 2008;12:R136.

153. McNabb B, Isakow W. Probiotics for the prevention of nosocomial pneumonia: current evidence and opinions. Curr Opin Pulm Med 2008;14:168-175.

154. Koretz RL. Probiotics, critical illness, and methodologic bias. Nutr Clin Pract 2009;24:45-49.

155. Bengmark S. Synbiotics to strengthen gut barrier function and reduce morbidity in critically ill patients. Clin Nutr 2004;23:441-445.

156. Cesaro S, Chinello P, Rossi L, Zanesco L. Saccharomyces cerevisiae fungemia in a neutropenic patient treated with Saccharomyces boulardii. Support Care Cancer 2000;8:504-505.

157. Land $\mathrm{MH}$, Rouster-Stevens K, Woods CR, Cannon ML, Cnota J, Shetty AK. Lactobacillus sepsis associated with probiotic therapy. Pediatrics 2005;115:178-181.

158. Sullivan A, Nord CE. Probiotic lactobacilli and bacteraemia in Stockholm. Scand J Infect Dis 2006;38: 327-331.

159. De Groote MA, Frank DN, Dowell E, Glode MP, Pace NR. Lactobacillus rhamnosus GG bacteremia associated with probiotic use in a child with short gut syndrome. Pediatr Infect Dis J 2005;24:278-280.

160. Hennequin C, Kauffmann-Lacroix C, Jobert A, Viard JP, Ricour C, Jacquemin JL, Berche P. Possible role of catheters in Saccharomyces boulardii fungemia. Eur J Clin Microbiol Infect Dis 2000;19:16-20.

161. Salminen MK, Tynkkynen S, Rautelin H, Saxelin M, Vaara M, Ruutu P, Sarna S, Valtonen V, Jarvinen A. Lactobacillus bacteremia during a rapid increase in probiotic use of Lactobacillus rhamnosus $\mathrm{GG}$ in Finland. Clin Infect Dis 2002;35:1155-1160.

162. Besselink MG, Van Santvoort HC, Renooij W, De Smet MB, Boermeester MA, Fischer K, Timmerman HM, Ahmed Ali U, Cirkel GA, Bollen TL, Van Ramshorst B, Schaapherder AF, Witteman BJ, Ploeg RJ, Van Goor H, Van Laarhoven CJ, Tan AC, Brink MA, Van der Harst E, Wahab PJ, Van Eijck CH, Dejong $\mathrm{CH}$, Van Erpecum KJ, Akkermans LM, Gooszen HG. Intestinal barrier dysfunction in a randomized trial of a specific probiotic composition in acute pancreatitis. Ann Surg 2009;250:712-719. 


\section{Chapter 2}

\section{Antimicrobial resistance in Escherichia coli and Pseudomonas aeruginosa from Intensive Care Units in The Netherlands, 1998-2005}




\section{Abstract}

\section{Purpose}

In 1998, a nationwide surveillance of antibiotic resistance among Escherichia coli and Pseudomonas aeruginosa isolates of patients from 14 Intensive Care Units in The Netherlands was initiated.

\section{Methods}

Minimal inhibitory concentrations (MICs) of broad-spectrum penicillins with and without betalactamase inhibitors, cephalosporins, aminoglycosides and fluoroquinolones were determined by a broth microdilution method.

\section{Results}

An increase in percentages of resistance of $E$. coli and $P$. aeruginosa to most antibiotics tested was observed, but rates were still lower than those described in other countries. For E. coli, resistance to amoxicillin was fairly stable at $44 \%$ until 2004 and increased to $56 \%(P=0.01)$ in 2005. Similarly, piperacillin had a resistance rate of ca. $11 \%$ until 2004 , which then increased to $38 \%$ in $2005(P<0.001)$. The MIC distributions of piperacillin and piperacillin-tazobactam for $P$. aeruginosa were almost identical, as were the resistance rates $(4-14 \%)$. Resistance to ciprofloxacin nearly doubled in 2005 compared to previous years. Changes in resistance to the antibiotics tested were confirmed by trend analysis.

\section{Conclusions}

Together with infection control measures, antibiotic resistance surveillance is an important tool to control the antibiotic resistance problem. 


\section{Introduction}

A worldwide increase in antibiotic resistance among Gram-negative and Grampositive bacteria has been observed, especially in isolates derived from Intensive Care Unit (ICU) patients ${ }^{1}$.

Appropriate therapy during the first $48-72 \mathrm{~h}$ after admittance to the ICU is crucial for a positive outcome ${ }^{2}$. Empirical therapy in The Netherlands comprises mostly a combination of a beta-lactam antibiotic (broad-spectrum penicillin or second- and third-generation cephalosporin) with an aminoglycoside, whereas carbapenems, fourth-generation cephalosporins and ciprofloxacin may be used as alternatives in some situations. Knowledge of the resistance level of these antibiotics is crucial for adequate (empirical) antibiotic therapy. Therefore, in 1998 an antibiotic resistance surveillance programme on specific wards in Dutch hospitals was initiated. This study reports the results for beta-lactam antibiotics, aminoglycosides and ciprofloxacin in two indicator organisms, Escherichia coli and Pseudomonas aeruginosa, from ICU patients admitted to 14 large hospitals in The Netherlands between 1998 and 2005.

\section{Materials and methods}

\section{Setting}

The surveillance programme started in 1998 and involved patients from adult ICUs of two university hospitals and 12 large referral hospitals from across The Netherlands. More than $25 \%$ of the Dutch population was covered by these hospitals.

\section{Isolates}

Yearly, from January to July, 100 unique, unrelated, consecutive clinical isolates, including E. coli and P. aeruginosa, of ICU patients were collected in each of the 14 hospitals. Only one isolate per patient and species was included. The strains were identified at the local laboratory, kept at $-20^{\circ} \mathrm{C}$ and sent to the central laboratory for batch-wise antimicrobial susceptibility testing.

\section{Susceptibility testing}

Minimal inhibitory concentrations (MIC) were determined by the broth microdilution method with Mueller-Hinton II cation adjusted broth (Becton, Dickinson and Company, Sparks, MD) according to the Clinical and Laboratory Standards Institute (CLSI, formerly the National Committee for Clinical Laboratory Standards) guidelines, as previously described ${ }^{3,4}$. Microtitre plates containing freeze-dried antibiotics were obtained from MCS Diagnostics BV (Swalmen, The Netherlands) after quality testing by the manufacturer and guarantee of a maximum shelf-life of ca. one year. 
The antibiotics tested were (concentration range in $\mathrm{mg} / \mathrm{l}$ ): amoxicillin (0.06-128); amoxicillin-clavulanic acid (co-amoxiclav, ratio 4:1, 0.06-128); piperacillin (0.25-512); piperacillin-tazobactam (0.25/4-512/4); cefuroxime (0.06-128); ceftazidime (0.06$128)$; cefotaxime (0.06-128); cefixime (0.06-128); ceftibuten (0.06-128); cefepime (0.12-128); imipenem (0.06-64); meropenem (0.03-64); gentamicin (0.03-64); tobramycin (0.06-128); amikacin (0.12-256); and ciprofloxacin (0.008-16). The MIC was defined as the lowest concentration showing no growth in the microtitre plates after $18 \mathrm{~h}$ of incubation at $37^{\circ} \mathrm{C}$.

Breakpoints for resistance were as defined by the CLSI ${ }^{3}$. E. coli ATCC 35218 and ATCC 25922 were used as control strains. The central laboratory used the same method throughout the whole study period.

\section{Statistical analysis}

A Mann-Whitney $U$ test was used to compare susceptibility percentages for individual antibiotics between different years of surveillance. A logistic regression analysis was performed to determine statistically significant trends over time in changes of resistance of the isolates to the antibiotics tested during the study period, adjusted for participating centres. A $P$-value of $<0.05$ was considered statistically significant.

\section{Results}

In total, 1267 E. coli isolates and 741 P. aeruginosa isolates were included.

\section{Escherichia coli}

Amoxicillin resistance fluctuated at around 44\% from 1998 to 2004 (Figure 2.1a), but increased to $56 \%(P=0.01)$ in 2005 . Trend analysis using a logistic regression model confirmed the increase in resistance (from 42 to 51\%; $P<0.001$ ). The distribution of MICs in 1998 and 2005 (Figure 2.2a) showed two subpopulations: a susceptible one with a broad MIC range from 1-8 $\mathrm{mg} / \mathrm{l}$ and a highly resistant one with MICs $>32 \mathrm{mg} / \mathrm{l}$. A shift was observed in the susceptible subpopulation, with more strains inhibited by $8 \mathrm{mg} / \mathrm{l}$ in 2005 compared to 1998. Similarly, in the resistant subpopulation more strains with MICs $>32 \mathrm{mg} / \mathrm{l}$ (mostly $>256 \mathrm{mg} / \mathrm{l}$ ) were observed in $2005(P<0.05)$ compared to 1998.

Co-amoxiclav resistance also fluctuated. It showed an increase to $22 \%$ in 2000 with a decrease to $8 \%$ in 2001 and thereafter an increase to $22 \%$ in 2005 (Figure 2.1a). Trend analysis confirmed the overall increase (from 13 to $18 \% ; P=0.001$ ). The MIC distribution showed a highly resistant subpopulation (MICs $>32 \mathrm{mg} / \mathrm{l}, 9 \%$ of the total population) and a growing percentage of strains (up to $40 \%$ ) with MICs $\geq 16 \mathrm{mg} / \mathrm{l}$ in 2005 (Figure 2.2b). 
The overall resistance level of piperacillin was ca. $11 \%$ until 2004, which increased to $38 \%$ in $2005(P<0.001$, Figure 2.1a). Trend analysis confirmed the increase in resistance (from 4 to $32 \% ; P<0.001$ ). The MIC distributions of piperacillin (Figure 2.2c) showed three subpopulations: one susceptible (MICs $0.5-4 \mathrm{mg} / \mathrm{I}$ ), one moderately susceptible (MICs 8-64 mg/l) and one resistant subpopulation (MICs >64 mg/l). Piperacillin showed higher activity than amoxicillin towards the same population: the peak of piperacillin MICs in the susceptible range was at $1-2 \mathrm{mg} / \mathrm{l}$ compared to $4 \mathrm{mg} / \mathrm{I}$ for amoxicillin (Figure 2.2a and 2.2c).

Cefuroxime resistance fluctuated during the study period from 1 to $12 \%$, with a mean of 6\%; no increase was observed (Figure 2.1b). Trend analysis even showed a slight decrease in resistance (from 7 to $5.5 \% ; P=0.029$ ).

Cefotaxime and ceftazidime showed stable resistance levels of ca. $2 \%$ and $1 \%$, respectively. The rates for ceftibuten and cefepime resembled those of cefotaxime and ceftazidime, respectively, and that of cefixime was comparable with that of cefuroxime (5.5\% in 2005, Figure $2.1 \mathrm{~b}$ ). Trend analysis showed no significant changes in resistance, except for cefixime with an increase to $5 \%(P=0.024)$, i.e. similar to the level of cefuroxime resistance. The MIC distribution of cefuroxime (Figure 2.2e) showed a marked difference between 1998 and 2005, with a shift towards lower MIC values in the latter year. Cefotaxime, ceftazidime and cefepime showed a unimodal distribution in 2005 over a very small range, with $90 \%$ of strains having MICs $\leq 0.25 \mathrm{mg} / \mathrm{l}$. Occasionally, resistant strains were recorded. The MIC distributions in 2005 of ceftibuten and cefixime ranged over a broader area, from 0.06-4 mg/l, with a MIC for $90 \%$ of the organisms of $1-2 \mathrm{mg} / \mathrm{l}$ (Figure $2.1 \mathrm{c}$ ).

Gentamicin resistance fluctuated between 1\% and 4\% (mean 3\%) until 2004 and showed an increase to 7\% in 2005 (not significant (NS), Figure 2.1a). However, trend analysis showed an overall significant increase in resistance (from 2 to $5 \% ; P=0.006$ ).

Ciprofloxacin resistance increased slowly but steadily to $9 \%$ in 2005 (Figure 2.1a). In 1998, resistant strains were only isolated in the ICUs of two hospitals, compared to five in 2002 and all 14 hospitals in 2005. Trend analysis showed an increase in resistance from $3 \%$ to $10 \%(P<0.001)$.

Multi-resistant $E$. coli isolates (i.e. resistant to three or more groups of antibiotics) were observed for various combinations, mostly at low levels. However, the number of combinations to which resistance was found increased during the years as well as the number of antibiotics within the combinations, but co-amoxiclav and gentamicin or ciprofloxacin were nearly always included. Until 1999, only resistance to a combination of three antibiotics was found (in 2\% of strains). From 2000 onwards, resistance to four or even five antibiotics was recorded. This comprised ca. $2 \%$ of the strains yearly, whereas the resistance rate to three antibiotics increased to $4 \%$ in 2004 and 2005. 
a

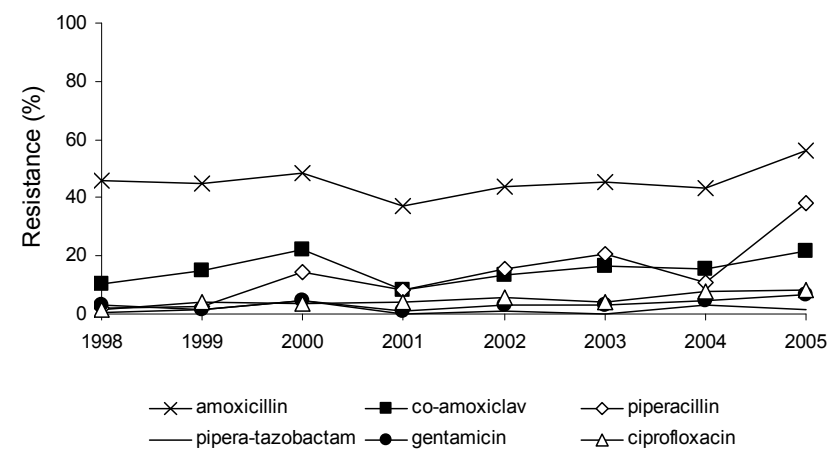

b

E. coli - Intensive Care Units

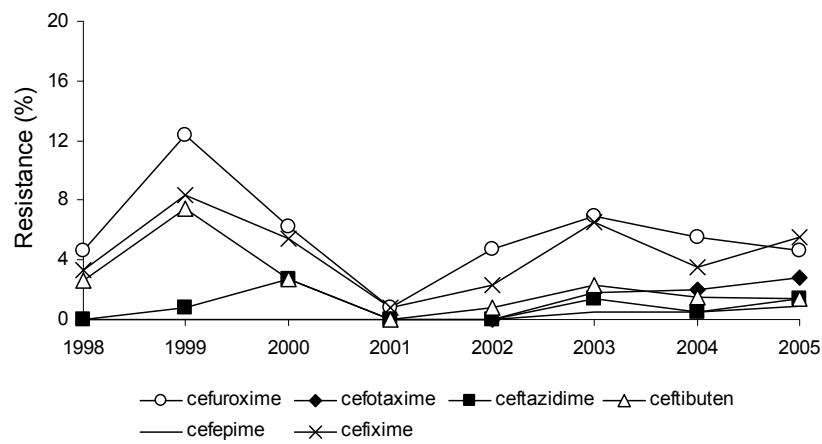

C

E. coli - Intensive Care Units 2005

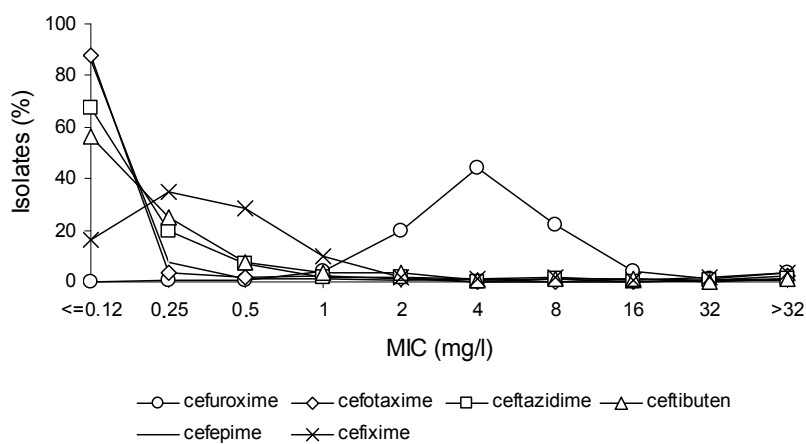

Figure 2.1 (a, b) Trends in resistance to 12 antibiotics among clinical isolates of Escherichia coli from Intensive Care Units (ICUs). (c) Minimal inhibitory concentration (MIC) distributions of six cephalosporins for E. coli from ICUs in 2005. 
a

E. coli - amoxicillin Intensive Care Units

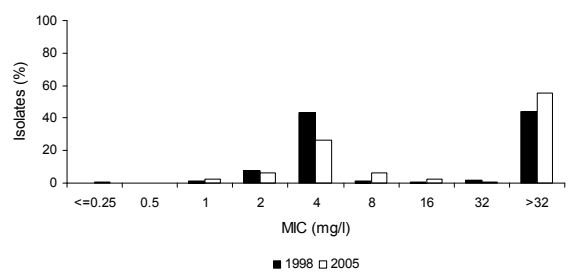

C

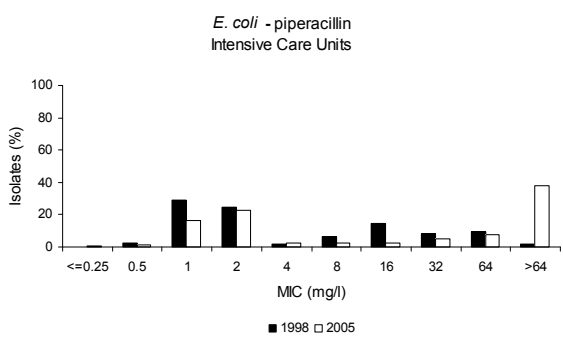

e

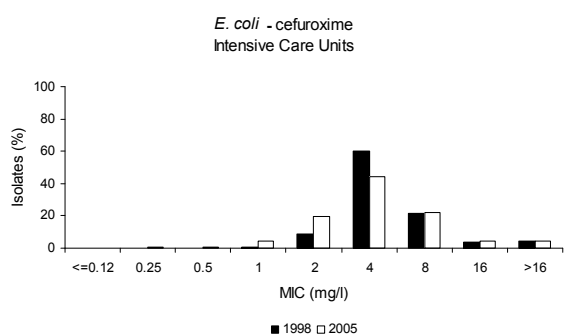

g
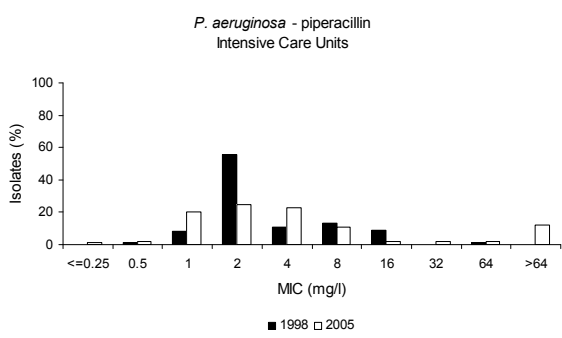

b

E. coli - co-amoxiclav Intensive Care Units

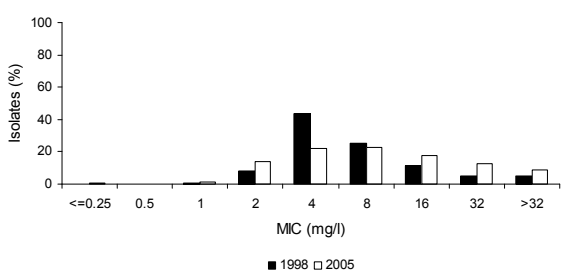

d

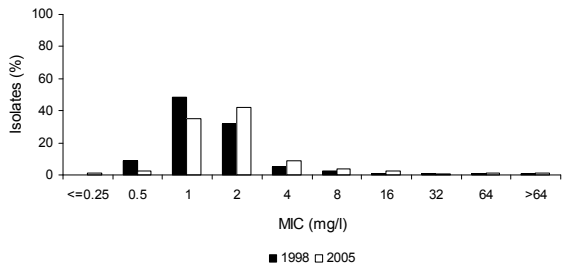

f E. coli - ceftazidime Intensive Care Units

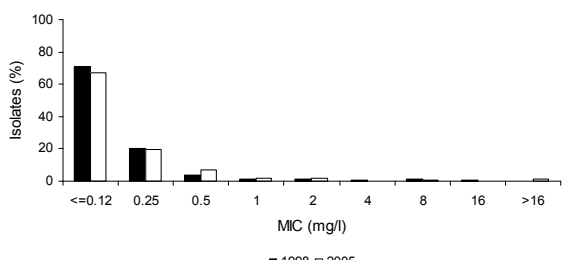

$\mathrm{h}$ P. aeruginosa - piperacillin-tazobactam Intensive Care Units

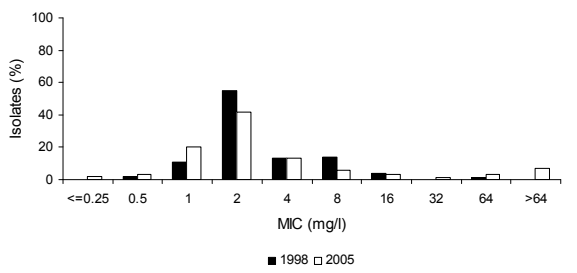

Figure 2.2 Minimal inhibitory concentration (MIC) distributions of beta-lactam antibiotics for (a-f) Escherichia coli and (g, h) Pseudomonas aeruginosa from Intensive Care Units in 1998 and in 2005.

\section{Pseudomonas aeruginosa}

Piperacillin resistance varied between $4 \%$ and $14 \%$ (mean 6\%) and piperacillintazobactam resistance varied between $3 \%$ and $8 \%$ (mean $4 \%$, Figure $2.3 \mathrm{a}$ ). Trend analysis showed an increase from $1.5 \%$ to $10 \%(P<0.001)$ and from $1 \%$ to $6 \%(P=0.017)$, respectively. The piperacillin and piperacillin-tazobactam MIC distributions had a 
44 Chapter 2

unimodal shape over a broad range. In 2005, a small shift was observed for piperacillin, with more resistant strains with MICs up to $1024 \mathrm{mg} / \mathrm{l}$ (Figure $2.2 \mathrm{~g}$ and 2.2h).

Ceftazidime resistance was low (0-4\%), with an incidental $10 \%$ resistance recorded in 2002 in five centres. This relatively high resistance level disappeared in the following years (Figure 2.3a). Trend analysis depicted an increase in resistance (from $1 \%$ to $3.5 \% ; P=0.049)$.

Gentamicin resistance was found yearly in two to five (the same) ICUs, responsible for the fluctuations in the overall resistance rate from $2 \%$ to $9 \%$, with $8 \%$ in 2005 (Figure 2.3a). Trend analysis showed a significant increase from $2 \%$ to $5 \%(P=0.001)$.

Ciprofloxacin resistance increased from 7\% in 1998 to $11 \%$ in 2002, thereafter a drop was observed to $6 \%$ in 2003. It increased again in 2004 to $9 \%$ and to $16 \%$ in 2005 (NS, Figure 2.3a). Trend analysis showed an overall significant increase in resistance (from 5 to $12 \% ; P=0.019)$.

\section{$P$. aeruginosa - Intensive Care Units}

a

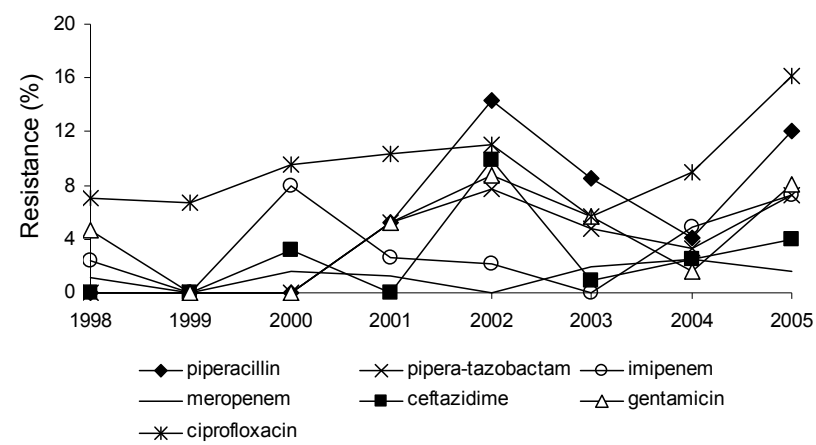

b P. aeruginosa - Intensive Care Units 2005

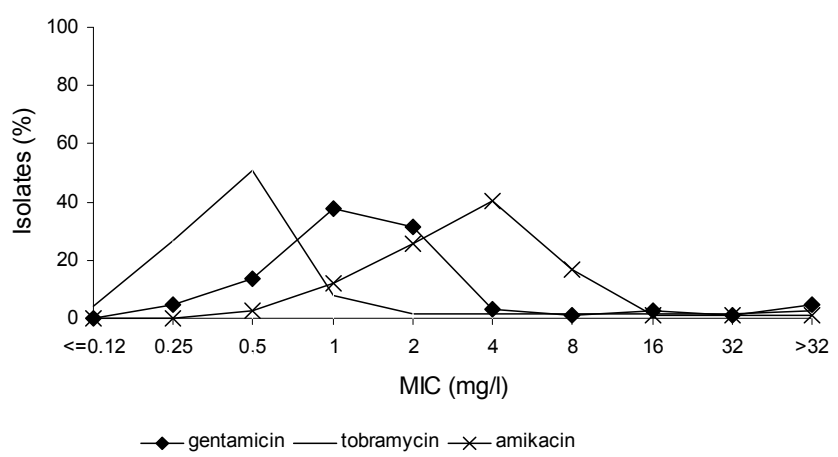

Figure 2.3 (a) Trends in resistance to seven antibiotics among clinical isolates of Pseudomonas aeruginosa from Intensive Care Units (ICUs). (b) Minimal inhibitory concentration (MIC) distributions of three aminoglycosides for P. aeruginosa from ICUs in 2005. 


\section{Discussion}

The resistance levels for $E$. coli and $P$. aeruginosa isolates from 14 ICUs in The Netherlands appeared lower for all antibiotics tested than those recorded in other European and North American countries ${ }^{5,6}$. However, a (slow) increase in resistance for several antibiotics, such as amoxicillin and piperacillin for $E$. coli and ciprofloxacin for $P$. aeruginosa, was observed during the study period. This is in accordance with the global observation of increased resistance to antibiotics, not only in hospitals but also in the community ${ }^{7,8}$. It is generally accepted that selective pressure (i.e. antibiotic use) is the main risk factor for emergence and dissemination of antibiotic resistance ${ }^{7}$. Set-up and implementation of guidelines regarding optimal antibiotic use based on actual local resistance data is essential, especially in patients admitted to an ICU, to reduce morbidity and mortality ${ }^{2}$.

The relatively low resistance rates are very likely a reflection of the prudent use of antibiotics in The Netherlands. The total antibiotic consumption in primary health care in The Netherlands from 2001-2005 was ca. 10 defined daily doses (DDD)/1000 inhabitant-days ${ }^{9}$, which is significantly lower than the use in several other countries such as France, Portugal, Greece and Germany ${ }^{10}$. Data on antibiotic use in ICUs showed a similar pattern, although the differences between the countries were smaller. The total antibiotic consumption varied between $92 \mathrm{DDD} / 100$ bed-days in a Dutch ICU and 115 DDD/100 bed-days in Swedish ICUs ${ }^{11,12}$.

The increase in amoxicillin resistance in E. coli between 1998 and 2005 cannot be explained by increased use in Dutch hospitals ${ }^{9}$, but may be the result of import from the community. Amoxicillin and co-amoxiclav are very frequently used in general practice. Steadily increased use of co-amoxiclav was observed during the last five years, whereas amoxicillin use stabilised at a high level, with simultaneously increased resistance in the community ${ }^{9}$.

The increase in resistance for piperacillin among $E$. coli during the study period is remarkable; resistance is now at the level reported in other studies ${ }^{5,6}$. The increase was in line with the increase in amoxicillin resistance.

Gentamicin resistance in $E$. coli was very low and remained constant across the years; it was of the same order of magnitude as found by others ${ }^{5}$. The increase in the last years of the study is a matter of concern.

The emergence and increasing trend of multi-drug resistance among $E$. coli isolates during the study period has also been reported by others ${ }^{13}$. This trend needs to be closely monitored during the next years of the surveillance programme, and in case of persistence or increase appropriate action is mandatory.

Both piperacillin and piperacillin-tazobactam were equally active against $P$. aeruginosa. Taking into account the prudent use of antibiotics, the former compound is preferable in case of a $P$. aeruginosa infection. The resistance rates of $P$. aeruginosa isolates against piperacillin and piperacillin-tazobactam were in line 
with those found by others ${ }^{6,14}$. The increase in resistance during the study period could not be explained by increased use of the two compounds ${ }^{9}$.

Gentamicin resistance among $P$. aeruginosa strains did increase, however, to levels lower than those found in other countries ${ }^{14}$. Aminoglycoside use in Dutch ICUs is very limited ${ }^{9}$.

The relatively low percentages of $E$. coli and $P$. aeruginosa resistant to the different cephalosporins tested are very likely due to the low use of cephalosporins in The Netherlands. These antibiotics are hardly used in general practice: the total use of oral cephalosporins in the community is $0.5 \%$ that of amoxicillin, whereas no parenteral cephalosporins are prescribed ${ }^{9}$. Cephalosporin use for systemic therapy in Dutch hospitals is considerable but lower than that of penicillins ${ }^{9}$. Drugs of first choice are cefotaxime, ceftriaxone or ceftazidime, the latter preferably in case of infections by $P$. aeruginosa. Susceptibility to cephalosporins was in accordance with findings from other studies in Northern Europe ${ }^{11}$.

The steady increase in ciprofloxacin resistance in $E$. coli and $P$. aeruginosa was in line with findings in other studies performed both in the community and in hospitals ${ }^{15}$. This increase is in parallel with the increased use of ciprofloxacin in the community in later years, from 0.2 DDD/1000 inhabitant-days in 1998 to 0.36 DDD/1000 inhabitantdays in $2005^{9}$. Also, increased use of ciprofloxacin in hospitals was observed during the study period, from 2.6 DDD/100 patient-days in 1999 to $4.6 \mathrm{DDD} / 100$ patient-days in $2004^{9}$.

The hospitals included in the study were distributed over the whole country, covering at least $25 \%$ of the population, which is a relatively high coverage. In general, the data presented are a good reflection of the antibiotic resistance situation in ICUs in The Netherlands.

\section{Conclusions}

The observed trends of increasing resistance rates against certain antibiotics during the study period underline the need to continue this surveillance programme. For antibiotic resistance surveillance studies, quantitative MIC determination gives the possibility to observe not only changes in percentages of resistance or susceptibility but also to observe shifts within the resistant or susceptible population.

Resistance patterns and trends over time are the cornerstones for the set-up of antibiotic guidelines, which form the basis for optimal antibiotic policy. Implementation of antibiotic guidelines is essential to control the antibiotic resistance problem and to reduce morbidity and mortality in ICUs. 


\section{References}

1. Jones ME, Draghi DC, Thornsberry C, Karlowsky JA, Sahm DF, Wenzel RP. Emerging resistance among bacterial pathogens in the intensive care unit--a European and North American Surveillance study (2000-2002). Ann Clin Microbiol Antimicrob 2004;3:14.

2. Ibrahim EH, Sherman G, Ward S, Fraser VJ, Kollef $M H$. The influence of inadequate antimicrobial treatment of bloodstream infections on patient outcomes in the ICU setting. Chest 2000;118:146-155.

3. National Committee for Clinical Laboratory Standards. Methods for Dilution Antimicrobial Susceptibility Tests for Bacteria that Grow Aerobically-Fifth Edition: Approved Standard M7-A5. NCCLS, Villanova, PA. 2002.

4. Nys S, Okeke IN, Kariuki S, Dinant GJ, Driessen C, Stobberingh EE. Antibiotic resistance of faecal Escherichia coli from healthy volunteers from eight developing countries. J Antimicrob Chemother 2004;54:952-955.

5. Streit JM, Jones RN, Sader HS, Fritsche TR. Assessment of pathogen occurrences and resistance profiles among infected patients in the intensive care unit: report from the SENTRY Antimicrobial Surveillance Program (North America, 2001). Int J Antimicrob Agents 2004;24:111-118.

6. Hanberger H, Diekema D, Fluit A, Jones R, Struelens M, Spencer R, Wolff M. Surveillance of antibiotic resistance in European ICUs. J Hosp Infect 2001;48:161-176.

7. Yagupsky P. Selection of antibiotic-resistant pathogens in the community. Pediatr Infect Dis $J$ 2006;25:974-976.

8. Goossens H, Ferech M, Vander Stichele R, Elseviers M. Outpatient antibiotic use in Europe and association with resistance: a cross-national database study. Lancet 2005;365:579-587.

9. SWAB. NethMap 2007 - Consumption of antimicrobial agents and antimicrobial resistance among medically important bacteria in The Netherlands. Accessed 15 December 2011. Available at http://www.swab.nl/swab/cms3.nsf/uploads/691731F771D8FFE9C125759400497CAD/\$FILE/NETHM AP_2007.pdf.

10. Cars O, Molstad S, Melander A. Variation in antibiotic use in the European Union. Lancet 2001;357:1851-1853.

11. Hanberger H, Erlandsson M, Burman LG, Cars O, Gill H, Lindgren S, Nilsson LE, Olsson-Liljequist B, Walther S; ICU-STRAMA Study Group. High antibiotic susceptibility among bacterial pathogens in Swedish ICUs. Report from a nation-wide surveillance program using TA90 as a novel index of susceptibility. Scand J Infect Dis 2004;36:24-30.

12. Bergmans DC, Bonten MJ, Gaillard CA, Van Tiel FH, Van der Geest S, De Leeuw PW, Stobberingh EE. Indications for antibiotic use in ICU patients: a one-year prospective surveillance. J Antimicrob Chemother 1997;39:527-535.

13. Filius PM, Gyssens IC, Kershof IM, Roovers PJ, Ott A, Vulto AG, Verbrugh HA, Endtz HP. Colonization and resistance dynamics of Gram-negative bacteria in patients during and after hospitalization. Antimicrob Agents Chemother 2005;49:2879-2886.

14. Sligl W, Taylor G, Brindley PG. Five years of nosocomial Gram-negative bacteremia in a general intensive care unit: epidemiology, antimicrobial susceptibility patterns, and outcomes. Int J Infect Dis 2006;10:320-325.

15. Hoogkamp-Korstanje JA, Roelofs-Willemse J. Antimicrobial resistance in Gram-negative bacteria from Intensive Care Units and Urology Services. A nationwide study in The Netherlands 1995-2000. Int J Antimicrob Agents 2003;21:547-556. 



\section{Chapter 3}

Soluble Triggering Receptor Expressed on

Myeloid cells-1 in bronchoalveolar lavage fluid

is not predictive for ventilator-associated pneumonia

Guy J Oudhuis, Judith Beuving, Dennis C Bergmans, Ellen E Stobberingh, Guul ten Velde, Catharina F Linssen, Annelies Verbon 


\section{Abstract}

\section{Purpose}

Soluble Triggering Receptor Expressed on Myeloid cells-1 (sTREM-1) has proven to be a good biomarker for sepsis. For the diagnosis ventilator-associated pneumonia (VAP), however, there have only been a few, relatively small, studies on the role of this receptor. The aim of the study was to evaluate the usefulness of STREM-1 in bronchoalveolar lavage fluid (BALF) from Intensive Care Unit patients as rapid diagnostic test for VAP.

\section{Methods}

The concentration of STREM- 1 in 240 BALF samples was measured using a quantitative sandwich enzyme immunoassay. Two researchers, who were blind to the assay results, determined whether a VAP was present or not. Clinical suspicion of a VAP was confirmed by the presence of $\geq 2 \%$ cells containing intracellular organisms and/or a quantitative culture result of $\geq 10^{4}$ colony forming units per millilitre BALF.

\section{Results}

The mean concentration of STREM-1 was significantly higher in the BALF of patients with confirmed VAP than in that of patients without confirmed VAP. However, the area under the receiver-operating characteristic curve was 0.58 ( $95 \%$ confidence interval $0.50-0.65, P=0.04$ ).

\section{Conclusions}

The results imply that the STREM-1 assay in BALF may not be discriminative for VAP. 
STREM-1 in BALF is not predictive for VAP $\mid$

\section{Introduction}

The diagnosis of ventilator-associated pneumonia (VAP), a complication that often arises in patients receiving mechanical ventilation, is difficult. Clinical suspicion alone is not reliable ${ }^{1}$ and may lead to an overestimation of VAP, resulting in unnecessary antibiotic therapy. Results from invasive procedures, such as quantitative culture of bronchoalveolar lavage fluid (BALF), have proven to be useful ${ }^{2}$, but these are not available for 24-48 $\mathrm{h}$.

A potential candidate as a rapid diagnostic test for VAP is soluble Triggering Receptor Expressed on Myeloid cells-1 (sTREM-1). Testing for STREM-1 in BALF has promising results with a sensitivity of $98 \%$ and a specificity of $90 \%{ }^{3}$.

TREM-1 is shed from membranes of activated phagocytes and is found in soluble form in body fluids. It is a glycoprotein, expressed as receptor on neutrophils and CD14 ${ }^{\text {high }}$ monocytes/macrophages ${ }^{4}$. The expression of TREM-1 is strongly up-regulated in tissues infected with extracellular microorganisms ${ }^{5}$.

In humans, STREM-1 in the blood proved to be a good biomarker for sepsis ${ }^{6}$. For pneumonia, however, the value of STREM-1 in BALF ${ }^{3,7-10}$ has received varying assessments. To evaluate the usefulness of STREM-1 as rapid diagnostic test for VAP, we tested 240 BALF samples from intensive care unit (ICU) patients.

\section{Materials and methods}

\section{Patients}

This is a retrospective study that included patients admitted to the ICU of Maastricht University Medical Centre, who underwent BAL while receiving mechanical ventilation. In all patients, mechanical ventilation was initiated on the day of admission. Patients were screened daily for VAP using clinical criteria, and BAL was performed on the day of clinical suspicion. For each patient receiving more than one $B A L$, the BALs were included in the study when the time period between BALs was $\geq 2$ weeks; when there was $<2$ weeks between BALs, only the first BAL was included.

Baseline criteria were recorded (Table 3.1). Time between ICU admission and BAL was also determined. Study protocols were approved by the institutional review board for human studies. Informed consent regarding the use of data for research purposes was obtained from patients or their legal representatives. 
52 Chapter 3

Table 3.1 Characteristics of the study population

\begin{tabular}{|c|c|c|c|c|}
\hline Characteristic & $\begin{array}{l}\text { All patients } \\
(\mathrm{n}=207)\end{array}$ & $\begin{array}{l}\text { Patients with } \\
\text { confirmed VAP } \\
(n=90)\end{array}$ & $\begin{array}{l}\text { Patients without } \\
\text { confirmed VAP } \\
(n=117)\end{array}$ & $\begin{array}{l}P \text {-value } \\
\text { (two groups } \\
\text { compared) }\end{array}$ \\
\hline \multicolumn{5}{|l|}{ Sex } \\
\hline male (\%) & $130(62.8)$ & $54(60)$ & $76(65)$ & \multirow[t]{2}{*}{0.46} \\
\hline female (\%) & $77(37.2)$ & $36(40)$ & $41(35)$ & \\
\hline \multicolumn{5}{|l|}{ Age in years } \\
\hline Median (interquartile range) & $62(47-72)$ & $65.50(47-73.25)$ & $61(47.50-71)$ & 0.43 \\
\hline \multicolumn{5}{|l|}{ Days in hospital } \\
\hline Mean ( \pm SEM) & $68.0(4.6)$ & $75.7(9.0)$ & $62.1(4.2)$ & \multirow[t]{2}{*}{0.76} \\
\hline Range & $6-540$ & $6-540$ & $8-322$ & \\
\hline \multicolumn{5}{|l|}{ Days in ICU } \\
\hline Mean $( \pm$ SEM) & $39.8(2.8)$ & $45.1(5.7)$ & $35.8(2.3)$ & \multirow[t]{2}{*}{0.77} \\
\hline Range & $6-397$ & $6-397$ & $7-168$ & \\
\hline \multicolumn{5}{|l|}{ Days in ICU before BAL ${ }^{b}$} \\
\hline Mean $( \pm$ SEM) & $15.5(0.9)$ & $15.3(1.5)$ & $15.7(1.2)$ & \multirow[t]{2}{*}{0.63} \\
\hline Range & $2-83$ & $3-83$ & $2-73$ & \\
\hline \multicolumn{5}{|l|}{ APACHE II score ${ }^{c}$} \\
\hline Mean ( \pm SEM) & $23(0.5)$ & $23(0.9)$ & $23(0.6)$ & \multirow[t]{2}{*}{0.83} \\
\hline Range & $4-44$ & $4-44$ & $7-40$ & \\
\hline Mortality in ICU (\%) & $72(34.8)$ & $33(36.7)$ & $39(33.3)$ & 0.62 \\
\hline Mortality in hospital (\%) & $83(40.1)$ & $41(45.6)$ & $42(35.9)$ & 0.16 \\
\hline History of COPD (\%) & $10(4.8)$ & $5(5.6)$ & $5(4.3)$ & 0.67 \\
\hline \multicolumn{5}{|l|}{ Medical specialty (\%) } \\
\hline medical & $71(34.3)$ & $24(26.7)$ & $47(40.2)$ & \multirow{5}{*}{0.26} \\
\hline surgical & $78(37.7)$ & 35 (38.9) & $43(36.8)$ & \\
\hline trauma & $34(16.4)$ & $19(21.1)$ & $15(12.8)$ & \\
\hline neurological & $18(8.7)$ & $9(10.0)$ & $9(7.7)$ & \\
\hline other $^{d}$ & $6(2.9)$ & $3(3.3)$ & $3(2.6)$ & \\
\hline \multicolumn{5}{|l|}{ Reason for ICU admission (\%) } \\
\hline respiratory insufficiency & $25(12.1)$ & $10(11.1)$ & 15 (12.8) & \multirow{7}{*}{0.21} \\
\hline trauma & $28(13.5)$ & 15 (16.7) & $13(11.1)$ & \\
\hline shock & $52(25.1)$ & $19(21.1)$ & $33(28.2)$ & \\
\hline cardiopulmonary failure & $17(8.2)$ & $4(4.4)$ & $13(11.1)$ & \\
\hline pneumonia & $32(15.5)$ & $13(14.4)$ & $19(16.2)$ & \\
\hline neurological disease & $15(7.2)$ & $7(7.8)$ & $8(6.8)$ & \\
\hline postoperative & $38(18.4)$ & $22(24.4)$ & $16(13.7)$ & \\
\hline
\end{tabular}

VAP, ventilator-associated pneumonia; BAL, bronchoalveolar lavage; SEM, standard error of the mean; ICU, intensive care unit; COPD, chronic obstructive pulmonary disease; APACHE II, acute physiology and chronic health evaluation II. ${ }^{a}$ Seven patients underwent three BALs, 19 patients two BALs and 181 patients had one BAL. None of these patients had more than one positive BAL within a time period of 14 days. ${ }^{b}$ all 240 BALs are included in this item. ${ }^{\mathrm{C}} 10 \%$ of the APACHE II scores could not be retrospectively calculated. The patients involved did not differ from the other patients in this study. ${ }^{\mathrm{d}}$ including otorhinolaryngology, paediatrics, gynaecology and oral surgery.

\section{VAP diagnosis}

Clinical suspicion of VAP was according to the definition of Bonten et al. ${ }^{11}$, and VAP was considered to be acquired upon manifestation of the disease after $\geq 48 \mathrm{~h}$ of mechanical ventilation. Clinically suspected VAP was considered confirmed VAP when 
the microbiological results met the following criteria ${ }^{11,12}$ : presence of $\geq 2 \%$ cells containing intracellular organisms (ICO) and/or quantitative culture result of $\geq 10^{4}$ colony forming units (cfu) per millilitre of BALF.

Following BAL, antibiotic therapy was started empirically in patients who had not previously received treatment. When patients developed a VAP while receiving antibiotics, the therapy was adjusted. Antibiotic treatment before and during BAL does not influence the predictive value of the percentage ICO in BALF in diagnosing $V A P^{12}$. Thus, due to the combination of quantitative BALF culture and presence of ICO, adjustment of the $\mathrm{cfu} / \mathrm{ml}$ threshold was unnecessary to diagnose VAP correctly when antibiotics were being used before the BAL.

Two researchers (GJO and $A V$ ) retrospectively determined whether patients met the criteria of clinically suspected and confirmed VAP, independently from one another and blind to the STREM-1 assay results. This yielded two study groups; a confirmed VAP group and a group in which VAP could not be confirmed. A consensus diagnosis was achieved in all cases.

\section{Bronchoalveolar lavage}

Bronchoscopy with directed BAL was performed as described previously ${ }^{12}$. Samples were processed within $1 \mathrm{~h}$ after the BAL. All aliquots were pooled, except for the first one. The BALF samples were Gram-stained, and quantitative culture was performed as described previously ${ }^{13}$. The urea concentration was determined by means of an enzymatic conductivity rate method using the SYNCHRON LX ${ }^{\circledR}$ System (Beckman Coulter BV, Mijdrecht, The Netherlands) as previously described ${ }^{14}$. The remaining BALF was centrifuged at $250 \mathrm{~g}$ for $10 \mathrm{~min}$. The supernatant was stored at $-80^{\circ} \mathrm{C}$ in six different aliquots until further processing.

\section{Soluble Triggering Receptor Expressed on Myeloid cells-1 assay}

A quantitative sandwich enzyme immunoassay (Quantikine Human TREM-1 Immunoassay; R\&D Systems, Minneapolis, MN) was used to detect STREM-1 in BALF in accordance to the manufacturers' instructions, as described previously ${ }^{7}$.

The measured concentration of STREM-1 in BALF samples is not identical to that in the epithelial lining fluid (ELF), secondary to dilution of the BALF. To calculate the concentration of STREM-1 in ELF from the concentration of STREM-1 in BALF, we applied a correction with a dilution factor using the ratio of urea concentration in the serum and $\mathrm{BALF}^{15}$.

\section{Statistical analysis}

The Mann-Whitney $U$ test was used for the numerical data; for STREM-1 concentrations, we used Student's $t$ test to compare logarithmic means. The Pearson $\chi^{2}$ test was used for categorical data. The analyses were corrected, by clustered 
54 Chapter 3

logistic regression, for the influence of multiple BALs performed in the same patient. To assess the diagnostic value of the STREM-1 assay, we produced a receiveroperating characteristic (ROC) curve and measured the area under the curve. Statistical significance was defined as a $P$-value of $<0.05$ in all cases. Analysis was performed with SPSS ver. 14.0 for Windows (SPSS, Chicago, IL).

\section{Results}

\section{Patients}

Between January 2001 and October 2006, 361 BALs were performed, of which 59 were excluded from our retrospective analysis since they did not meet the quality criteria $^{12}$, and 62 were excluded because they were performed within $48 \mathrm{~h}$ after ICU admission. The remaining 240 BALs, performed in 207 patients, were included in our study.

Seven patients underwent three BALs, 19 patients underwent two BALs and 181 patients had one BAL. The presence of VAP was confirmed in 97 cases (40.4\%) and not confirmed in 143 cases (59.6\%).

Confirmed VAP cases did not differ significantly from unconfirmed cases, and both groups did not differ significantly in terms of in-hospital mortality and ICU mortality (Table 3.1). The number of patients with chronic obstructive pulmonary disease (COPD) was low and did not differ between both study groups (Table 3.1).

\section{Soluble Triggering Receptor Expressed on Myeloid cells-1 levels}

The mean STREM-1 concentration was significantly higher in the BALF of patients with confirmed VAP (1849 pg/ml, 95\% confidence interval $(\mathrm{Cl}) 1515-2256 \mathrm{pg} / \mathrm{ml}$ ) than in those without confirmed VAP $(1424 \mathrm{pg} / \mathrm{ml}, 95 \% \mathrm{Cl} 1218-1664 \mathrm{pg} / \mathrm{ml} ; P=0.04$; Figure 3.1a).

Mean sTREM-1 levels did not differ between patients with COPD $(1570 \mathrm{pg} / \mathrm{ml}, 95 \% \mathrm{Cl}$ $1081-2279 \mathrm{pg} / \mathrm{ml}$ ) and those without (1617 pg/ml, 95\% Cl $1404-1863 \mathrm{pg} / \mathrm{ml} ; P=0.93)$. No significant difference in mean STREM-1 level was observed between medical patients $(1676 \mathrm{pg} / \mathrm{ml}, 95 \% \mathrm{Cl} 1352-2077 \mathrm{pg} / \mathrm{ml})$ and surgical patients $(2233 \mathrm{pg} / \mathrm{ml}$, $95 \% \mathrm{Cl} 1769-2817 \mathrm{pg} / \mathrm{ml} ; P=0.08)$, while the number of confirmed VAP cases did not differ between both groups $(P=0.17)$.

\section{Diagnostic value of sTREM-1}

A ROC curve analysis showed an area under the curve of 0.58 (95\% $\mathrm{Cl} 0.50-0.65$; $P=0.04$; Figure 3.1b). Therefore, the sTREM-1 levels in our hands were not discriminative for VAP. Choosing a sensitivity of $95 \%$ resulted in a positive predictive 
value (PPV) of $41 \%$ and a negative predictive value (NPV) of $62 \%$ in our population. A specificity of $95 \%$ led to a PPV of $67 \%$ and a NPV of $62 \%$.

a

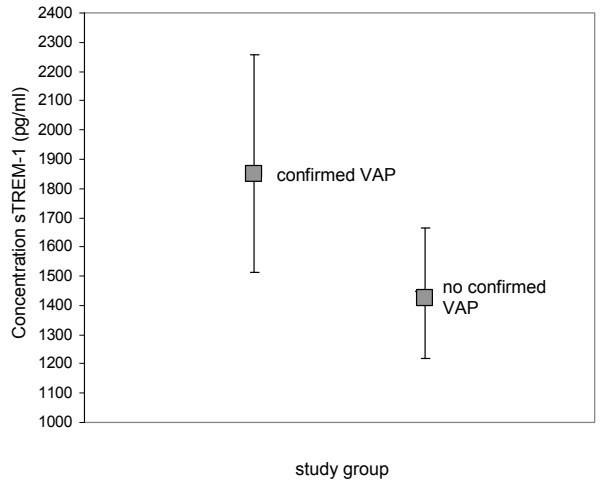

b

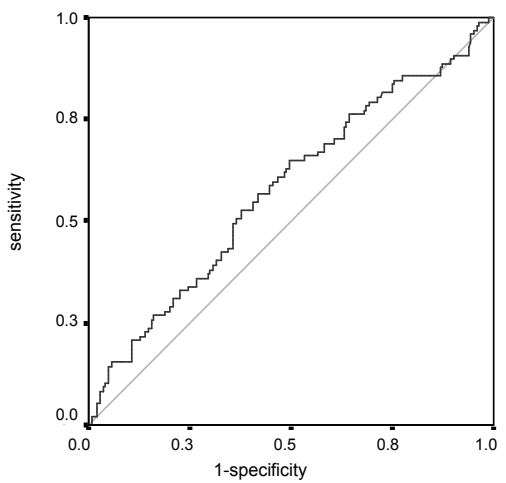

Figure 3.1 (a) Mean soluble Triggering Receptor Expressed on Myeloid cells-1 (sTREM-1) levels in bronchoalveolar lavage fluid (BALF) samples of confirmed $(n=97)$ and non-confirmed $(n=143)$ ventilator-associated pneumonia (VAP) cases. Vertical bars $95 \%$ confidence intervals of the mean. (b) Receiver-operating characteristic (ROC) curve analysis of sTREM-1 in BALF samples of patients with and without confirmed VAP.

\section{Discussion}

In this study, STREM-1 levels were not discriminative for VAP. The differences between the results of our study and those of five other trials in terms of STREM-1 and pneumonia are highlighted in Table 3.2. These may explain the differences in results. A correction for the dilution of $\mathrm{BAL}$ has been found to allow a better representation of the actual concentration of STREM- 1 in the alveoli ${ }^{15}$. However, this does not appear to explain the major differences in outcome, since using the concentration of STREM-1 without correction for dilution did not result in a significantly better ROC analysis in our study (data not shown).

Samples from medical and surgical patients were included in this study. Our results show that the STREM-1 levels tended to be higher in surgical patients, which is in accordance with the results of other studies in which surgery was reported to increase TREM-1 expression levels in peripheral blood monocytes independent of infection ${ }^{16}$. We therefore conclude that in terms of diagnosing VAP in an every day ICU setting, the measurement of STREM-1 levels in BALF does not seem to be discriminative for VAP. 
The levels of sTREM-1 are not only increased by infecting microorganisms ${ }^{17}$; cancer cells have also been shown to be able to directly up-regulate TREM-1 expression in patients' macrophages ${ }^{18}$. A number of inflammatory disorders, such as pancreatitis, are also known to increase levels of sTREM- $1^{19}$. By contrast, TREM-1 is not upregulated in samples from patients with other inflammatory disorders, such as psoriasis, ulcerative colitis or vasculitis caused by immune complexes ${ }^{5}$.

The strength of this study is that it was performed in a large, well-defined group of both medical and surgical ICU patients. One limitation may be that the analysis was performed retrospectively. Only patients that underwent $\mathrm{BAL} \geq 48 \mathrm{~h}$ after being admitted to the ICU were included in the study. Therefore, these patients stayed longer in an ICU than the general ICU population. A second limitation may be that VAP is still difficult to diagnose. However, we used the widely accepted modified criteria of the Centers for Disease Control and Prevention ${ }^{11}$ to diagnose VAP and confirmed the diagnosis by both staining for ICO and culturing BALF samples ${ }^{12}$.

Table 3.2 Characteristics of the six clinical studies regarding STREM-1 and pneumonia

\begin{tabular}{|c|c|c|c|c|c|c|}
\hline & Gibot $^{3}$ & Determann $^{7}$ & Horonenko $^{8}$ & Huh $^{9}$ & Anand $^{10}$ & $\begin{array}{l}\text { Present } \\
\text { study }\end{array}$ \\
\hline Number of cases & 148 & 28 & 23 & 80 & 105 & 240 \\
\hline Setting & $\begin{array}{l}\text { medical } \\
\mathrm{ICU}\end{array}$ & $\begin{array}{l}\text { general } \\
\text { ICU }\end{array}$ & $\begin{array}{l}\text { medical } \\
\mathrm{ICU}\end{array}$ & $\begin{array}{l}\text { medical } \\
\mathrm{ICU}\end{array}$ & $\begin{array}{l}\text { medical } \\
\mathrm{ICU}\end{array}$ & $\begin{array}{l}\text { general } \\
\text { ICU }\end{array}$ \\
\hline Assay & immunoblot & ELISA & ELISA & ELISA & ELISA & ELISA \\
\hline Correction for dilution & no & no & yes & no & no & yes \\
\hline Type of BAL & mini-BAL & non-directed & BAL, NS & non-directed & directed & directed \\
\hline Sensitivity/specificity & $98 / 90$ & $75 / 84$ & NS & $86 / 90$ & $42 / 76$ & $65 / 48$ \\
\hline Diagnosis & CAP/VAP & VAP & VAP & $\begin{array}{l}\text { bilateral lung } \\
\text { infiltrates }\end{array}$ & VAP & VAP \\
\hline Confirmation of VAP & $>10^{3} \mathrm{cfu} / \mathrm{ml}$ & $\geq 10^{4} \mathrm{cfu} / \mathrm{ml}$ & $\geq 10^{3} \mathrm{cfu} / \mathrm{ml}$ & $>10^{4} \mathrm{cfu} / \mathrm{ml}$ & $>10^{3} \mathrm{cfu} / \mathrm{ml}$ & $\begin{array}{l}\geq 10^{4} \mathrm{cfu} / \mathrm{ml} \\
\text { and/or } \\
\geq 2 \% \text { ICO }\end{array}$ \\
\hline $\begin{array}{l}\text { Patients with confirmed } \\
\text { VAP (\%) }\end{array}$ & $46(31)$ & $9(32)$ & $14(61)$ & $29(36)$ & $19(18)$ & $90(43)$ \\
\hline $\begin{array}{l}\text { Mean sTREM-1 level } \\
\text { (in pg/ml) VAP patients }{ }^{a}\end{array}$ & 34 & 894 & 403 & 521 & 172 & 227 \\
\hline
\end{tabular}

BAL, bronchoalveolar lavage; CAP, community-acquired pneumonia; cfu, colony forming units; ELISA, enzyme-linked immunosorbent assay; ICO, intracellular organisms; ICU, intensive care unit; NS, not specified; sTREM-1, soluble Triggering Receptor Expressed on Myeloid cells-1; VAP, ventilator-associated pneumonia. ${ }^{a}$ non-dilution corrected levels are presented.

\section{Conclusion}

The results of this study imply that the STREM-1 assay on BALF samples as a rapid diagnostic test for VAP may not be discriminative. 
\begin{tabular}{l|l} 
& \\
STREM-1 in BALF is not predictive for VAP & 57
\end{tabular}

\section{References}

1. Torres A, Ewig S. Diagnosing ventilator-associated pneumonia. N Engl J Med 2004;350:433-435.

2. Torres A, El-Ebiary M. Bronchoscopic BAL in the diagnosis of ventilator-associated pneumonia. Chest 2000;117:198S-202S.

3. Gibot S, Cravoisy A, Levy B, Bene MC, Faure G, Bollaert PE. Soluble Triggering Receptor Expressed on Myeloid cells and the diagnosis of pneumonia. N Engl J Med 2004;350:451-458.

4. Bouchon A, Dietrich J, Colonna M. Cutting edge: inflammatory responses can be triggered by TREM-1, a novel receptor expressed on neutrophils and monocytes. J Immunol 2000;164:4991-4995.

5. Bouchon A, Facchetti F, Weigand MA, Colonna M. TREM-1 amplifies inflammation and is a crucial mediator of septic shock. Nature 2001;410:1103-1107.

6. Gibot S, Kolopp-Sarda MN, Bene MC, Cravoisy A, Levy B, Faure GC, Bollaert PE. Plasma level of a Triggering Receptor Expressed on Myeloid cells-1: its diagnostic accuracy in patients with suspected sepsis. Ann Intern Med 2004;141:9-15.

7. Determann RM, Millo JL, Gibot S, Korevaar JC, Vroom MB, Van der Poll T, Garrard CS, Schultz MJ. Serial changes in soluble Triggering Receptor Expressed on Myeloid cells in the lung during development of ventilator-associated pneumonia. Intensive Care Med 2005;31:1495-1500.

8. Horonenko G, Hoyt JC, Robbins RA, Singarajah CU, Umar A, Pattengill J, Hayden JM. Soluble Triggering Receptor Expressed on Myeloid cells-1 is increased in patients with ventilator-associated pneumonia: a preliminary report. Chest 2007;132:58-63.

9. Huh JW, Lim CM, Koh Y, Oh YM, Shim TS, Lee SD, Kim WS, Kim DS, Kim WD, Hong SB. Diagnostic utility of the soluble Triggering Receptor Expressed on Myeloid cells-1 in bronchoalveolar lavage fluid from patients with bilateral lung infiltrates. Crit Care 2008;12:R6.

10. Anand NJ, Zuick S, Klesney-Tait J, Kollef MH. Diagnostic implications of soluble Triggering Receptor Expressed on Myeloid cells-1 in BAL fluid of patients with pulmonary infiltrates in the ICU. Chest 2009; 135:641-647.

11. Bonten MJ, Bergmans DC, Stobberingh EE, Van der Geest S, De Leeuw PW, Van Tiel FH, Gaillard CA. Implementation of bronchoscopic techniques in the diagnosis of ventilator-associated pneumonia to reduce antibiotic use. Am J Respir Crit Care Med 1997;156:1820-1824.

12. Linssen CF, Jacobs JA, Schouten JS, Van Mook WN, Ramsay G, Drent M. Influence of antibiotic therapy on the cytological diagnosis of ventilator-associated pneumonia. Intensive Care Med 2008;34: 865-872.

13. Jacobs JA, De Brauwer El, Cornelissen El, Drent M. Accuracy and precision of quantitative calibrated loops in transfer of bronchoalveolar lavage fluid. J Clin Microbiol 2000;38:2117-2121.

14. Horak E, Sunderman FW Jr. Measurements of serum urea nitrogen by conductivimetric urease assay. Ann Clin Lab Sci 1972;2:425-431.

15. Wiedermann FJ, Mayr AJ, Kaneider NC, Fuchs D, Mutz NJ, Schobersberger W. Alveolar granulocyte colony-stimulating factor and alpha-chemokines in relation to serum levels, pulmonary neutrophilia, and severity of lung injury in ARDS. Chest 2004;125:212-219.

16. Gonzalez-Roldan N, Ferat-Osorio E, Aduna-Vicente R, Wong-Baeza I, Esquivel-Callejas N, Astudillo-de la Vega H, Sanchez-Fernandez P, Arriaga-Pizano L, Villasis-Keever MA, Lopez-Macias C, Isibasi A. Expression of Triggering Receptor on Myeloid cells-1 and histocompatibility complex molecules in sepsis and major abdominal surgery. World J Gastroenterol 2005;11:7473-7479.

17. Phua J, Koay ES, Zhang D, Tai LK, Boo XL, Lim KC, Lim TK. Soluble Triggering Receptor Expressed on Myeloid cells-1 in acute respiratory infections. Eur Respir J 2006;28:695-702.

18. Ho CC, Liao WY, Wang CY, Lu YH, Huang HY, Chen HY, Chan WK, Chen HW, Yang PC. TREM-1 expression in tumor-associated macrophages and clinical outcome in lung cancer. Am J Respir Crit Care Med 2008;177:763-770.

19. Yasuda T, Takeyama Y, Ueda T, Shinzeki M, Sawa H, Takahiro N, Kamei K, Ku Y, Kuroda Y, Ohyanagi H. Increased levels of soluble Triggering Receptor Expressed on Myeloid cells-1 in patients with acute pancreatitis. Crit Care Med 2008;36:2048-2053. 



\section{Chapter 4}

\section{Probiotics versus antibiotic decontamination of the digestive tract: infection and mortality}

Guy J Oudhuis, Dennis C Bergmans, Tom Dormans, Jan-Harm Zwaveling, Alfons Kessels, Martin H Prins, Ellen E Stobberingh, Annelies Verbon Intensive Care Med 2011;37:110-117 


\section{Abstract}

\section{Purpose}

Selective decontamination of the digestive tract (SDD) has been shown to decrease the infection rate and mortality in intensive care units (ICUs); Lactobacillus plantarum 299/299v plus fibre (LAB) has been used for infection prevention and does not harbour the potential disadvantages of antibiotics. The objective was to assess whether LAB is not inferior to SDD in infection prevention.

\section{Methods}

Two hundred fifty-four consecutive ICU patients with expected mechanical ventilation $\geq 48 \mathrm{~h}$ and/or expected ICU stay $\geq 72 \mathrm{~h}$ were assigned to receive SDD: four times daily an oral paste (polymyxin E, gentamicin, amphotericin B), enteral solution (same antibiotics), intravenous cefotaxime (first four days) or LAB: two times daily L. plantarum 299/299v with rose-hip.

\section{Results}

The primary endpoint was infection rate. A difference $<12 \%$ between both groups indicated non-inferiority of LAB. The trial was prematurely stopped after a study reporting increased mortality in critically ill pancreatitis patients receiving probiotics. No significant difference in infection rate $(31 \%$ in the LAB group, $24 \%$ in the SDD group; odds ratio $1.68,95 \%$ confidence interval $0.91-3.08 ; P=0.10$ ) was found. ICU mortality was $26 \%$ and not significantly different between the LAB and SDD groups. Gram-positive cocci and Pseudomonas aeruginosa were significantly more frequently isolated from surveillance cultures in the SDD group compared to the LAB group (for sputum: 18 vs. $10 \%$ and 33 vs. $14 \%$, respectively). Significantly more Enterobacteriaceae were found in the LAB group (23 vs. 50\%). No increase in antibiotic resistance was found during and after SDD or LAB use.

\section{Conclusions}

The trial could not demonstrate the non-inferiority of LAB compared to SDD in infection prevention. Results suggest no increased ICU mortality risk in the LAB group. 


\section{Introduction}

Intensive care unit (ICU)-acquired infections have been estimated to occur in at least $17 \%$ of patients ${ }^{1}$ and are associated with increased ICU stay, mortality and health care costs $^{2}$. Most of these infections are thought to be preceded by oropharyngeal and intestinal colonisation with potentially pathogenic microorganisms ${ }^{3}$. Selective decontamination of the digestive tract (SDD) and oropharynx (SOD), used in the ICU ${ }^{4}$, aim at the elimination of potentially pathogenic microorganisms from the oropharyngeal cavity, stomach and gut, while leaving the anaerobic flora intact. Since the introduction of SDD, randomised clinical trials and meta-analyses have shown a decrease in mortality ${ }^{5-8}$. However, SDD has been associated with the emergence of antibiotic-resistant microorganisms during and after intervention ${ }^{9}$.

A method with the beneficial effects of SDD, but without the risk of selection of antibiotic-resistant microorganisms would be ideal.

After ingestion, lactic acid bacteria and fermentable fibre enhance intestinal barrier function, and compete with pathogens for adhesion and nutrients to create an unfavourable local milieu for pathogen colonisation ${ }^{10,11}$. Use of Lactobacillus plantarum 299/299v and fibre (LAB) decreased hospital-acquired infections in patients that had abdominal surgery and acute pancreatitis, compared to placebo ${ }^{12,13}$. In liver transplant patients, these lactobacilli were superior to SDD in the prevention of nosocomial infections ${ }^{14}$. The aim of the study was to investigate whether treatment with Lactobacillus plantarum $299 / 299 v$ and rose-hip is non-inferior to SDD in preventing infections in a general ICU population.

\section{Materials and methods}

\section{Setting and participants}

Consecutive patients admitted to the ICU at the Maastricht University Medical Centre (MUMC, 715 beds) and the Atrium Medical Centre Heerlen (a 545-bed teaching hospital) were enrolled from June 2005 to January 2008 and September 2006 to January 2008, respectively. The participating ICUs are similar in patient population, severity of disease (mean APACHE II scores are comparable) and mortality rates (data not shown).

Eligibility criteria were as applied before ${ }^{5}$. However, amphotericin B suspension and lactobacilli plus rose-hip do not pass through nasoduodenal tubes. Therefore, use of these tubes was added as an exclusion criterion, in addition to contraindications for enteral feeding.

The study protocol was approved by the institutional review boards for human studies of both participating centres. Procedures followed were in accordance with the Helsinki Declaration of 1964. Written informed consent was obtained from patients or 
their legal representatives before enrolment in the trial. The trial has been registered in the Dutch Trial Register (http://www.trialregister.nl/trialreg/index.asp), no. NTR1411.

\section{Allocation and interventions}

In the MUMC, the study had an open label, cross-over of units design. The Intensive Care department consists of two separate units (nine and eight beds) with different case mix and disease burden. To prevent cross-colonisation, randomisation on a patient level was not possible, and allocation on a unit level was instituted. Cross-over of units was necessary to correct for possible differences in case mix, disease burden and other possible confounders. Patients were allocated to a unit by medical staff not involved in the study. In case more than one bed was available in the ICU, patients were randomly assigned to a unit. The first inclusion period lasted 18 months, followed by a wash-out period of three months. Due to results of the PROPATRIA trial, in which increased mortality in critically ill patients with severe pancreatitis receiving probiotics was shown ${ }^{15}$, the second inclusion period was prematurely stopped after 11 months. In the Atrium MC, one ICU (six beds) participated in the study. A 10-month intervention period of $L A B$ was followed by a 3-month wash-out period and a prematurely stopped 4-month intervention period of SDD.

SDD patients received a regimen as previously described ${ }^{5}$, except that gentamicin was applied instead of tobramycin. Topical study medication was manufactured and the quality tested by the pharmacy of the MUMC.

LAB patients received a solution of viable Lactobacillus plantarum 299/299v in a dose of $5 \times 10^{9}$ colony forming units (cfu) together with $6 \mathrm{~g}$ of rose-hip (Probi AB, Lund, Sweden). The manufactured freeze-dried powder was dissolved in $75 \mathrm{ml}$ of water and applied two times daily through a nasogastric tube.

In case of gastric retention, defined as $>1,000 \mathrm{ml} / 24 \mathrm{~h}$, either tube feeding was administered through a nasoduodenal tube or a prokinetic agent was prescribed at the physician's discretion. Administration of study product was continued by nasogastric tube until ICU discharge, death or final removal of the tube. Therapeutic use of antibiotics was left to the attending physician's discretion, whereas administration of prophylaxis was continued without dose adjustments.

\section{Outcomes and follow-up}

Infections were retrospectively determined using the Centers for Disease Control and Prevention (CDC) criteria ${ }^{16}$ and modified CDC criteria ${ }^{17}$ in case of clinical suspicion of a ventilator-associated pneumonia (VAP). Urinary tract infections (UTIs) were only assigned when other infections could be ruled out. Events occurring $>48 \mathrm{~h}$ after ICU admission were considered ICU-acquired. When a VAP was clinically suspected, bronchoalveolar lavage (BAL) was performed to the attending intensivist's discretion, and antibiotic therapy was started or adjusted empirically. Confirmation of clinically 
suspected VAP required $\geq 2 \%$ cells containing intracellular organisms and/or a quantitative culture result of $\geq 10^{4} \mathrm{cfu} / \mathrm{ml}$ in BAL fluid ${ }^{16,17}$. Two researchers (GJO and AV) determined whether patients met the criteria of infection using predefined criteria, independently from one another and unaware of the study regimen. Necessary data were coded without information about study arm. Whenever no consensus was reached, a third author (DCB) reviewed the data.

In ICU, surveillance cultures of sputum and urine were taken twice weekly. A rectal swab was taken prior to first administration of either study product. Thereafter, swabs were taken weekly until death or a maximum of two weeks after ICU discharge. E. coli and enterococci were isolated from the swabs as indicator organisms. CLSI breakpoints for antibiotic resistance were applied ${ }^{18}$. Data on antibiotic consumption, other than SDD agents, were recorded using the Anatomical Therapeutic Chemical (ATC) classification system and were expressed as defined daily doses (DDD) per 100 patient days $^{19,20}$.

Medical files of patients who died during ICU stay were retrospectively screened for signs and symptoms of small bowel ischemia.

The primary endpoint was infection during ICU stay. Assuming that SDD use results in an estimated infection prevalence of $25 \%{ }^{21}$, a difference larger than half of this percentage (i.e. 12\%) had to be excluded to hypothesise an equivalent efficacy of LAB compared to SDD (non-inferiority). One hundred eighty-five patients had to be enrolled in each group, based on $\alpha=0.05$ (one-sided) and a power of $80 \%$.

Early-onset infections were defined as infections occurring within 48-96 $\mathrm{h}$ after ICU admission. Infection at ICU admission was defined as a combination of clinical diagnosis of infection by the attending intensivist and antibiotic use at admission.

Secondary endpoints were ICU mortality and in-hospital mortality. In-hospital mortality was not regarded as a proper endpoint within this open label study design ${ }^{7,22,23}$ and was retrospectively discarded. Mortality at day 28 was added.

Other secondary endpoints were additional use of systemic antibiotics and prevalence of (antibiotic-resistant) microorganisms in surveillance cultures.

\section{Statistical analysis}

To compare specific variables, the Pearson $\chi^{2}$ and Mann-Whitney $U$ test were used. A two-way contingency table analysis was performed to calculate differences in proportions, regarding patients with infectious events, and the respective $95 \%$ confidence intervals $(\mathrm{Cl})$. Logistic regression models, regarding mortality and proportion of patients with infections, were used to adjust for differences in prognostic variables and severity of disease, using the APACHE II score ${ }^{7,24}$, age ${ }^{7}$, sex ${ }^{7}$, body mass index (BMI) ${ }^{25}$ and ICU as covariates.

For time-to-infectious event analysis, a Kaplan-Meier curve with log rank test was generated. Analysis was done with SPSS 15.0 for Windows (SPSS Benelux BV, Gorinchem, The Netherlands). A Poisson analysis, with the number of infections per 
$64 \mid$ Chapter 4

patient as dependent variable, and the intervention and the above-mentioned covariates as independent variables, was performed using STATA 10.0 (STATA Corporation, College Station, TX). All analyses were based on the intention-to-treat principle. No interim analysis was performed because of the cross-over design. Statistical significance was defined as a $P$-value of less than 0.05 in all cases.

\section{Results}

\section{Patient population}

Enrolment involved 254 consecutive ICU patients (i.e. 73\% of eligible patients, Figure 4.1), 222 in the MUMC and 32 in the Atrium MC. Inclusion rates were similar in both hospitals. Both study groups were comparable for all baseline and follow-up characteristics (Table 4.1), as were patients in the two participating centres (data not shown). The prevalence of infection at admission was 39\% in the SDD group and 32\% in the LAB group $(P=0.29)$.

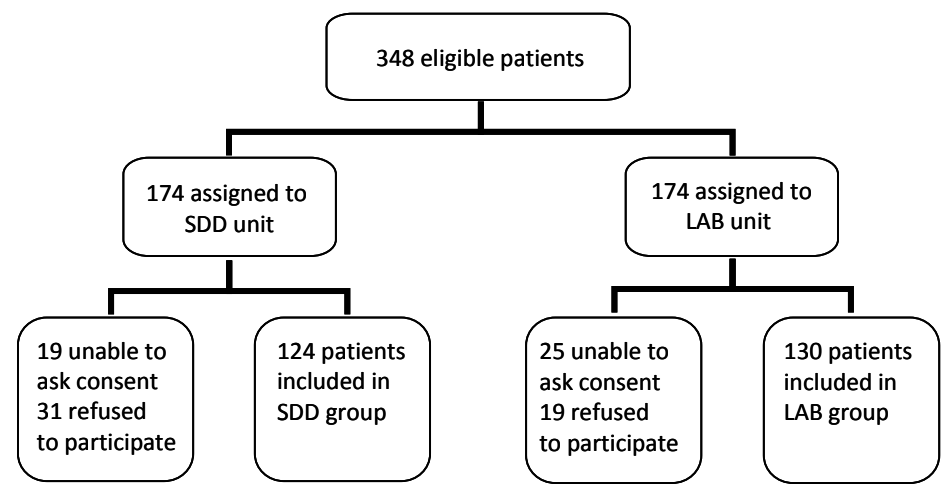

Figure 4.1 Flowchart of patient enrolment. SDD, selective decontamination of the digestive tract; $L A B$, L. plantarum 299/299v plus fibre. 
Table 4.1 Characteristics of the study population

\begin{tabular}{|c|c|c|c|}
\hline Characteristic & $\begin{array}{l}\text { LAB group } \\
(n=130)\end{array}$ & $\begin{array}{l}\text { SDD group } \\
(n=124)\end{array}$ & $P$-value \\
\hline \multicolumn{4}{|l|}{ Sex } \\
\hline male (\%) & $84(65)$ & $73(59)$ & 0.35 \\
\hline \multicolumn{4}{|l|}{ Age in years } \\
\hline Mean (SD) & $63.5(16.4)$ & $61.9(16.0)$ & 0.26 \\
\hline Range & $20-90$ & $17-90$ & \\
\hline \multicolumn{4}{|l|}{$\mathrm{BMI}$ in $\mathrm{kg} / \mathrm{m}^{2}$} \\
\hline Mean (SD) & $25.5(4.9)$ & $25.4(4.5)$ & 0.98 \\
\hline Range & $17.3-55.9$ & $16.6-47.8$ & \\
\hline \multicolumn{4}{|l|}{ APACHE II score } \\
\hline Mean (SD) & $23(7.7)$ & $21(7.6)$ & 0.11 \\
\hline Range & $7-44$ & $7-40$ & \\
\hline \multicolumn{4}{|l|}{ Days in hospital } \\
\hline Mean (SD) & 36.7 (33.9) & $38.5(33.5)$ & 0.35 \\
\hline Range & $2-193$ & $1-227$ & \\
\hline \multicolumn{4}{|l|}{ Days in ICU } \\
\hline Mean (SD) & $18.0(24.8)$ & $15.0(17.8)$ & 0.78 \\
\hline Range & $1-155$ & $1-105$ & \\
\hline \multicolumn{4}{|c|}{ Reason for ICU admission (\%): } \\
\hline respiratory insufficiency & $46(35.4)$ & $39(31.5)$ & \\
\hline neurological & $31(23.8)$ & $36(29.0)$ & \\
\hline hemodynamic & $13(10.0)$ & $9(7.3)$ & 0.68 \\
\hline sepsis/shock & $17(13.1)$ & 21 (16.9) & \\
\hline peritonitis & $9(6.9)$ & $5(4.0)$ & \\
\hline trauma/other $^{\mathrm{a}}$ & $14(10.8)$ & $14(11.3)$ & \\
\hline \multicolumn{4}{|l|}{ Admission group (\%): } \\
\hline surgical & $64(49.2)$ & $69(55.6)$ & \\
\hline medical & $62(47.7)$ & $50(40.3)$ & 0.49 \\
\hline trauma & $4(3.1)$ & $5(4.0)$ & \\
\hline Patients on MV (\%) & $129(99.2)$ & $119(96.0)$ & 0.09 \\
\hline \multicolumn{4}{|l|}{ Days on MV } \\
\hline Mean (SD) & $16.7(23.6)$ & $14.1(17.2)$ & 0.60 \\
\hline Range & $2-152$ & $1-100$ & \\
\hline \multicolumn{4}{|c|}{$\begin{array}{l}\text { Days with administration of study } \\
\text { product }^{\text {b }}\end{array}$} \\
\hline Mean (SD) & $11.0(14.3)$ & $10.5(13.8)$ & 0.87 \\
\hline Range & $0-73$ & $0-94.25$ & \\
\hline \multicolumn{4}{|c|}{ Cumulative gastric retention in $\mathrm{ml}$} \\
\hline Mean (SD) & $3002(6368)$ & $2264(3713)$ & 0.74 \\
\hline Range & $0-53670$ & $0-23885$ & \\
\hline
\end{tabular}

LAB, L. plantarum 299/299v plus fibre; SDD, selective decontamination of the digestive tract; BMI, body mass index; APACHE, acute physiology and chronic health evaluation; ICU, Intensive Care Unit; MV, mechanical ventilation. " Including acidosis, bowel ischemia, meningitis, renal insufficiency, weaning problems, Guillain-Barré syndrome, retroperitoneal haematoma, pancreatitis, encephalopathy, necrotising fasciïtis, pelvic exenteration, traumatic spinal cord injury. ${ }^{b}$ In LAB group two times daily, in SDD group four times daily. 


\section{ICU-acquired infections}

The acquired infection rate was $28 \%$ (70/254); 40 of 130 patients given LAB (31\%) and 30 of 124 patients receiving SDD (24\%, Table 4.2). Adjusted for BMI, age, sex, APACHE II score and ICU, the difference between both groups was not statistically significant (odds ratio (OR) $1.68,95 \% \mathrm{Cl} 0.91-3.08 ; P=0.10)$. The time-to-infection was similar in both study groups ( $P=0.38$, Figure 4.2$)$. When UTIs were excluded from the analysis, differences remained non-significant (OR 1.23, 95\% $\mathrm{Cl} 0.63-2.40 ; P=0.54$ for infections and $P=0.90$ for time-to-infection). The total number of infections was not significantly different $(P=0.25$, Table 4.2$)$, nor was the number of infections per patient with ( $P=0.35$, Table 4.2 ) or without UTIs ( $P=0.43$, data not shown). In the SDD group, nine episodes of VAP occurred during 1,674 days of mechanical ventilation (MV, $5.4 \mathrm{VAPs} / 1,000$ days). In the LAB group, ten episodes of VAP occurred during 2,156 days of MV (4.6 VAPs/1,000 days, not significant (NS)). Four out of 30 infectious events in the SDD group were early-onset (13.3\%) versus $7 / 40$ in the LAB group $(17.5 \%, P=0.64)$. The difference in infection rate between both study groups was $7 \%$ (95\% Cl -4.4 to $17.1 \%)$ in the 254 included patients. When extrapolated to the calculated necessary sample size of 370 patients, the $95 \% \mathrm{Cl}$ ranged from -2.6 to $15.3 \%$. With UTIs excluded, the difference in infection rate was $2 \%$ (95\% Cls -8.3 to $10.9 \%$ and -7 to $9.1 \%$, respectively).

Table 4.2 Number and type of infectious events

\begin{tabular}{lcc}
\hline & $\begin{array}{c}\text { LAB group } \\
(\mathrm{n}=130)\end{array}$ & $\begin{array}{c}\text { SDD group } \\
(\mathrm{n}=124)\end{array}$ \\
\hline Type of infection & $67(100)$ & $42(100)$ \\
total events (\%) & $10(14.9)$ & $9(21.4)$ \\
ventilator-associated pneumonia (\%) $^{*}$ & $2(3.0)$ & - \\
pneumonia $^{\text {(\%) }}$ & $30(44.8)$ & $8(19.0)$ \\
urinary tract infection (\%) & $16(23.9)$ & $16(38.1)$ \\
(catheter-related) bloodstream infection (\%) & $2(3.0)$ & $3(7.1)$ \\
wound infection (\%) & $4(6.0)$ & $3(7.1)$ \\
intra-abdominal infection (\%) & $3(4.5)$ & $3(7.1)$ \\
other (\%) & & $94(75.8)$ \\
Number of infections** & $90(69.2)$ & $20(16.1)$ \\
patients with 0 infections (\%) & $23(17.7)$ & $9(7.3)$ \\
patients with 1 infection (\%) & $12(9.2)$ & $1(0.8)$ \\
patients with 2 infections (\%) & $5(3.8)$ & \\
patients with $\geq 3$ infections (\%) & & \\
\hline
\end{tabular}

LAB, L. plantarum 299/299v plus fibre; SDD, selective decontamination of the digestive tract. ${ }^{\text {a }}$ Involved patients were not mechanically ventilated. ${ }^{\mathrm{b}}$ Including (pulmonary) abscess, sinusitis, empyema.

$* P=0.25$. ** $P=0.35$.

The absolute number of Gram-positive cocci and $P$. aeruginosa causing infections was comparable between both groups. However, proportionally, significant differences in prevalence were present (Table 4.3). Between both groups, no significant differences 
in antibiotic resistance of microorganisms of the same species were found during the study period for any antibiotic. Moreover, resistance levels did not increase over time.
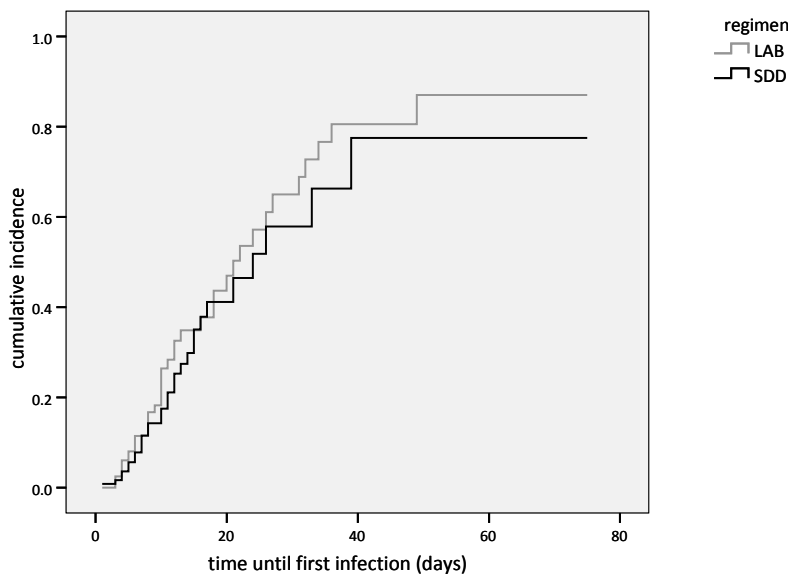

Figure 4.2 Kaplan-Meier time-to-event analysis for the incidence of infectious events. $P=0.38$, by log rank test. SDD, selective decontamination of the digestive tract; LAB, L. plantarum 299/299v plus fibre.

Table 4.3 Microorganisms that caused infectious events

\begin{tabular}{lcc}
\hline & LAB group & SDD group \\
\hline Total number of microorganisms (\%) & $97(100)$ & $51(100)$ \\
Gram-positive & & \\
Enterococcus species (\%) & $10(10)$ & $11(22)^{*}$ \\
Coagulase-negative staphylococci (\%) & $7(7)$ & $10(20)^{*}$ \\
Staphylococcus aureus (\%) & $6(6)$ & $3(6)$ \\
Other (\%) & $4(4)$ & $2(4)$ \\
Gram-negative & & $12(24)^{*}$ \\
Pseudomonas aeruginosa (\%) & $10(10)$ & $9(18)$ \\
Enterobacteriaceae (\%) & $44(45)^{*}$ & $1(2)$ \\
Other (\%) & $7(7)$ & $3(6)$ \\
Candida species (\%) & $9(9)$ & \\
\hline
\end{tabular}

LAB, L. plantarum 299/299v plus fibre; SDD, selective decontamination of the digestive tract. * $P<0.05$.

\section{Mortality}

Overall ICU mortality was $26 \%$. ICU mortality, adjusted for the above-mentioned confounders, was not significantly different between SDD and LAB (OR $0.99,95 \% \mathrm{Cl}$ 0.51-1.92; $P=0.97$ ), nor was adjusted mortality at day 28 (OR 1.31, 95\% $\mathrm{Cl} 0.68-2.53$; $P=0.43$ ). Mortality rates were similar for both participating centres. No patients receiving $L A B$ or SDD developed bowel ischemia as considered by autopsy and/or chart review. 


\section{Additional antibiotic use}

The total mean number of DDD/100 patient days was significantly higher in the LAB group than in the SDD group (141.7 vs. $108.7, P=0.008$, Table 4.4$)$. This could be explained by the significantly higher use of co-amoxiclav in the LAB group $(P=0.003$, Table 4.4). During the first $72 \mathrm{~h}$ after ICU admission, 103 SDD patients and 108 LAB patients used a total of 368 DDD and 411 DDD, with a mean of 3.6 and 3.8 $\mathrm{DDD} /$ patient (NS), respectively.

Table 4.4 Additional antibiotic use in both study groups in mean DDD/100 patient days

\begin{tabular}{lcc}
\hline Antibiotic & SDD group & LAB group \\
\hline amoxicillin & 4.8 & 5.7 \\
piperacillin & 2.5 & 0.9 \\
flucloxacillin & 8.4 & 15.3 \\
co-amoxiclav & 34.7 & $49.3^{* *}$ \\
piperacillin-tazobactam & 9.4 & 12.8 \\
cefazoline & 2.1 & 0.5 \\
cefuroxime & 0.8 & - \\
ceftazidime & 2.9 & 0.7 \\
ceftriaxone & 0.5 & $7.7^{* *}$ \\
carbapenems & 2.7 & 0.9 \\
co-trimoxazole & 1.2 & 3.0 \\
macrolides ${ }^{\text {clindamycin }}$ & 5.0 & 2.9 \\
gentamicin & 3.4 & 8.5 \\
fluoroquinolones $^{*}$ & 15.5 & 22.0 \\
vancomycin $_{\text {other }}{ }^{b}$ & $4.6^{*}$ & 1.1 \\
total & 10.2 & 10.4 \\
\hline
\end{tabular}

Antibiotics for systemic administration, unless stated otherwise. DDD, defined daily dose; SDD, selective decontamination of the digestive tract; LAB, L. plantarum 299/299v plus fibre. ${ }^{\text {a }}$ clarithromycin was administered orally. ${ }^{b}$ including benzylpenicillin, aztreonam, metronidazole, rifampicin and colistin. * $P<0.05$, by Mann-Whitney $U$ test. ${ }^{* *} P<0.01$, by Mann-Whitney $U$ test.

\section{Surveillance cultures}

In 64 patients, 277 isolates were cultured from 215 positive sputum samples in the SDD group and 516/326 from 73 patients in the LAB group $(P<0.001)$. Significantly more Gram-positive cocci (50/277 isolates vs. 52/516, 25 vs. 23 patients) and Pseudomonas aeruginosa (92/277 vs. 70/516, 18 vs. 14 patients) were cultured in the SDD group ( $P=0.001$ and $P<0.001$, respectively), whereas more Enterobacteriaceae (63/277 vs. 259/516, 24 vs. 57 patients) and Acinetobacter species (1/277 vs. 23/516, one vs. four patients) were found in the $L A B$ group $(P<0.001$ and $P=0.001$, respectively).

In 22 patients, 57 isolates were cultured from 54 positive urine samples in the SDD group and 136/111 from 42 patients in the LAB group $(P<0.001)$. The prevalence of enterococci (10/57 isolates vs. $12 / 136$, eight vs. seven patients) and $P$. aeruginosa (14/57 vs. $10 / 136$, six vs. six patients) was higher in the SDD group ( $P=0.08$ and 
$P=0.001$, respectively), and of Enterobacteriaceae (for $E$. coli $7 / 57$ vs. $38 / 136$, four vs. 18 patients) in the LAB group ( $P=0.02)$.

The prevalence of enterococci in rectal swabs (not different at $t=0$ ) significantly increased over time during prophylaxis with both SDD and $\angle A B$, to a respective maximum of 96 and $88 \%$ (NS). After cessation of prophylaxis, this increased percentage persisted. The prevalence of $E$. coli (not different at $\mathrm{t}=0$ ) diminished over time during prophylaxis to 0 and $24 \%$, respectively $(P<0.001)$. After cessation of prophylaxis, the prevalence tended to increase (NS).

Antibiotic resistance among Enterobacteriaceae, non-fermenting species other than Pseudomonas, Candida species, staphylococci and enterococci in sputum and urine samples did not differ significantly between both study groups at any time point throughout the entire study period (data not shown). Among $P$. aeruginosa isolates, resistance to ceftazidime $(P=0.02)$, ciprofloxacin $(P<0.001)$, piperacillin $(P=0.004)$ and piperacillin-tazobactam ( $P=0.02)$ was significantly higher in the LAB group than in the SDD group. Prevalence of resistance in both groups did not increase significantly over time. No putative ESBL producers were found among Klebsiella pneumoniae isolates.

\section{Discussion}

This trial failed to demonstrate non-inferiority of the probiotic L. plantarum 299/299v plus rose-hip (LAB) compared to SDD in prevention of ICU-acquired infections. Rather, the results suggest that $L A B$ might be inferior to SDD. The difference in ICU mortality and mortality at day 28 was not statistically significant between both groups. No significant difference in prevalence of antibiotic-resistant bacteria was recorded between clinical isolates of 130 patients receiving LAB and 124 patients receiving SDD. Infection rates in ICU studies have been shown to vary from 28 to $90 \%$ when no infection prevention regimen is used ${ }^{12,15,26,27}$. Infection rates using probiotics for prevention varied from 10 to $30 \%{ }^{12,14,15}$. Using $L A B$, an infection rate of $31 \%$ was found in our study. A large proportion of these infections was due to UTIs (Table 4.2), which seemed to be prevented by SDD. Exclusion of UTIs resulted in a rate of $21 \%$ in the LAB group. The higher additional antibiotic use in the LAB group, in particular coamoxiclav, may have masked or prevented infectious complications.

The infection rates with SDD in our study were lower than those previously reported $(34-43 \%)^{6,28}$. The proportional differences in prevalence of microorganisms (of infectious events as well as surveillance cultures) between both study groups were as expected, since SDD mainly eliminates Enterobacteriaceae ${ }^{29}$. Resistance levels among bacteria causing infections were comparable to those described in Dutch ICUs ${ }^{30}$.

The overall mortality rate of $26 \%$ in the present study was within the range described by Knaus et al. for (a group of) patients with a (mean) APACHE II score of $22^{24}$. The ICU mortality in the LAB group was not significantly different from that in the SDD group. 
SDD has already been proven to reduce mortality compared to placebo or standard care $^{5-8}$.

Effects of probiotics on mortality depend on the kind of probiotics used ${ }^{26,27}$. Our study was not powered to detect a difference in mortality, and inclusion was prematurely stopped. Therefore, no benefit of SDD versus LAB on mortality could be evaluated. Our data do suggest that not all probiotics administered to critically ill patients result in an increased risk of mortality. The increased mortality risk in patients with severe pancreatitis and probiotic prophylaxis $(16 \%)$ compared to placebo $(6 \%)^{15}$ could not be confirmed by our trial, which had a similar sample size. There are several differences between our study and the PROPATRIA trial. Firstly, the study populations were different. Secondly, the probiotic $L$. plantarum 299/299v differed from the PROPATRIA trial probiotic mixture (six different strains) $)^{15}$, and the antimicrobial and immunological properties of the different probiotic strains vary greatly ${ }^{31,32}$. Thirdly, patients in the present study received probiotics via nasogastric tubes. In the PROPATRIA trial, nasojejunal tubes were used ${ }^{15}$. Small bowel feeding has been shown to be associated with ischemic bowel disease in patients started on early enteral feeding after an abdominal procedure ${ }^{33}$.

One limitation of the present study is the premature ending, which prevented the completion of patient enrolment. Cross-over of units was deemed necessary after allocation on a unit level to prevent cross-colonisation ${ }^{34,35}$. However, the cross-over of units was not completed, resulting in an unequal mix of patients and disease burden, so the adjustments in the analyses, as mentioned above, had to be made. Another limitation could be that the study was not double-blinded, because surveillance cultures reveal on which unit SDD was used and on which unit not. Masking of these cultures would be impossible and unethical since additional antibiotic treatment has to be based on these culture results. Furthermore, one unit was designated the SDD unit and the other the $L A B$ unit to prevent cross-colonisation between SDD and LAB patients. The fact that infections were defined retrospectively may have been a limitation, despite the fact that the examiners were blinded for the preventive treatment assigned to the patients.

A fourth limitation could be that only $E$. coli and enterococci were isolated from rectal swabs, whereas no oropharyngeal cultures were taken, thereby hampering the classification of infections in endogenous and exogenous. Thus, a concomitant exogenous problem affecting both study groups and causing infections cannot be ruled out.

\section{Conclusions}

The 130 critically ill patients receiving probiotics did not show a significantly increased ICU mortality or mortality at day 28 compared to the 124 patients receiving SDD. On the other hand, there was a tendency towards more infections in patients receiving LAB compared to SDD. 
\begin{tabular}{l|l} 
& \\
Probiotics vs. antibiotics: infection and mortality & 71
\end{tabular}

\section{References}

1. Inan D, Saba R, Gunseren F, Ongut G, Turhan O, Yalcin AN, Mamikoglu L. Daily antibiotic cost of nosocomial infections in a Turkish university hospital. BMC Infect Dis 2005;5:5.

2. Vincent JL. Nosocomial infections in adult intensive care units. Lancet 2003;361:2068-2077.

3. Park DR. The microbiology of ventilator-associated pneumonia. Respir Care 2005;50:742-763.

4. Stoutenbeek CP, Van Saene HK, Miranda DR, Zandstra DF. The effect of selective decontamination of the digestive tract on colonisation and infection rate in multiple trauma patients. Intensive Care Med 1984;10:185-192.

5. De Jonge E, Schultz MJ, Spanjaard L, Bossuyt PM, Vroom MB, Dankert J, Kesecioglu J. Effects of selective decontamination of digestive tract on mortality and acquisition of resistant bacteria in intensive care: a randomised controlled trial. Lancet 2003;362:1011-1016.

6. De la Cal MA, Cerda E, Garcia-Hierro P, Van Saene HK, Gomez-Santos D, Negro E, Lorente JA. Survival benefit in critically ill burned patients receiving selective decontamination of the digestive tract: a randomized, placebo-controlled, double-blind trial. Ann Surg 2005;241:424-430.

7. De Smet AM, Kluytmans JA, Cooper BS, Mascini EM, Benus RF, Van der Werf TS, Van der Hoeven JG, Pickkers P, Bogaers-Hofman D, Van der Meer NJ, Bernards AT, Kuijper EJ, Joore JC, Leverstein-van Hall MA, Bindels AJ, Jansz AR, Wesselink RM, De Jongh BM, Dennesen PJ, Van Asselt GJ, Te Velde LF, Frenay IH, Kaasjager K, Bosch FH, Van Iterson M, Thijsen SF, Kluge GH, Pauw W, De Vries JW, Kaan JA, Arends JP, Aarts LP, Sturm PD, Harinck HI, Voss A, Uijtendaal EV, Blok HE, Thieme Groen ES, Pouw ME, Kalkman CJ, Bonten MJ. Decontamination of the digestive tract and oropharynx in ICU patients. N Engl J Med 2009;360:20-31.

8. Liberati A, D'Amico R, Pifferi S, Torri V, Brazzi L, Parmelli E. Antibiotic prophylaxis to reduce respiratory tract infections and mortality in adults receiving intensive care. Cochrane Database Syst Rev 2009;CD000022.

9. Oostdijk EA, De Smet AM, Blok HE, Thieme Groen ES, Van Asselt GJ, Benus RF, Bernards SA, Frenay IH, Jansz AR, De Jongh BM, Kaan JA, Leverstein-van Hall MA, Mascini EM, Pauw W, Sturm PD, Thijsen SF, Kluytmans JA, Bonten MJ. Ecological effects of selective decontamination on resistant Gram-negative bacterial colonization. Am J Respir Crit Care Med 2010;181:452-457.

10. Isakow W, Morrow LE, Kollef MH. Probiotics for preventing and treating nosocomial infections: review of current evidence and recommendations. Chest 2007;132:286-294.

11. Madsen K. Probiotics in critically ill patients. J Clin Gastroenterol 2008;42 (Suppl 3 Pt 1):S116-118.

12. Rayes N, Hansen S, Seehofer D, Muller AR, Serke S, Bengmark S, Neuhaus P. Early enteral supply of fiber and lactobacilli versus conventional nutrition: a controlled trial in patients with major abdominal surgery. Nutrition 2002;18:609-615.

13. Olah A, Belagyi T, Issekutz A, Gamal ME, Bengmark S. Randomized clinical trial of specific Lactobacillus and fibre supplement to early enteral nutrition in patients with acute pancreatitis. $\mathrm{Br} J \mathrm{Surg}$ 2002;89:1103-1107.

14. Rayes N, Seehofer D, Hansen S, Boucsein K, Muller AR, Serke S, Bengmark S, Neuhaus P. Early enteral supply of Lactobacillus and fiber versus selective bowel decontamination: a controlled trial in liver transplant recipients. Transplantation 2002;74:123-127.

15. Besselink MG, Van Santvoort HC, Buskens E, Boermeester MA, Van Goor H, Timmerman HM, Nieuwenhuijs VB, Bollen TL, Van Ramshorst B, Witteman BJ, Rosman C, Ploeg RJ, Brink MA, Schaapherder AF, Dejong CH, Wahab PJ, Van Laarhoven CJ, Van der Harst E, Van Eijck CH, Cuesta MA, Akkermans LM, Gooszen HG. Probiotic prophylaxis in predicted severe acute pancreatitis: a randomised, double-blind, placebo-controlled trial. Lancet 2008;371:651-659.

16. Garner JS, Jarvis WR, Emori TG, Horan TC, Hughes JM. CDC definitions for nosocomial infections, 1988. Am J Infect Control 1988;16:128-140.

17. Linssen CF, Jacobs JA, Schouten JS, Van Mook WN, Ramsay G, Drent M. Influence of antibiotic therapy on the cytological diagnosis of ventilator-associated pneumonia. Intensive Care Med 2008;34: 865-872.

18. Clinical and Laboratory Standards Institute. Methods for Dilution Antimicrobial Susceptibility Tests for Bacteria that Grow Aerobically-Seventh Edition: Approved Standard M7-A7. CLSI, Wayne, PA. 2006. 
19. WHO Collaborating Centre for Drug Statistics Methodology. Anatomical Therapeutic Chemical (ATC) classification index with Defined Daily Doses (DDDs). WHO Collaborating Centre, Oslo, Norway. 2006.

20. Filius PM, Liem TB, Van der Linden PD, Janknegt R, Natsch S, Vulto AG, Verbrugh HA. An additional measure for quantifying antibiotic use in hospitals. J Antimicrob Chemother 2005;55:805-808.

21. Bonten MJ, Kullberg BJ, Van Dalen R, Girbes AR, Hoepelman IM, Hustinx W, Van der Meer JW, Speelman P, Stobberingh EE, Verbrugh HA, Verhoef J, Zwaveling JH. Selective digestive decontamination in patients in intensive care. The Dutch Working Group on Antibiotic Policy. $J$ Antimicrob Chemother 2000;46:351-362.

22. Puffer $S$, Torgerson D, Watson J. Evidence for risk of bias in cluster randomised trials: review of recent trials published in three general medical journals. BMJ 2003;327:785-789.

23. Campbell MK, Elbourne DR, Altman DG. CONSORT statement: extension to cluster randomised trials. BMJ 2004;328:702-708.

24. Knaus WA, Draper EA, Wagner DP, Zimmerman JE. APACHE II: a severity of disease classification system. Crit Care Med 1985;13:818-829.

25. Garrouste-Orgeas M, Troche G, Azoulay E, Caubel A, De Lassence A, Cheval C, Montesino L, Thuong $M$, Vincent $F$, Cohen $Y$, Timsit JF. Body mass index. An additional prognostic factor in ICU patients. Intensive Care Med 2004;30:437-443.

26. Jain PK, McNaught CE, Anderson AD, MacFie J, Mitchell CJ. Influence of synbiotic containing Lactobacillus acidophilus La5, Bifidobacterium lactis Bb 12, Streptococcus thermophilus, Lactobacillus bulgaricus and oligofructose on gut barrier function and sepsis in critically ill patients: a randomised controlled trial. Clin Nutr 2004;23:467-475.

27. Kotzampassi K, Giamarellos-Bourboulis EJ, Voudouris A, Kazamias P, Eleftheriadis E. Benefits of a synbiotic formula (Synbiotic 2000Forte) in critically III trauma patients: early results of a randomized controlled trial. World J Surg 2006;30:1848-1855.

28. Krueger WA, Lenhart FP, Neeser G, Ruckdeschel G, Schreckhase H, Eissner HJ, Forst H, Eckart J, Peter $K$, Unertl KE. Influence of combined intravenous and topical antibiotic prophylaxis on the incidence of infections, organ dysfunctions, and mortality in critically ill surgical patients: a prospective, stratified, randomized, double-blind, placebo-controlled clinical trial. Am J Respir Crit Care Med 2002;166: 1029-1037.

29. Heininger A, Meyer E, Schwab F, Marschal M, Unertl K, Krueger WA. Effects of long-term routine use of selective digestive decontamination on antimicrobial resistance. Intensive Care Med 2006;32: 1569-1576.

30. SWAB. NethMap 2009 - Consumption of antimicrobial agents and antimicrobial resistance among medically important bacteria in The Netherlands. Accessed 3 March 2010. Available at http://www.swab.nl/swab/cms3.nsf/ viewdoc/2E7389A33973953BC12575D1002A01C3.

31. Timmerman HM, Niers LE, Ridwan BU, Koning CJ, Mulder L, Akkermans LM, Rombouts FM, Rijkers GT. Design of a multispecies probiotic mixture to prevent infectious complications in critically ill patients. Clin Nutr 2007;26:450-459.

32. Bengmark S. Synbiotics to strengthen gut barrier function and reduce morbidity in critically ill patients. Clin Nutr 2004;23:441-445.

33. Melis M, Fichera A, Ferguson MK. Bowel necrosis associated with early jejunal tube feeding: a complication of postoperative enteral nutrition. Arch Surg 2006;141:701-704.

34. Bonten MJ, Kluytmans J, De Smet AM, Bootsma M, Hoes A. Selective decontamination of digestive tract in intensive care. Lancet 2003;362:2118-2119 (author reply 2119-2120).

35. Verbrugh HA. Selective decontamination of digestive tract in intensive care. Lancet 2003;362: 2117-2118. 


\section{Chapter 5}

Antibiotic resistance among $E$. coli isolates of Intensive Care patients receiving selective digestive tract decontamination or probiotics

Guy J Oudhuis, Ellen E Stobberingh, Dennis C Bergmans, Tom Dormans, Annelies Verbon 


\section{Abstract}

\section{Purpose}

The influence of selective digestive tract decontamination (SDD) and Lactobacillus plantarum $299 / 299 v$ ( $L A B$ ) on the prevalence or selection of antibiotic-resistant bacteria in the distal digestive tract might preclude their use as preventive measures for hospital-acquired infections. We therefore determined the prevalence of antibiotic-resistant Escherichia coli in rectal surveillance samples and in clinical samples from Intensive Care Unit (ICU) patients receiving either type of prophylaxis.

\section{Methods}

E. coli was isolated from consecutive rectal swabs and clinical samples of ICU patients receiving either SDD $(n=124)$ or LAB $(n=130)$. Minimal inhibitory concentrations (MICs) of penicillins, cephalosporins, aminoglycosides and fluoroquinolones were determined using broth microdilution. Confirmation of putative ESBL production was performed with a disk diffusion test and PCR.

\section{Results}

Antibiotic resistance of rectal $E$. coli isolates only differed significantly between both regimens after stopping prophylaxis, with amoxicillin resistance being higher in the LAB group ( $74 \%$ vs. $50 \%, P=0.04$ ). Comparing antibiotic resistance at $\mathrm{t}=0$ with subsequent time points, resistance to amoxicillin-clavulanic acid increased significantly in the LAB group (from 7 to $19 \%, P=0.03$ ). Neither regimen resulted in an increased prevalence of ESBL-producing $E$. coli. A similar result was found for clinical $E$. coli isolates.

\section{Conclusions}

With SDD use, no significantly increased resistance of $E$. coli to the antibiotics tested was found. In the LAB group, amoxicillin and co-amoxiclav resistance significantly increased after start of prophylaxis and during follow-up. A possible relationship with co-amoxiclav use could be established in this patient group. Emergence of co-amoxiclav resistance was independently associated with length of hospital stay. 


\section{Introduction}

Hospital-acquired infections (HAI) in Intensive Care Units (ICUs) contribute to an increase in ICU stay, mortality and healthcare costs ${ }^{1}$. To prevent HAI, several methods have been described, such as selective decontamination of the digestive tract (SDD), which decreases the prevalence of nosocomial infections and mortality among ICU patients $^{2-5}$ and use of probiotics and prebiotics such as Lactobacillus plantarum $299 / 299 v$ plus fibre (LAB), which has also been reported to reduce the prevalence of hospital-acquired infections ${ }^{6,7}$.

The putative mechanism of protection by SDD is to decrease the number of facultative aerobic Gram-negative bacilli in the gut, while leaving the anaerobic flora intact ${ }^{8}$. Lactic acid bacteria and fermentable fibre enhance intestinal barrier function and compete with potential pathogens for adhesion and nutrients to create an unfavourable local milieu for potential pathogen-colonisation ${ }^{9-12}$.

A concern about SDD is the emergence of antibiotic-resistant microorganisms during and after intervention ${ }^{13}$. Probiotics, theoretically, do not harbour the risk of selection of antibiotic-resistant microorganisms ${ }^{14}$. Moreover, the influence of LAB in comparison with SDD on selection of antibiotic-resistant bacteria in the distal digestive tract has not been reported yet.

Here, we describe the prevalence of antibiotic-resistant Escherichia coli from the distal digestive tract and from clinical samples, both in individual ICU patients receiving either LAB or SDD and on the ICU population level.

\section{Materials and methods}

\section{Patients}

Between June 2005 and January 2008, consecutive patients admitted to the ICU of the Maastricht University Medical Centre (MUMC, 715 beds) and the Atrium Medical Centre Heerlen (a 545-bed teaching hospital) were enrolled in the study. Eligibility criteria and exclusion criteria were as described previously ${ }^{15}$. The research was conducted in accordance with the 1964 Declaration of Helsinki and national and institutional standards. The protocol of the study has been approved by the institutional review boards for human studies of both participating centres, respective reference numbers: P04-176 and 06-P-31. Written informed consent was obtained from participating patients or their legal representatives before enrolment in the trial. The trial has been registered in the Dutch Trial Register (http://www.trialregister.nl/ trialreg/index.asp), number NTR1411.

Other data concerning the trial have been described previously ${ }^{15}$. 


\section{Procedures}

SDD patients received a four times daily applied regimen, as previously described ${ }^{2,4}$, except that gentamicin was administered instead of tobramycin. Patients in the LAB group received a solution of viable $L$. plantarum $299 / 299 \mathrm{v}$ in a dose of $5 \times 10^{9}$ colony forming units together with 6 grams of rose-hip (Probi $A B$, Lund, Sweden), applied twice daily through a nasogastric tube. Administration of either study product continued until discharge from the ICU, death or final removal of the nasogastric tube. Prior to the first administration of either study product, a rectal swab was taken $(t=0)$ and thereafter, swabs were taken weekly until death or until a maximum of two weeks after ICU discharge.

Clinical samples of different origin were taken at the attending physician's discretion, whenever signs and symptoms of an infection developed. Data on antibiotic consumption in ICU were recorded as described previously and expressed as defined daily doses (DDD) ${ }^{15}$.

\section{Microbiological analysis}

At the laboratory of the MUMC, rectal swabs of both centres were processed and species identification was performed as described previously ${ }^{16,17}$. Isolates identified as E. coli were stored in $0.9 \% \mathrm{NaCl}(\mathrm{w} / \mathrm{v})$ with $20 \%$ glycerol $(\mathrm{v} / \mathrm{v})$ at $-80^{\circ} \mathrm{C}$ until further processing. For rectal $E$. coli isolates, a broth microdilution method was used to determine minimal inhibitory concentrations (MICs) of the 11 antibiotics tested, according to the CLSI guidelines ${ }^{18,19}$. E. coli ATCC 35218 and ATCC 25922 were used as control strains.

Isolates with a MIC value for ceftazidime and/or cefotaxime of $\geq 2 \mathrm{mg} / \mathrm{l}$ were considered putative extended-spectrum beta-lactamase (ESBL) producers. Confirmation of ESBL production was done according to the guidelines of the Dutch Society of Medical Microbiology ${ }^{20}$. In addition, a PCR was performed to further characterise the phenotypically positive ESBL isolates ${ }^{21}$.

Pulsed field gel electrophoresis (PFGE) was performed on co-amoxiclav-resistant E. coli isolates in the LAB group ${ }^{22}$.

Culturing and susceptibility testing of clinical samples were performed according to local standard operating procedures ${ }^{23}$.

\section{Statistical analysis}

A Mann-Whitney $U$ test was used to compare continuous variables. The Pearson $\chi^{2}$ test was used to compare categorical data. Student's $t$ test was used to compare means. Logistic regression was applied as multivariate analysis. Analysis was done with SPSS 15.0 for Windows (SPSS Benelux BV, Gorinchem, The Netherlands). Statistical significance was defined as $P$-value of less than 0.05 in all cases. 


\section{Results}

In total, 254 patients were included in the trial; 124 in the SDD group and 130 in the LAB group. Baseline and follow-up characteristics were not significantly different between both patient groups and between patients from both hospitals ${ }^{15}$.

\section{Prevalence of antibiotic-resistant $E$. coli in rectal swabs}

A total of 910 rectal swabs were taken from the 254 patients included in the trial (Figure 5.1). Resistance percentages were similar in both participating centres for all antibiotics tested, at all time points. Antibiotic resistance, both before and during prophylaxis, was not significantly different between the two prophylaxis groups, for any antibiotic tested (Figure 5.2a). However, after cessation of prophylaxis, resistance to amoxicillin was significantly higher in the LAB group than in the SDD group ( $74 \%$ vs. $50 \%, P=0.04$, Figure 5.2a).

In the SDD group, no significant increase in antibiotic resistance was found over time. In the LAB group, a significant increase in co-amoxiclav resistance was found during prophylaxis compared to $t=0$ (from 7 to $19 \%, P=0.03$, Figure $5.2 \mathrm{a}$ ). This increase persisted after cessation of $\operatorname{LAB}(24 \%, P=0.01$ compared to $t=0$, Figure $5.2 a)$. Coamoxiclav-resistant strains were isolated from 17 different patients, throughout the entire 2.5-year study period. PFGE patterns were different using the criteria from Tenover (data not shown) ${ }^{22}$. The mean length of ICU stay of these patients was 32 days, which was significantly longer than the mean 16 days of the patients without coamoxiclav resistance $(P=0.01)$.

Cefotaxime resistance was low in the SDD group (1-3\%), whereas it was absent in the LAB group (Figure 5.2a). Neither a significant increase in resistance to other cephalosporins, nor a significant shift in MIC distributions towards more resistant values (data not shown) was found over time in both groups (Figure 5.2a).

In total, 17 isolates (5\%) were putative ESBL producers: nine (7\%) in the SDD group (six at $\mathrm{t}=0$, one during and two after prophylaxis) and eight (3\%) in the LAB group (three at $t=0$ and five during prophylaxis). Only two of the nine SDD isolates (from one patient, at $t=0$ and $t=1$ ), and none of the eight $L A B$ isolates were confirmed ESBL-producers, resulting in an overall ESBL prevalence of $0.5 \%$ (2/367). Both isolates carried the bla CTX-M gene. 


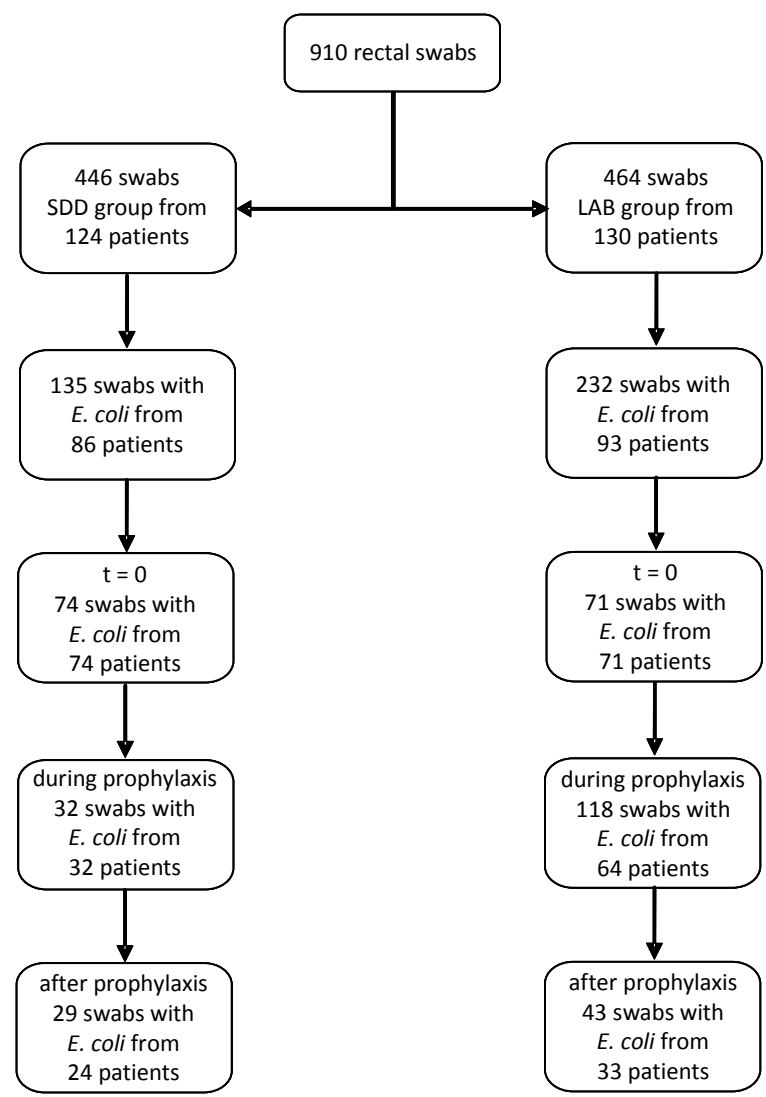

Figure 5.1 Flowchart of evaluated rectal swabs.

SDD, selective decontamination of the digestive tract; $L A B$, L. plantarum 299/299v plus fibre; $t=0$, before start of study product.

\section{Factors associated with emergence of co-amoxiclav resistance}

Patient characteristics as well as infectious events were compared between patients with newly developed co-amoxiclav resistance during prophylaxis $(n=19)$ and those without ( $n=235$, Table 5.1 and Table 5.2, respectively). Patients with $E$. coli that became resistant to co-amoxiclav had a significantly longer length of stay in the ICU, longer duration of mechanical ventilation and longer hospital stay. Study medication (both SDD ( $n=7)$ and lactobacilli $(n=12)$ ) was administered significantly longer in the 19 patients with co-amoxiclav-resistant $E$. coli (Table 5.1). However, only the length of hospital stay was an independent predisposing factor for co-amoxiclav resistance, with an odds ratio (OR) of 0.99 (95\% confidence interval $(\mathrm{Cl})$ 0.971-0.999; $P=0.03$ ) in the multivariate analysis. Infectious events were similar in patients with $E$. coli resistant to co-amoxiclav and those with susceptible $E$. coli (Table 5.2). 


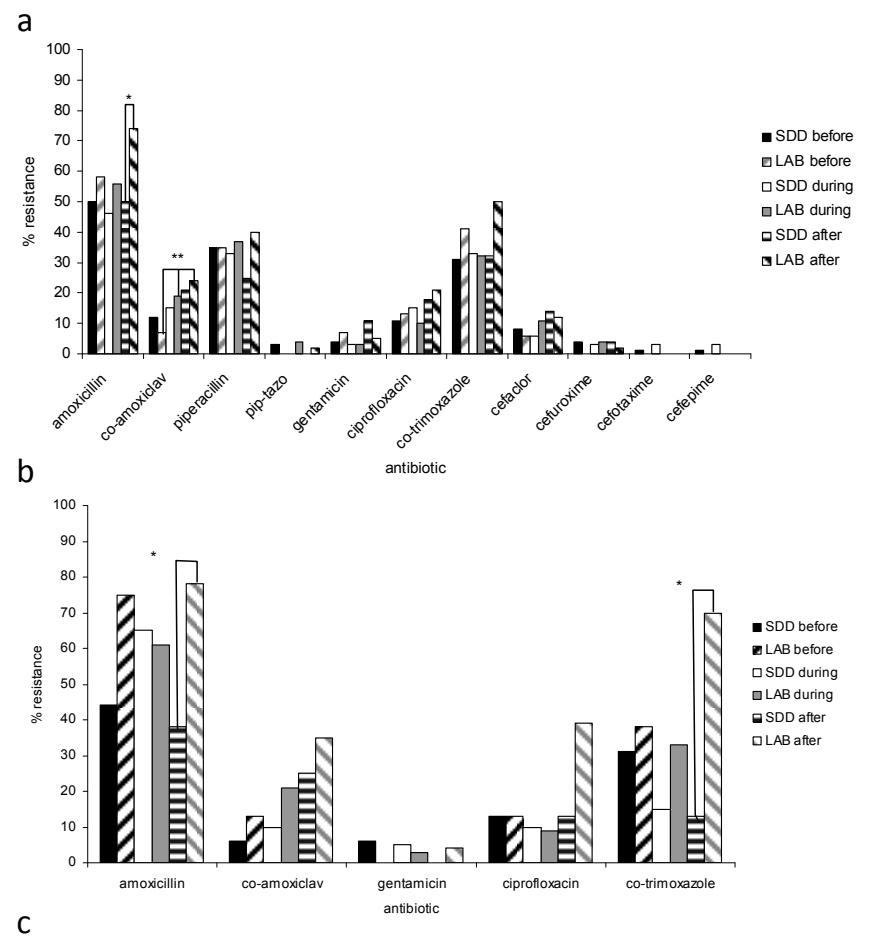

C

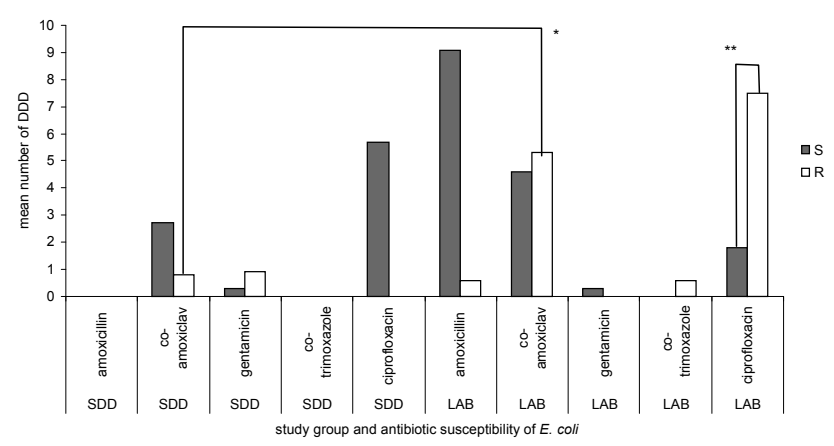

Figure 5.2 (a) Prevalence (\%) of rectally obtained antibiotic-resistant $E$. coli $(n=367)$ in both study groups before ( $n=74(S D D)$ and $71(L A B)$, respectively), during ( $n=33$ and 119$)$ and after prophylaxis ( $n=28$ and 42 ). $* P<0.05$ LAB after prophylaxis compared to SDD, by Pearson $\chi^{2}$ test. $* * P<0.05$ LAB during and after prophylaxis compared to LAB before prophylaxis, by Pearson $\chi^{2}$ test. (b) Prevalence (\%) of clinically isolated antibiotic-resistant $E$. coli $(n=108)$ in both study groups before ( $n=16$ (SDD) and 8 (LAB), respectively), during ( $n=20$ and 33$)$ and after prophylaxis ( $n=8$ and 23).* $P<0.05$ LAB after prophylaxis compared to SDD, by Pearson $\chi^{2}$ test. (c) Antibiotic use of 20 SDD (left panel) and 26 LAB (right panel) patients with $E$. coli in clinical samples either resistant or susceptible to these antibiotics. ${ }^{*} P<0.05$ co-amoxiclav-resistant strains $L A B$ group compared to SDD, by Mann-Whitney $U$ test. ${ }^{* *} P<0.05$ ciprofloxacin LAB group: resistant group compared to susceptible group, by Mann-Whitney $U$ test. SDD, selective decontamination of the digestive tract; LAB, L. plantarum 299/299v plus fibre; pip-tazo, piperacillin-tazobactam; $R$, resistant; $S$, susceptible; DDD, defined daily doses. 


\section{Prevalence of antibiotic-resistant $E$. coli in clinical samples}

E. coli was isolated from 44 clinical samples of 20 patients in the SDD group and from 64 clinical samples of 26 patients in the LAB group. Similar to the rectal swabs, antibiotic resistance among clinical samples, both before and during prophylaxis, was not significantly different between the two prophylaxis groups, for any antibiotic tested (Figure 5.2b). However, after cessation of prophylaxis, resistance to amoxicillin was significantly higher in the LAB group than in the SDD group ( $78 \%$ vs. $38 \%, P=0.03$, Figure 5.2b). Moreover, co-trimoxazole resistance differed significantly (70\% in the LAB group vs. $13 \%$ in the SDD group, $P=0.005$ ). Neither in the SDD group, nor in the LAB group, was a significant increase in antibiotic resistance found over time. The (resistant) strains were isolated from different types of patient samples, during the entire study period.

In the SDD group, two patients had co-amoxiclav-resistant $E$. coli both in rectal swabs and in clinical samples (three samples, sample types were catheter tip, tissue, and wound fluid), in the LAB group four patients (six samples, sample types were sputum, bronchial lavage, pus, punctate). Antibiotic susceptibility patterns were comparable between rectal and clinical samples of these six patients. Only one ESBL-producing E. coli strain was found among the clinical isolates, from the SDD group. This strain was not present in the rectal swabs of this patient.

\section{The additional use of antibiotics and resistance}

Comparing the additional antibiotic use of patients with either resistant or susceptible $E$. coli in clinical samples (Figure 5.2c), only patients with co-amoxiclav-resistant E. coli in the LAB group received significantly more co-amoxiclav than patients in the SDD group ( $P=0.046$, Figure $5.2 \mathrm{c}$ ). Regarding ciprofloxacin resistance and use, a trend towards a higher use in the LAB group was recorded $(P=0.06$, Figure $5.2 \mathrm{c})$. When comparing the antibiotic use between the susceptible and resistant subgroups within the LAB group, ciprofloxacin use was significantly higher in the ciprofloxacin-resistant subgroup ( $P=0.008$, Figure $5.2 \mathrm{c})$.

In the 16 patients receiving SDD and 17 patients receiving LAB with co-amoxiclavresistant $E$. coli in rectal swabs, the mean number of DDD of co-amoxiclav was 1.5 (range 0-8 DDD) and 5.7 (range 0-23 DDD), respectively $(P=0.01)$. The mean length of hospital stay prior to ICU admission (as a marker of antibiotic use prior to ICU admission) was 4.9 days among the 16 SDD and 7.2 days among the 17 LAB patients $(P=0.35)$.

A similar result was found among the patients with co-amoxiclav resistance both in rectal swabs as well as clinical samples; the two SDD patients did not receive additional co-amoxiclav, but the four patients in the LAB group received a total of 32.4 DDD of co-amoxiclav (mean 8.1 DDD, $P=0.02$ compared to SDD) during ICU stay. Length of hospital stay prior to ICU admission was not significantly different between the respective two and four patients. 
The higher resistance to co-trimoxazole in the LAB group, however, was not (completely) related to a higher use, since the additional use of co-trimoxazole was not significantly different between the SDD and LAB group (1.2 vs. 3.0 DDD/100 patient days ${ }^{15}$ ).

Table 5.1 Characteristics of the patients with and without newly developed co-amoxiclav resistance among $E$. coli isolates during prophylaxis

\begin{tabular}{|c|c|c|}
\hline Characteristic & $\begin{array}{l}\text { AMC R } \\
(n=19)\end{array}$ & $\begin{array}{l}\text { AMC S } \\
(n=235)\end{array}$ \\
\hline \multicolumn{3}{|l|}{ Sex } \\
\hline male (\%) & $9(47)$ & $148(63)$ \\
\hline \multicolumn{3}{|l|}{ Age in years } \\
\hline Mean (SD) & $57.7(18.6)$ & $63.1(16.0)$ \\
\hline Range & $28-85$ & $17-90$ \\
\hline \multicolumn{3}{|l|}{$\mathrm{BMI}$ in $\mathrm{kg} / \mathrm{m}^{2}$} \\
\hline Mean (SD) & $25.8(4.1)$ & $25.5(4.8)$ \\
\hline Range & $20.0-37.6$ & $16.6-55.9$ \\
\hline \multicolumn{3}{|l|}{ APACHE II score } \\
\hline Mean (SD) & $21(6.9)$ & $22(7.8)$ \\
\hline Range & $10-33$ & $7-44$ \\
\hline \multicolumn{3}{|l|}{ Days in hospital } \\
\hline Mean (SD) & $57.0(25.9)^{* *}$ & $36.0(33.8)$ \\
\hline Range & $16-112$ & $1-227$ \\
\hline \multicolumn{3}{|l|}{ Days in ICU } \\
\hline Mean (SD) & $22.7(17.9)^{*}$ & 16.1 (21.9) \\
\hline Range & $3-59$ & $1-155$ \\
\hline \multicolumn{3}{|l|}{ Reason for ICU admission (\%): } \\
\hline respiratory insufficiency & $4(21.1)$ & $81(34.5)$ \\
\hline neurological & $7(36.8)$ & $60(25.5)$ \\
\hline hemodynamic & $2(10.5)$ & $20(8.5)$ \\
\hline sepsis/shock & $4(21.1)$ & $34(14.5)$ \\
\hline peritonitis & - & $14(6.0)$ \\
\hline trauma/other $^{\mathrm{a}}$ & $2(10.5)$ & $26(11.1)$ \\
\hline \multicolumn{3}{|l|}{ Admission group (\%): } \\
\hline surgical & $12(63.2)$ & $121(51.5)$ \\
\hline medical & $7(36.8)$ & $105(44.7)$ \\
\hline trauma & - & $9(3.8)$ \\
\hline Patients on MV (\%) & $19(100)$ & $229(97.4)$ \\
\hline \multicolumn{3}{|l|}{ Days on MV } \\
\hline Mean (SD) & $20.7(16.7)^{*}$ & 14.6 (20.9) \\
\hline Range & $2-53$ & $0-152$ \\
\hline \multicolumn{3}{|c|}{ Days with administration of study product ${ }^{b}$} \\
\hline Mean (SD) & $18.0(15.9)^{* *}$ & $10.2(13.7)$ \\
\hline Range & $1-52.5$ & $0-94.25$ \\
\hline \multicolumn{3}{|c|}{ Cumulative gastric retention in $\mathrm{ml}$} \\
\hline Mean (SD) & $2632(3586)$ & $2642(5363)$ \\
\hline Range & $0-12235$ & $0-53670$ \\
\hline
\end{tabular}

AMC, co-amoxiclav; $\mathrm{R}$, newly developed resistance during prophylaxis; $\mathrm{S}$, no newly developed resistance during prophylaxis; BMI, Body Mass Index; APACHE, acute physiology and chronic health evaluation; ICU, Intensive Care Unit; MV, mechanical ventilation. ${ }^{a}$ Including acidosis, bowel ischemia, meningitis, renal insufficiency, weaning problems, Guillain-Barré syndrome, retroperitoneal haematoma, pancreatitis, encephalopathy, necrotising fasciïtis, pelvic exenteration, traumatic spinal cord injury. ${ }^{b}$ In LAB group two times daily, in SDD group four times daily. * $P<0.05$ compared to "AMC S". ** $P<0.01$ compared to "AMC S". 
Table 5.2 Number and type of infectious events

\begin{tabular}{|c|c|c|}
\hline & $\begin{array}{l}\text { AMC R } \\
(n=19)\end{array}$ & $\begin{array}{c}\text { AMC S } \\
(n=235)\end{array}$ \\
\hline \multicolumn{3}{|l|}{ Type of infection } \\
\hline total events (\%) & $14(100)$ & $95(100)$ \\
\hline ventilator-associated pneumonia (\%) & - & $19(20.0)$ \\
\hline pneumonia $^{a}(\%)$ & $1(7.1)$ & $1(1.1)$ \\
\hline urinary tract infection (\%) & $4(28.6)$ & $34(35.8)$ \\
\hline (catheter-related) bloodstream infection (\%) & $4(28.6)$ & $28(29.5)$ \\
\hline wound infection (\%) & $1(7.1)$ & $4(4.2)$ \\
\hline intra-abdominal infection (\%) & $3(21.4)$ & $4(4.2)$ \\
\hline other $^{b}(\%)$ & $1(7.1)$ & $5(5.3)$ \\
\hline \multicolumn{3}{|l|}{ Number of infections } \\
\hline patients with 0 infections (\%) & $12(63.2)$ & $172(73.2)$ \\
\hline patients with 1 infection (\%) & $3(15.8)$ & $40(17.0)$ \\
\hline patients with 2 infections (\%) & $2(10.5)$ & $19(8.1)$ \\
\hline patients with $\geq 3$ infections (\%) & $2(10.5)$ & $4(1.7)$ \\
\hline
\end{tabular}

AMC, co-amoxiclav; $\mathrm{R}$, newly developed resistance during prophylaxis; $\mathrm{S}$, no newly developed resistance during prophylaxis. ${ }^{a}$ Involved patients were not mechanically ventilated. ${ }^{b}$ Including (pulmonary) abscess, sinusitis, empyema.

\section{Discussion}

As colonisation of the gut precedes clinical infections ${ }^{24}$, we evaluated the effect of two prophylactic regimens on the prevalence of antibiotic-resistant $E$. coli, both from rectal surveillance cultures (indigenous $E$. coli) as well as clinical samples, during a 2.5-year study period. Before and during prophylaxis, no differences in resistance between both groups were observed among the rectal isolates. During and after prophylaxis, no increased prevalence of ESBL-positive E. coli was found with both regimens compared to $t=0$. However, after cessation of prophylaxis, the prevalence of amoxicillin-resistant $E$. coli was significantly higher in the LAB group than in the SDD group. The higher use of co-amoxiclav in the $L A B$ group ${ }^{15}$, resulted in an increase of co-amoxiclav-resistant $E$. coli after start of prophylaxis. The prevalence of resistance to amoxicillin and co-trimoxazole among clinical samples was significantly higher in the LAB group compared to the SDD group after cessation of prophylaxis. ESBLproduction was only sporadically present.

Despite a higher prevalence of resistance to co-trimoxazole among clinical isolates of the LAB group compared to the SDD group, no difference in co-trimoxazole use between both groups was observed. The only (major) difference in antibiotic use was the higher consumption of co-amoxiclav in the LAB group compared to that in the SDD group $^{15}$. Although this difference does not result in a direct difference in co-amoxiclav resistance between both study groups during prophylaxis, the number of patients with co-amoxiclav-resistant strains associated with co-amoxiclav use was higher in the 
LAB group compared to those on SDD. Moreover, the higher co-amoxiclav use might result in the higher co-trimoxazole resistance in the LAB group, as the genes conferring resistance to both agents can be located on the same plasmid ${ }^{25}$. Also the significantly higher amoxicillin resistance levels in the LAB group after prophylaxis might be attributed to the increased co-amoxiclav use.

PFGE analysis revealed that the co-amoxiclav-resistant strains isolated during the study period in the LAB group were not clonally related (data not shown). Consequently, spread of a co-amoxiclav-resistant clone in the ICU during the study period has not been taking place.

In contrast to findings by Oostdijk et al., the use of cefotaxime in this study did not lead to significantly increased resistance to cephalosporins over time, while the prevalence of rectal cephalosporin resistance at baseline was comparable (6\% vs. $8 \%$ overall in our study $)^{13}$. Possible explanations for this difference are that only $E$. coli was used as indicator organism, the number of isolates tested was relatively low and the follow-up time was shorter. Cephalosporin use in The Netherlands is low, and is not prescribed outside hospitals ${ }^{26}$. Use of third-generation cephalosporins has previously been associated with the emergence of ESBLs ${ }^{27}$. During the study period, the consumption of cefotaxime in the SDD group did not increase the prevalence of ESBL-producing faecal and clinical $E$. coli isolates. The prevalence was of the same order of magnitude as that reported previously, i.e. $0.5 \%$ vs. $0.7 \%{ }^{28}$, although the numbers were small.

The additional use of systemic antibiotics had no influence on (the effects of) L. plantarum 299/299v, since this strain is (intrinsically) resistant to the antibiotics used in the current study (data not shown).

A limitation of the study is the two weeks follow-up period after cessation of prophylaxis, which is relatively short. To study the ecological effect of both SDD and $L A B$, i.e. a return of the faecal microbiota to baseline values, a longer follow-up period might be necessary ${ }^{13}$. Since every probiotic has its own specific properties, which could lead to different results, the data of this study with L. plantarum 299/299v might not be readily extrapolated to other studies using different probiotics.

The association between antibiotic use and antibiotic resistance has been generally accepted on a population level; Oostdijk et al. described this association in their study for the ICU patient population ${ }^{13}$. Prescription of antibiotics and subsequent antibiotic resistance on an individual patient level was observed in primary care patients ${ }^{29}$. For the majority of antibiotics described in this study, no clear association between the quantity of antibiotic use and development of antibiotic resistance in the individual patient was observed. However, as suggested by the present study, prescribing coamoxiclav to ICU patients resulted in colonisation (and possibly subsequent infection) with co-amoxiclav-resistant strains (isolated from both surveillance and clinical 
cultures) in the individual ICU patient. Within the ICU patient population, effects of antibiotic use on the prevalence of antibiotic resistance were greater in the LAB group, probably due to a significantly higher use of co-amoxiclav. These data indicate that prescription of antibiotics in the ICU needs to be balanced against the risk of antibiotic resistance in the entire ICU ward as well as in the individual patient.

\section{Conclusions}

In the group using probiotics as non-antibiotic prophylactic regimen, a significantly increased resistance of $E$. coli to amoxicillin and co-amoxiclav occurred after start of prophylaxis and during follow-up. A relationship with co-amoxiclav use could be possible in this patient group. The emergence of co-amoxiclav resistance during prophylaxis was independently associated with the duration of hospital stay. By contrast, patients using SDD, i.e. prophylaxis with antibiotics, did not develop a significant increase in prevalence of resistance. No increase in the prevalence of ESBLproducing $E$. coli was observed with both regimens. 


\section{References}

1. Vincent JL. Nosocomial infections in adult intensive care units. Lancet 2003;361:2068-2077.

2. De Jonge E, Schultz MJ, Spanjaard L, Bossuyt PM, Vroom MB, Dankert J, Kesecioglu J. Effects of selective decontamination of digestive tract on mortality and acquisition of resistant bacteria in intensive care: a randomised controlled trial. Lancet 2003;362:1011-1016.

3. De la Cal MA, Cerda E, Garcia-Hierro P, Van Saene HK, Gomez-Santos D, Negro E, Lorente JA. Survival benefit in critically ill burned patients receiving selective decontamination of the digestive tract: a randomized, placebo-controlled, double-blind trial. Ann Surg 2005;241:424-430.

4. De Smet AM, Kluytmans JA, Cooper BS, Mascini EM, Benus RF, Van der Werf TS, Van der Hoeven JG, Pickkers P, Bogaers-Hofman D, Van der Meer NJ, Bernards AT, Kuijper EJ, Joore JC, Leverstein-van Hall MA, Bindels AJ, Jansz AR, Wesselink RM, De Jongh BM, Dennesen PJ, Van Asselt GJ, Te Velde LF, Frenay IH, Kaasjager K, Bosch FH, Van Iterson M, Thijsen SF, Kluge GH, Pauw W, De Vries JW, Kaan JA, Arends JP, Aarts LP, Sturm PD, Harinck HI, Voss A, Uijtendaal EV, Blok HE, Thieme Groen ES, Pouw ME, Kalkman CJ, Bonten MJ. Decontamination of the digestive tract and oropharynx in ICU patients. N Engl J Med 2009;360:20-31.

5. Liberati A, D'Amico R, Pifferi S, Torri V, Brazzi L, Parmelli E. Antibiotic prophylaxis to reduce respiratory tract infections and mortality in adults receiving intensive care. Cochrane Database Syst Rev 2009:CD000022.

6. Olah A, Belagyi T, Issekutz A, Gamal ME, Bengmark S. Randomized clinical trial of specific Lactobacillus and fibre supplement to early enteral nutrition in patients with acute pancreatitis. $\mathrm{Br} J \mathrm{Surg}$ 2002;89:1103-1107.

7. Rayes N, Hansen S, Seehofer D, Muller AR, Serke S, Bengmark S, Neuhaus P. Early enteral supply of fiber and lactobacilli versus conventional nutrition: a controlled trial in patients with major abdominal surgery. Nutrition 2002;18:609-615.

8. Stoutenbeek CP, Van Saene HK, Miranda DR, Zandstra DF. The effect of selective decontamination of the digestive tract on colonisation and infection rate in multiple trauma patients. Intensive Care Med 1984;10:185-192.

9. Isakow W, Morrow LE, Kollef MH. Probiotics for preventing and treating nosocomial infections: review of current evidence and recommendations. Chest 2007;132:286-294.

10. Madsen K. Probiotics in critically ill patients. J Clin Gastroenterol 2008;42 Suppl 3 Pt 1:S116-118.

11. Klarin B, Johansson ML, Molin G, Larsson A, Jeppsson B. Adhesion of the probiotic bacterium Lactobacillus plantarum $299 \mathrm{v}$ onto the gut mucosa in critically ill patients: a randomised open trial. Crit Care 2005;9:R285-293.

12. Klarin B, Wullt M, Palmquist I, Molin G, Larsson A, Jeppsson B. Lactobacillus plantarum 299v reduces colonisation of Clostridium difficile in critically ill patients treated with antibiotics. Acta Anaesthesiol Scand 2008;52:1096-1102.

13. Oostdijk EA, De Smet AM, Blok HE, Thieme Groen ES, Van Asselt GJ, Benus RF, Bernards SA, Frenay IH, Jansz AR, De Jongh BM, Kaan JA, Leverstein-van Hall MA, Mascini EM, Pauw W, Sturm PD, Thijsen SF, Kluytmans JA, Bonten MJ. Ecological effects of selective decontamination on resistant Gram-negative bacterial colonization. Am J Respir Crit Care Med 2010;181:452-457.

14. Snydman DR. The safety of probiotics. Clin Infect Dis 2008;46 Suppl 2:S104-111.

15. Oudhuis GJ, Bergmans DC, Dormans T, Zwaveling JH, Kessels A, Prins MH, Stobberingh EE, Verbon A. Probiotics versus antibiotic decontamination of the digestive tract: infection and mortality. Intensive Care Med 2011;37:110-117.

16. Nys S, Okeke IN, Kariuki S, Dinant GJ, Driessen C, Stobberingh EE. Antibiotic resistance of faecal Escherichia coli from healthy volunteers from eight developing countries. I Antimicrob Chemother 2004;54:952-955.

17. Nys S, Bruinsma N, Filius PM, Van den Bogaard AE, Hoffman L, Terporten PH, Wildeboer-Veloo AC, Degener J, Endtz HP, Stobberingh EE. Effect of hospitalization on the antibiotic resistance of fecal Enterococcus faecalis of surgical patients over time. Microb Drug Resist 2005;11:154-158.

18. Oudhuis GJ, Verbon A, Hoogkamp-Korstanje JA, Stobberingh EE. Antimicrobial resistance in Escherichia coli and Pseudomonas aeruginosa from Intensive Care Units in The Netherlands, 19982005. Int J Antimicrob Agents 2008;31:58-63. 
19. Clinical and Laboratory Standards Institute. Methods for Dilution Antimicrobial Susceptibility Tests for Bacteria that Grow Aerobically-Seventh Edition: Approved Standard M7-A7. CLSI, Wayne, PA. 2006.

20. Dutch Society of Medical Microbiology (NVMM). NVMM-guideline for screening and confirmation of extended-spectrum beta-lactamases (ESBLs) in Enterobacteriaceae. Accessed 8 April 2010. Available at http://www.nvmm.nl/nvmm/ nvmmcms.nsf/viewdoc/DC9C2B8FB0A0B7A8C12571FF0037BED0.

21. Nyberg SD, Osterblad M, Hakanen AJ, Huovinen $\mathrm{P}$, Jalava J. Detection and molecular genetics of extended-spectrum beta-lactamases among cefuroxime-resistant Escherichia coli and Klebsiella spp. isolates from Finland, 2002-2004. Scand J Infect Dis 2007;39:417-424.

22. Tenover FC, Arbeit RD, Goering RV, Mickelsen PA, Murray BE, Persing DH, Swaminathan B. Interpreting chromosomal DNA restriction patterns produced by pulsed-field gel electrophoresis: criteria for bacterial strain typing. J Clin Microbiol 1995;33:2233-2239.

23. Isenberg HD. Clinical Microbiology Procedures Handbook. ASM press, Washington, DC. 2004.

24. Park DR. The microbiology of ventilator-associated pneumonia. Respir Care 2005;50:742-763.

25. Huovinen P. Resistance to trimethoprim-sulfamethoxazole. Clin Infect Dis 2001;32:1608-1614.

26. Goossens H, Ferech M, Vander Stichele R, Elseviers M. Outpatient antibiotic use in Europe and association with resistance: a cross-national database study. Lancet 2005;365:579-587.

27. Al Naiemi N, Heddema ER, Bart A, De Jonge E, Vandenbroucke-Grauls CM, Savelkoul PH, Duim B. Emergence of multidrug-resistant Gram-negative bacteria during selective decontamination of the digestive tract on an intensive care unit. J Antimicrob Chemother 2006;58:853-856.

28. SWAB. NethMap 2008 - Consumption of antimicrobial agents and antimicrobial resistance among medically important bacteria in The Netherlands. Accessed 6 October 2011. Available at http://www.swab.nl/swab/cms3.nsf/ viewdoc/20BCD3983B5C390AC12575850031D33D.

29. Costelloe C, Metcalfe C, Lovering A, Mant D, Hay AD. Effect of antibiotic prescribing in primary care on antimicrobial resistance in individual patients: systematic review and meta-analysis. $B M J$ 2010;340:c2096. 


\section{Chapter 6}

\section{Infection prevention in Intensive Care patients} using the probiotic Lactobacillus plantarum 299/299v

Guy J Oudhuis, Ellen E Stobberingh, Alfons Kessels, Dennis C Bergmans, Tom Dormans, Annelies Verbon 


\section{Abstract}

\section{Purpose}

The clinical effectiveness of probiotics as infection prevention measure in critically ill patients has not been unequivocally determined, since several studies showed different results. Moreover, the association with rectal (or faecal) presence of the applied probiotic strain has never been thoroughly established. Aim of the study was to determine presence of L. plantarum 299/299v (LAB) in rectal swabs from intensive care unit (ICU) patients receiving this strain twice daily as probiotic, in association with outcome.

\section{Methods}

The presence of $L A B$ was determined with randomly amplified polymorphic DNA analysis. Data on infectious events, mortality, rectal colonisation with $E$. coli and enterococci, and antibiotic use were collected.

\section{Results}

Rectal carriage of LAB could be detected in $24 \%$ of the patients. Antibiotic use was not significantly different between the groups with and without detectable LAB; 122 vs. 160 defined daily doses $/ 100$ patient days, respectively, $P=0.07$. Length of hospital stay was significantly longer in patients with proven $L A B$ colonisation $(L A B+)$. Significantly more patients in the $L A B+$ group had persistent rectal colonisation with $E$. coli (55\% vs. $29 \%, P=0.009$ ). However, the acquired infection rate and ICU- and 28-day mortality rates were not significantly different between the two groups.

\section{Conclusions}

L. plantarum 299/299v could be rectally demonstrated in a quarter of patients receiving probiotic prophylaxis. The results of this study indicate that supposed infection prevention with $L A B$ seems not to be associated with $L A B$ colonisation of the lower intestinal tract of ICU patients. 


\section{Introduction}

The effect of synbiotics such as Lactobacillus plantarum 299/299v plus fibre (LAB) on prevention of infections is hypothesised to be competition for adhesion and nutrients with potentially pathogenic microorganisms (PPMs) to create an unfavourable local milieu for colonisation with these PPMs ${ }^{1-4}$. Decreasing intestinal colonisation with PPMs is thought to prevent the majority of nosocomial infections, which are caused by these pathogens via the so-called endogenous route ${ }^{5,6}$. However, the effect of probiotics/synbiotics on prevention of infections in critically ill patients is still a matter of debate. A recent meta-analysis showed that use of probiotics in mechanically ventilated patients was associated with a lower incidence of ventilator-associated pneumonia (VAP) compared to controls ${ }^{7}$. On the other hand, four other reviews/ meta-analyses ${ }^{3,8-10}$ failed to show a reduction in infections among critically ill patients, which used probiotics as prophylaxis. Several factors such as differences in underlying disease, use of different probiotics and varying definitions of endpoints may play a role in this variable outcome $e^{7,8}$. Until now, only one (small) trial ${ }^{1}$ reported on intestinal colonisation ( $3 / 8$ patients) with probiotics, which is one of the proposed factors for prevention of infections.

L. plantarum 299v (administered together with fibre) has been found in almost all faecal samples of healthy volunteers during intake ${ }^{11-13}$, but it is not clear to what extent $L A B$ can colonise the intestinal tract of a large group of critically ill patients. These patients, for instance, have decreased intestinal motility or increased gastric retention compared to healthy individuals ${ }^{14,15}$.

We therefore studied the retrieval of LAB from rectal samples (as marker for intestinal colonisation) and the supposed prevention of infections in patients in an Intensive Care Unit (ICU).

\section{Materials and Methods}

\section{Patients, setting and procedures}

Between June 2005 and January 2008, a clinical trial comparing selective digestive tract decontamination (SDD) and LAB for prevention of nosocomial infections was performed in the ICU at the Maastricht University Medical Centre (715 beds) and the Atrium Medical Centre Heerlen (a 545-bed teaching hospital) ${ }^{16}$. The trial has been registered in the Dutch Trial Register (http://www.trialregister.nl/trialreg/index.asp), number NTR1411. The present study describes all 130 patients receiving a solution of viable L. plantarum $299 / 299 \mathrm{v}$ in a dose of $5 \times 10^{9}$ colony forming units (cfu) together with 6 grams of rose-hip (Probi AB, Lund, Sweden). The solution was applied twice daily through a nasogastric tube ${ }^{16}$. Prior to the first administration of $L A B$, a rectal swab was taken $(t=0)$ and thereafter, swabs were taken every Monday until a maximum of two weeks after discharge from the ICU or death. 
Data on antibiotic consumption were recorded using the Anatomical Therapeutic Chemical (ATC) classification system and were expressed as Defined Daily Doses (DDD) per 100 patient days ${ }^{17}$.

\section{Microbiological and molecular analysis}

Rectal swabs were suspended in $1 \mathrm{ml}$ sterile $0.9 \% \mathrm{NaCl}(\mathrm{w} / \mathrm{v})$. The suspension was tenfold diluted until $10^{-6}$. Three dilutions $\left(10^{-2}, 10^{-4}, 10^{-6}\right)$ were used to inoculate $40 \mu \mathrm{l}$ of the suspension, using an Eddy Jet spiral plater (IUL instruments, SA, Barcelona, Spain), on Lactobacillus Anaerobic MRS with Vancomycin and Bromocresol green (LAMVAB) agar plates ${ }^{18}$ and incubated anaerobically at $37^{\circ} \mathrm{C}$ for $48 \mathrm{~h}$. Isolates were stored in $0.9 \% \mathrm{NaCl}(\mathrm{w} / \mathrm{v})$ with $20 \%$ glycerol $(\mathrm{v} / \mathrm{v})$ at $-80^{\circ} \mathrm{C}$ until further processing. After thawing, samples from time points $t=0$ (day of enrolment), $t=1$ (taken on $a$ Monday, 1-7 days after $t=0$, depending on the day of enrolment) and $t=2$ (8-14 days after $\mathrm{t}=0$ ) were cultured on LAMVAB and Schaedler agar plates with vitamin $\mathrm{K}_{1}$ and $5 \%$ sheep blood. Macroscopically distinct colonies were Gram-stained and the Grampositive rods (mean 2.2 colonies per sample) were processed with a randomly amplified polymorphic DNA (RAPD) analysis as described previously ${ }^{19}$. The analysis was deemed positive when at least one colony per sample was positive. Taq polymerase, DNA bases and buffer were not added separately but via a Mastermix (Taq PCR Mastermix (Cat. nr. 201445), Qiagen GmbH, Hilden, Germany). The oligonucleotide primer used: 5' CCGCAGCCAA 3' (Product nr. 1146-3534, Scandinavian Gene Synthesis AB, Köping, Sweden).

Patients were allocated to the LAB-positive group when at least one of their samples $(t=1 / t=2)$ was positive. Regarding PPM colonisation, rectal swabs were processed and species identification of $E$. coli and enterococci was performed as described previously ${ }^{20,21}$. Persistent colonisation with these microorganisms was defined as colonisation at $\mathrm{t}=0$ and at least one subsequent time point.

\section{Statistical analysis}

The timeframe $t=0$ to $t=2$ (maximum 14 days) was chosen to correct for possible differences in outcome caused by patients with a long length of ICU stay. For LABpositive and $L A B$-negative patients, an incidence density ratio of infection was calculated within the $t=0$ to $t=2$ timeframe. In this calculation, the number of patients with infection and number of days with LAB protection (defined as seven days before and seven days after the actual day of molecular detection) and non-protection were applied as variables. For this analysis STATA 11.1 (STATA Corporation, College Station, TX) was used.

To compare mortality, a logistic regression model was used to adjust for differences in prognostic variables and severity of disease, using APACHE II score, age, sex, BMI, and Intensive Care Unit as covariates ${ }^{16}$. Logistic regression was also applied as multivariate analysis. For time-to-infectious event analysis within the timeframe, a Kaplan-Meier 
curve with log rank test was generated. The additional use of antibiotics was compared between groups with a Mann-Whitney $U$ test. Analysis was performed on an intention-to-treat basis and was done with SPSS 15.0 for Windows (SPSS Benelux BV, Gorinchem, The Netherlands). Statistical significance was defined as $P$-value of less than 0.05 in all cases.

\section{Results}

Of the 130 patients who received LAB during their ICU stay, 68 patients (52\%, with 95 samples) had rectal swabs with growth of Gram-positive rods. Using RAPD, 31 of these patients ( $24 \%$, with 35 positive samples) were confirmed to be colonised with $L A B$ ( $L A B+$ group). The LAB- group consists of the 37 patients $(28 \%$, with 50 negative samples) with a negative RAPD test plus the 62 patients (48\%) with a negative Lactobacillus culture. The LAB+ and LAB- group did not significantly differ in baseline characteristics (Table 6.1).

Table 6.1 Characteristics of the study population

\begin{tabular}{|c|c|c|c|}
\hline Characteristic & $\mathrm{LAB}+\mathrm{n}=31$ & LAB- $n=99$ & $P$-value \\
\hline \multicolumn{4}{|l|}{ Sex } \\
\hline male (\%) & $18(58.1)$ & $66(66.7)$ & 0.38 \\
\hline \multicolumn{4}{|l|}{ Age in years } \\
\hline Mean (SD) & $61.6(14.4)$ & $64.1(17.1)$ & 0.16 \\
\hline Range & $22-82$ & $20-90$ & \\
\hline \multicolumn{4}{|l|}{$\mathrm{BMI}$ in $\mathrm{kg} / \mathrm{m}^{2}$} \\
\hline Mean (SD) & $24.5(4.4)$ & $25.8(5.0)$ & 0.18 \\
\hline Range & $18.3-43.3$ & 17.3-55.9 & \\
\hline \multicolumn{4}{|c|}{ APACHE II score } \\
\hline Mean (SD) & $21.5(7.0)$ & $23.6(7.9)$ & 0.22 \\
\hline Range & $9-36$ & $7-44$ & \\
\hline \multicolumn{4}{|c|}{ Cumulative gastric retention in $\mathrm{ml}$} \\
\hline Mean (SD) & $2543(5302)$ & $3145(6684)$ & 0.87 \\
\hline Range & $0-29550$ & $0-53670$ & \\
\hline \multicolumn{4}{|c|}{ Days with administration of study product } \\
\hline Mean (SD) & $8.7(3.3)$ & $5.7(4.1)$ & $<0.001$ \\
\hline Range & $2-14$ & $0-14$ & \\
\hline \multicolumn{4}{|l|}{ Days in ICU } \\
\hline Mean (SD) & $10.6(3.0)$ & $7.9(4.2)$ & 0.003 \\
\hline Range & $5-16$ & $1-16$ & \\
\hline \multicolumn{4}{|l|}{ Days in hospital } \\
\hline Mean (SD) & 16.7 (7.9) & $12.9(5.8)$ & 0.02 \\
\hline Range & $7-41$ & $2-39$ & \\
\hline \multicolumn{4}{|c|}{ Total antibiotic use in DDD/100 patient days } \\
\hline Mean (SD) & $122.0(96.9)$ & $159.6(122.3)$ & 0.07 \\
\hline
\end{tabular}

LAB, Lactobacillus plantarum 299/299v; BMI, Body Mass Index; APACHE, acute physiology and chronic health evaluation; ICU, Intensive Care Unit; DDD, defined daily doses. 


\section{Rectal colonisation rate of E. coli and enterococci}

E. coli colonisation was present in $84 \%$ of $L A B+$ patients and $68 \%$ of LAB-patients at one or more time points, $P=0.08$, and was not significantly different at $t=0$ (65 and $52 \%$, respectively). However, significantly more $L A B+$ patients had persistent colonisation with $E$. coli (55\%) compared to only $29 \%$ of the patients in the LAB- group $(P=0.009)$. Enterococcal colonisation was present in $87 \%$ of $L A B+$ patients and $71 \%$ of LAB- patients at one or more time points, $P=0.07$, was not different at $\mathrm{t}=0$ (55 and $54 \%$, respectively) and persisted in 45 and $36 \%$, respectively $(P=0.38)$.

\section{Outcome}

No statistically significant difference in infection rate was found between the LAB+ group (29\%) and the LAB- group (19\%, $P=0.24$, Table 6.2). Neither could we demonstrate a significant incidence density ratio for infection, i.e. $1.76(95 \% \mathrm{Cl} 0.70-$ 4.09), $P=0.17$. The incidence density was 0.04 in the $L A B+$ group ( 9 patients developed infection during 227 days of LAB-protection) and 0.02 in the LAB- group (19 patients developed infection in 845 days of non-protection). The mean APACHE II scores of the infectious patients were $21.3(\mathrm{LAB}+)$ and 22.4 ( $\mathrm{LAB}-)$, respectively, $P>0.05$. The timeto-first infection was also similar in both study groups $(P=0.44$ by log rank test, Figure 6.1).

Table 6.2 Number and type of infectious events

\begin{tabular}{|c|c|c|}
\hline & $\begin{array}{c}\mathrm{LAB}+ \\
(\mathrm{n}=31)\end{array}$ & $\begin{array}{c}\text { LAB- } \\
(n=99)\end{array}$ \\
\hline \multicolumn{3}{|l|}{ Type of infection } \\
\hline total events (\%) & $11(100)$ & $20(100)$ \\
\hline ventilator-associated pneumonia (\%) & $1(9)$ & $6(30)$ \\
\hline pneumonia $^{\mathrm{a}}(\%)$ & $2(18)$ & - \\
\hline urinary tract infection (\%) & $6(55)$ & $6(30)$ \\
\hline (catheter-related) bloodstream infection (\%) & $1(9)$ & $3(15)$ \\
\hline wound infection (\%) & - & $2(10)$ \\
\hline intra-abdominal infection (\%) & - & $3(15)$ \\
\hline other $^{b}(\%)$ & $1(9)$ & - \\
\hline \multicolumn{3}{|l|}{ Number of infections } \\
\hline patients with 0 infections (\%) & $22(71)$ & $80(81)$ \\
\hline patients with 1 infection (\%) & $7(23)$ & $18(18)$ \\
\hline patients with 2 infections (\%) & $2(6)$ & $1(1)$ \\
\hline
\end{tabular}

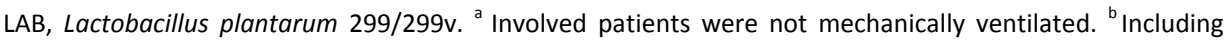
(pulmonary) abscess, sinusitis, empyema. 


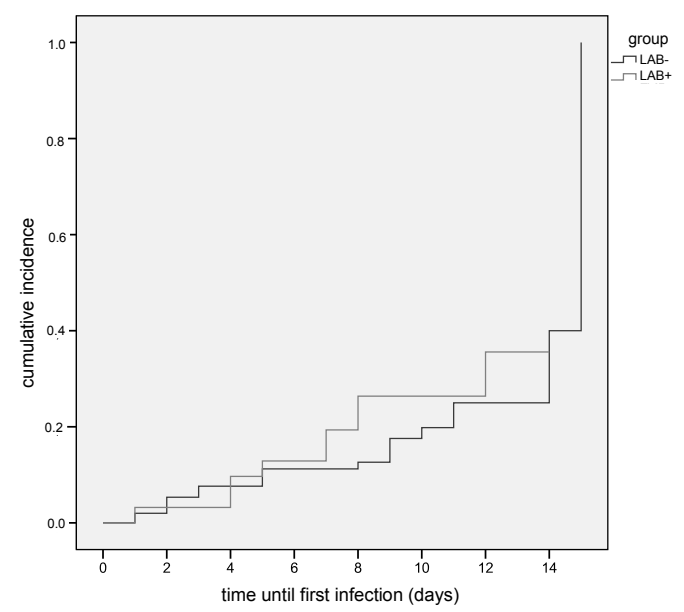

Figure 6.1 Kaplan-Meier time-to-event analysis for the incidence of infectious events. $P=0.44$, by log rank test. Dark line, LAB- group; light line, LAB+ group; LAB, Lactobacillus plantarum 299/299v.

Presence of $L A B$ in rectal samples was associated with an increased length of ICU and hospital stay and number of days that LAB was administered, compared to the LABgroup (Table 6.1). There was no significant difference in total concurrent antibiotic use between the LAB+ and LAB- group, although the mean number of DDD/100 patient days tended to be higher in the LAB- group (Table 6.1). Co-amoxiclav was significantly more administered to the LAB- group $(P=0.03)$, and piperacillin-tazobactam was more administered to the $\mathrm{LAB}+$ group $(P=0.02$, data not shown). In the multivariate analysis, length of hospital stay was shown to be an independent factor associated with confirmed LAB colonisation, with an odds ratio (OR) of 1.08 per day $(95 \% \mathrm{Cl} 1.01-$ 1.16; $P=0.02$ ).

Overall ICU mortality, after adjustment for APACHE II score, age, sex, BMI and Intensive Care Unit, was $18 \%$ and not statistically different between the $\mathrm{LAB}+$ and LAB- group (OR 0.60, 95\% $\mathrm{Cl} 0.15-2.44 ; P=0.48$ ). Neither was adjusted mortality at day 28 (OR $0.38,95 \% \mathrm{Cl} 0.10-1.48 ; P=0.16$ ).

\section{Discussion}

We found that $24 \%$ of the 130 patients receiving $L A B$ were colonised with this probiotic. In the multivariate analysis, colonisation with $L A B$ was not significantly associated with concurrent antibiotic use, number of days of $L A B$ administration or length of ICU stay. Length of hospital stay, however, was significantly longer in LAB+ 
patients. A decrease in colonisation with PPMs (E. coli) was not found in the LAB+ group, and only to a minor extent in the LAB- group. Taken together, our data could not confirm the hypothesis that intestinal colonisation with LAB and subsequent change in PPM colonisation result in lower nosocomial infection or mortality rates in ICU patients.

Although the odds of confirmed LAB colonisation increased with every day of hospital stay, LAB was only retrieved from rectal swabs in approximately a quarter of ICU patients in our study. By contrast, retrieval from faecal samples in healthy persons was nearly $100 \%{ }^{11-13}$. It is unlikely that this difference is caused by the sampling method since sensitivity for positive cultures was found to be similar for rectal swabs and stool samples ${ }^{22}$. In a small study, intestinal biopsies seemed superior for retrieval of $L A B^{23}$. However, lower retrieval rates for $L A B$ were shown in intestinal biopsies compared to stool samples in both healthy controls and critically ill patients ${ }^{1,24}$.

Other factors such as impaired intestinal motility may have resulted in lower LAB colonisation $^{25}$, but gastric retention, although high, was not statistically significantly different between $\mathrm{LAB}+$ and $\mathrm{LAB}$ - patients. Also, total concurrent antibiotic use was comparable between the $\angle A B+$ and $\angle A B$ - group, and concurrent antibiotic use has been shown not to influence $L A B$ colonisation ${ }^{1}$. However, differences in individual antibiotics have been established between the two groups, for which no explanation could be found. The use of proton pump inhibitors (PPIs) is known to alter the gastrointestinal flora by influencing colonisation through $\mathrm{pH}$ changes ${ }^{26}$ or a direct antibacterial effect ${ }^{27}$. Proton pumps have previously been described to be present in the colon ${ }^{28}$, concurrent use of PPIs may therefore have decreased LAB colonisation in some patients. Furthermore, use of corticosteroids can alter the composition of the intestinal microbiota and was found to decrease the number of (live) bacteria ${ }^{29,30}$, possibly through reducing the sites for microbe attachment. Thus, we cannot exclude that concurrent drug use (not specified), other than antibiotics, has influenced LAB colonisation in these ICU patients and further research towards colonisationinfluencing factors seems warranted.

Colonisation with $L A B$ was not associated with supposed prevention of nosocomial infections or mortality. In a clinical trial comparing $L A B$ to SDD, no difference in infection rate and mortality could be demonstrated either ${ }^{16}$. The mechanistic effect of infection prevention by SDD is thought to be a decrease of intestinal (facultative) aerobic Gram-negative bacilli and yeasts, which is accompanied by a relative increase of intestinal enterococci ${ }^{31}$. A comparable mechanism has also been suggested for probiotics $^{8}$. However, we found persistent colonisation with $E$. coli, despite proven colonisation with $L A B$, as previously described ${ }^{11,12,32}$. This suggests that $L A B$ colonisation by itself may not change the intestinal microbiota to the same extent as SDD, through competition for adherence sites on the intestinal mucosa ${ }^{33}$. Other mechanisms such as a positive effect on the immune system and/or mucosal barrier 
function, alteration of local $\mathrm{pH}$, production of bacteriocins or scavenging of superoxide radicals ${ }^{34-39}$ may result in decreased infection rates as found in several studies ${ }^{7}$.

Our study has some limitations. The (qualitative) detection method for $L$. plantarum 299/299v, E. coli and enterococci, was partially culture-based which may give falsely negative results when bacteria are present below the detection limit. However, specific selective culture media were used to minimise this effect. Furthermore, the small number of patients may have influenced the fact that no statistically significant differences in infection and mortality rates between the $\mathrm{LAB}+$ and $\mathrm{LAB}$ - group could be established. Finally, the results of the present study with L. plantarum 299/299v and fibre should not be readily extrapolated to other studies using different pro/synbiotics (with different properties) in different patient populations.

\section{Conclusions}

The results of this study suggest that supposed infection prevention with LAB probably is not associated with intestinal LAB colonisation in ICU patients. More research is needed to elucidate the alternative mechanism(s) of action of probiotics for infection prevention, especially in the critically ill. 


\section{References}

1. Klarin B, Johansson ML, Molin G, Larsson A, Jeppsson B. Adhesion of the probiotic bacterium Lactobacillus plantarum $299 \mathrm{v}$ onto the gut mucosa in critically ill patients: a randomised open trial. Crit Care 2005;9:R285-293.

2. Klarin B, Wullt M, Palmquist I, Molin G, Larsson A, Jeppsson B. Lactobacillus plantarum 299v reduces colonisation of Clostridium difficile in critically ill patients treated with antibiotics. Acta Anaesthesiol Scand 2008;52:1096-1102.

3. Isakow W, Morrow LE, Kollef MH. Probiotics for preventing and treating nosocomial infections: review of current evidence and recommendations. Chest 2007;132:286-294.

4. Madsen K. Probiotics in critically ill patients. J Clin Gastroenterol 2008;42 (Suppl 3 Pt 1):S116-118.

5. Bergmann OJ, Kilian M, Ellegaard J. Potentially pathogenic microorganisms in the oral cavity during febrile episodes in immunocompromised patients with haematologic malignancies. Scand J Infect Dis 1989;21:43-51.

6. Van der Waaij D, Tieleman-Speltie TM, De Roeck-Houben AM. Relation between the faecal concentration of various potentially pathogenic microorganisms and infections in individuals (mice) with severely decreased resistance to infection. Antonie Van Leeuwenhoek 1978;44:395-405.

7. Siempos II, Ntaidou TK, Falagas ME. Impact of the administration of probiotics on the incidence of ventilator-associated pneumonia: a meta-analysis of randomized controlled trials. Crit Care Med 2010;38:954-962.

8. Watkinson PJ, Barber VS, Dark P, Young JD. The use of pre- pro- and synbiotics in adult intensive care unit patients: systematic review. Clin Nutr 2007;26:182-192.

9. McNabb B, Isakow W. Probiotics for the prevention of nosocomial pneumonia: current evidence and opinions. Curr Opin Pulm Med 2008;14:168-175.

10. Koretz RL. Probiotics, critical illness, and methodologic bias. Nutr Clin Pract 2009;24:45-49.

11. Goossens D, Jonkers D, Russel M, Stobberingh E, Van den Bogaard A, Stockbrügger R. The effect of Lactobacillus plantarum $299 \mathrm{v}$ on the bacterial composition and metabolic activity in faeces of healthy volunteers: a placebo-controlled study on the onset and duration of effects. Aliment Pharmacol Ther 2003;18:495-505.

12. Goossens D, Jonkers D, Russel M, Thijs A, Van den Bogaard A, Stobberingh E, Stockbrügger R. Survival of the probiotic, L. plantarum $299 \mathrm{v}$ and its effects on the faecal bacterial flora, with and without gastric acid inhibition. Dig Liver Dis 2005;37:44-50.

13. Johansson ML, Nobaek S, Berggren A, Nyman M, Bjorck I, Ahrne S, Jeppsson B, Molin G. Survival of Lactobacillus plantarum DSM 9843 (299v), and effect on the short-chain fatty acid content of faeces after ingestion of a rose-hip drink with fermented oats. Int J Food Microbiol 1998;42:29-38.

14. Fruhwald S, Holzer $\mathrm{P}$, Metzler $\mathrm{H}$. Intestinal motility disturbances in intensive care patients pathogenesis and clinical impact. Intensive Care Med 2007;33:36-44.

15. Adam S, Batson S. A study of problems associated with the delivery of enteral feed in critically ill patients in five ICUs in the UK. Intensive Care Med 1997;23:261-266.

16. Oudhuis GJ, Bergmans DC, Dormans T, Zwaveling JH, Kessels A, Prins MH, Stobberingh EE, Verbon A. Probiotics versus antibiotic decontamination of the digestive tract: infection and mortality. Intensive Care Med 2011;37:110-117.

17. WHO Collaborating Centre for Drug Statistics Methodology. Anatomical Therapeutic Chemical (ATC) classification index with Defined Daily Doses (DDDs). WHO Collaborating Centre, Oslo, Norway. 2006.

18. Hartemink $R$, Domenech V, Rombouts F. LAMVAB--A new selective medium for the isolation of lactobacilli from faeces. J Microbiol Methods 1997;29:77-84.

19. Johansson ML, Quednau M, Molin G, Ahrne S. Randomly amplified polymorphic DNA (RAPD) for rapid typing of Lactobacillus plantarum strains. Lett Appl Microbiol 1995;21:155-159.

20. Nys S, Okeke IN, Kariuki S, Dinant GJ, Driessen C, Stobberingh EE. Antibiotic resistance of faecal Escherichia coli from healthy volunteers from eight developing countries. J Antimicrob Chemother 2004;54:952-955.

21. Nys S, Bruinsma N, Filius PM, Van den Bogaard AE, Hoffman L, Terporten PH, Wildeboer-Veloo AC, Degener J, Endtz HP, Stobberingh EE. Effect of hospitalization on the antibiotic resistance of fecal Enterococcus faecalis of surgical patients over time. Microb Drug Resist 2005;11:154-158. 
22. Lautenbach E, Harris AD, Perencevich EN, Nachamkin I, Tolomeo P, Metlay JP. Test characteristics of perirectal and rectal swab compared to stool sample for detection of fluoroquinolone-resistant Escherichia coli in the gastrointestinal tract. Antimicrob Agents Chemother 2005;49:798-800.

23. Johansson ML, Molin G, Jeppsson B, Nobaek S, Ahrne S, Bengmark S. Administration of different Lactobacillus strains in fermented oatmeal soup: in vivo colonization of human intestinal mucosa and effect on the indigenous flora. Appl Environ Microbiol 1993;59:15-20.

24. Goossens DA, Jonkers DM, Russel MG, Stobberingh EE, Stockbrügger RW. The effect of a probiotic drink with Lactobacillus plantarum $299 \mathrm{v}$ on the bacterial composition in faeces and mucosal biopsies of rectum and ascending colon. Aliment Pharmacol Ther 2006;23:255-263.

25. Besselink MG, Timmerman HM, Van Minnen LP, Akkermans LM, Gooszen HG. Prevention of infectious complications in surgical patients: potential role of probiotics. Dig Surg 2005;22:234-244.

26. Thorens J, Froehlich F, Schwizer W, Saraga E, Bille J, Gyr K, Duroux P, Nicolet M, Pignatelli B, Blum AL, Gonvers JJ, Fried M. Bacterial overgrowth during treatment with omeprazole compared with cimetidine: a prospective randomised double blind study. Gut 1996;39:54-59.

27. Jonkers D, Stobberingh E, Stockbrügger R. Omeprazole inhibits growth of Gram-positive and Gramnegative bacteria including Helicobacter pylori in vitro. J Antimicrob Chemother 1996;37:145-150.

28. Mukherjee S. Diarrhea associated with lansoprazole. J Gastroenterol Hepatol 2003;18:602-603.

29. Wenzl HH, Schimpl G, Feierl G, Steinwender G. Effect of prenatal cortisone on spontaneous bacterial translocation from gastrointestinal tract in neonatal rat. Dig Dis Sci 2003;48:1171-1176.

30. Schiffrin EJ, Carter EA, Walker WA, Frieberg E, Benjamin J, Israel EJ. Influence of prenatal corticosteroids on bacterial colonization in the newborn rat. J Pediatr Gastroenterol Nutr 1993; 17:271-275.

31. Humphreys $\mathrm{H}$, Winter R, Pick $\mathrm{A}$. The effect of selective decontamination of the digestive tract on gastrointestinal enterococcal colonization in ITU patients. Intensive Care Med 1992;18:459-463.

32. McNaught C, Woodcock N, Anderson A, MacFie J. A prospective randomised trial of probiotics in critically ill patients. Clinical Nutrition 2005;24:211-219.

33. Adlerberth I, Ahrne S, Johansson ML, Molin G, Hanson LA, Wold AE. A mannose-specific adherence mechanism in Lactobacillus plantarum conferring binding to the human colonic cell line HT-29. Appl Environ Microbiol 1996;62:2244-2251.

34. Aiba Y, Suzuki N, Kabir AM, Takagi A, Koga Y. Lactic acid-mediated suppression of Helicobacter pylori by the oral administration of Lactobacillus salivarius as a probiotic in a gnotobiotic murine model. Am J Gastroenterol 1998;93:2097-2101.

35. Eckmann L. Innate immunity and mucosal bacterial interactions in the intestine. Curr Opin Gastroenterol 2004;20:82-88.

36. Gionchetti P, Lammers KM, Rizzello F, Campieri M. Probiotics and barrier function in colitis. Gut 2005; 54:898-900.

37. Akisu M, Baka M, Yalaz M, Huseyinov A, Kultursay N. Supplementation with Saccharomyces boulardii ameliorates hypoxia/reoxygenation-induced necrotizing enterocolitis in young mice. Eur J Pediatr Surg 2003;13:319-323.

38. Qamar A, Aboudola S, Warny M, Michetti P, Pothoulakis C, LaMont JT, Kelly CP. Saccharomyces boulardii stimulates intestinal immunoglobulin $\mathrm{A}$ immune response to Clostridium difficile toxin $\mathrm{A}$ in mice. Infect Immun 2001;69:2762-2765.

39. Rachmilewitz D, Katakura K, Karmeli F, Hayashi T, Reinus C, Rudensky B, Akira S, Takeda K, Lee J, Takabayashi K, Raz E. Toll-like receptor 9 signaling mediates the anti-inflammatory effects of probiotics in murine experimental colitis. Gastroenterology 2004;126:520-528. 

Chapter 7

General discussion and future perspectives 
100 Chapter 7 
Vulnerable Intensive Care Unit (ICU) patients are prone to develop infections. Prevention is mandatory, given the associated morbidity and mortality. For prevention of infections, both antibiotic and non-antibiotic measures are available. However, the benefits of antibiotic prophylaxis always need to be balanced against the risk of developing antimicrobial resistance. Moreover, there is no consensus about the beneficial effects of several other prophylactic measures.

An example of a non-antibiotic measure is the use of biomarkers as rapid reliable diagnostic testing for ventilator-associated pneumonia (VAP). Biomarkers could contribute to a rapid diagnosis and, through earlier initiation of therapy, decrease morbidity and mortality. They could also diminish the amount of unnecessary antibiotics prescribed, based on false clinical suspicion of VAP. A decreased antibiotic pressure helps to control the antibiotic resistance problem. Notwithstanding promising previous reports, the measurement of soluble Triggering Receptor Expressed on Myeloid cells-1 (sTREM-1) levels in bronchoalveolar lavage fluid to diagnose VAP in a mixed ICU setting was not discriminative in our hands. The negative result was mainly due to a lack of specificity, despite sound diagnostic criteria, thorough quantitative measurements of STREM-1 and a sufficiently large patient population. Since other biomarkers did not appear to be useful either so far for diagnosing $\mathrm{VAP}^{1}$, more research towards their usefulness and applicability is warranted.

Selective digestive tract decontamination (SDD) has been used in Dutch ICUs as antibiotic prophylaxis ever since its introduction in the early 1980s. In a recent survey among 98 Dutch ICUs, with a $100 \%$ response rate, SDD was reported to be applied in $30 \%$ of the (mainly higher level) ICUs ${ }^{2}$. So, despite the recommendation of this intervention in the 2006 national guideline of the Dutch Society of Intensive Care, the majority of Dutch ICUs still does not use SDD ${ }^{2}$. Supposed absence of effectiveness was the most important reason for not applying SDD ${ }^{2}$. This illustrates the ongoing debate about the position of this intervention ${ }^{3}$, as its efficacy in reducing infections and mortality has been established ${ }^{4,5}$. While it is not clear whether SDD actually reduces the amount of therapeutic antibiotics, the use of SDD has been linked with the (longterm) emergence of antibiotic-resistant bacteria ${ }^{6}$. All of this against a background of worldwide increases in antibiotic use and antimicrobial resistance in general. Since 2005, the systemic antibiotic use in primary care in The Netherlands gradually increased from 10 to 11 defined daily doses (DDD)/1000 inhabitant-days ${ }^{7}$. Although this number is still low compared to other European countries ${ }^{8}$, it indicates a rise in antibiotic pressure. In Dutch hospitals the same increase was visible, i.e. between 2000 and 2009 the total systemic antibiotic use increased from 43 to 71 DDD/100 patient-days ${ }^{7}$. With regard to antibiotic resistance in Dutch ICUs, we reported a trend in increase over the last decade for Enterobacteriaceae and P. aeruginosa. Moreover, rates of multi-resistance and extended-spectrum beta-lactamase (ESBL)-producing 
K. pneumoniae are increasing ${ }^{7}$ and carbapenem-resistant $K$. pneumoniae Oxa-48 has recently emerged. By contrast, methicillin-resistant S. aureus (MRSA) and vancomycinresistant enterococci (VRE) still play a minor role in ICUs in The Netherlands ${ }^{7}$, probably due to a successful search-and-destroy policy, ${ }^{9,10}$.

So, in the era of increasing antibiotic use and antimicrobial resistance, even in traditionally low-level resistance settings like The Netherlands or for instance the Scandinavian countries, and with SDD being subject to controversies, the search for alternatives for antibiotic prophylaxis in ICU is a logic step.

The application of probiotics in ICU settings could be another option as a nonantibiotic prophylactic measure, given its absent risk of emergence of antibiotic resistance, ease of application against low costs and reported efficacy against infections in surgical patient populations. In one trial probiotics were even superior to $S D D^{11}$. However, it is unknown whether probiotics are also effective in critically ill ICU patients. Moreover, questions have been raised recently about their safety profile. These concerns are mainly based on a single study with pancreatitis patients (PROPATRIA), reporting increased mortality due to bowel ischaemia compared to placebo, using a multi-species probiotic ${ }^{12}$. The authors warned against the use of probiotics among critically ill patients. Although the proposed underlying mechanisms for development of bowel ischaemia seem to be plausible ${ }^{13}$, these findings have not been confirmed so far, and no other studies have been performed afterwards. The question is whether these results are confined only to severe acute pancreatitis patients with organ failure using a particular probiotic. In other words, the use of different probiotics might just as well be safe in a general critically ill patient population.

We aimed at a direct comparison of SDD with a well-described and widely used probiotic strain, L. plantarum 299/299v (LAB), which is also commercially available in Sweden under the name ProViva ${ }^{{ }^{14}}$. Infectious events served as the primary endpoint. Unfortunately we failed in the attempt, since the trial had to be put on hold prematurely as a safety precaution. Results suggested that LAB might have been inferior to SDD in preventing nosocomial infections. The infection rate in the LAB group, however, was comparable with or lower than the rates reported by others ${ }^{15,16}$, given the differences in patient population, applied strains and diagnostic criteria. Since the trial was not powered on mortality and ended prematurely, no firm conclusion could be drawn. Results implied, however, that $L$. plantarum 299/299v did not increase the risk of mortality in a critically ill patient population with a size similar to the PROPATRIA population. No bowel ischaemia has been observed.

It is generally accepted that antibiotic use leads to antibiotic resistance ${ }^{17}$. Indeed, a significantly higher use of co-amoxiclav in the LAB group resulted in an increased number of rectal co-amoxiclav-resistant $E$. coli isolates. This higher use might be due 
to the treatment of supposed infections in the first few days of ICU stay, in absence of cefotaxime prophylaxis. However, primary endogenous infections were not an endpoint of the study, and therefore not established retrospectively. The significantly higher total antibiotic use in the LAB group might be explained by the tendency towards more infections in this group. Therefore, more antibiotics could have been applied to treat these (presumably) secondary endogenous nosocomial infections.

By contrast, no significant changes in antibiotic resistance could be demonstrated in the SDD group, with a lower additional antibiotic use compared to the LAB group. The increased use of cefotaxime did not result in the emergence of ESBL-producing strains. However, our follow-up time was relatively short, with a low number of tested isolates and potential pathogens other than rectal $E$. coli were not evaluated. Another remarkable finding was that $P$. aeruginosa was significantly more present, compared to $L A B$, in cultures associated with infectious events as well as in sputum and urine surveillance cultures. Moreover, E. coli was not completely eradicated from the aerodigestive and intestinal tract. This is contradictory to the supposed effect of SDD on oropharyngeal and intestinal carriage of (facultative) aerobic Gram-negative bacilli ${ }^{18}$. The presence of an exogenous source for these potential pathogens was not very likely. Endogenous causes such as relatively high gastric retention, i.e. impaired intestinal motility, may have contributed to the lack of eradication. Other causes could be not applying SDD paste on the skin around tracheostomies or SDD suspension as suppository in case of blind bowel loops $s^{2,4,5}$. Results of the announced SDD/selective oropharyngeal decontamination (SOD) trial $^{19}$ could perhaps shed light on the colonisation and long-term antimicrobial resistance issues.

The way that probiotics work has not been completely elucidated. Within our LAB population, molecularly proven rectal colonisation with L. plantarum $299 / 299 \mathrm{v}$, only present in a minority of patients, was associated with a significant lack of decrease in rectal $E$. coli colonisation. This is reflected by the relatively high number of Enterobacteriaceae in other surveillance samples and as causative agents of infections in the LAB group. We were therefore not able to confirm the hypothesis that intestinal $L A B$ colonisation and subsequent decline in potentially pathogenic microorganism (PPM) carriage result in a lower incidence of infection. The working mechanism of LAB seems to be multi-factorial ${ }^{20-22}$. Modulation of the local immune system and intestinal barrier function could play a role as well, although these mechanisms could have been neutralised by other factors such as concurrent drug use and intestinal motility issues in this specific patient population. One has to bear in mind that probiotic properties can be very different from strain to strain, especially when other conditions differ as well. Probiotics should therefore not be disregarded as prophylactic entity in the ICU. 


\section{Future perspectives and recommendations for research}

The results of the currently conducted Dutch SDD/SOD trial might influence the position of SDD as prophylactic intervention. When no significant emergence or selection of antimicrobial resistance can be established, its use in settings with a low resistance rate can be regarded as safe. A next step would then be a similar, large trial in an endemic resistance setting (Southern Europe, USA) to establish the same endpoint. When emergence of resistance appears to be a significant problem however, this could be the end of SDD, despite its effects on clinical outcome. Alternatives, such as probiotics, could be evaluated on a larger scale. A study with probiotics in critically ill patients then becomes mandatory.

Similar to the SDD/SOD study, a large, well-described and well-designed three-armed placebo-controlled trial with sufficient power should be initiated in a general ICU population. It should compare a single strain regimen (e.g. "experienced" strains with a good safety profile like L. plantarum 299 or L. rhamnosus GG) to a multi-species regimen (e.g. Synbiotic $2000^{\circledR}$ ). The endpoint should be unequivocal, like 28-day mortality, in order to properly demonstrate the clinical effectiveness of probiotic intervention. Moreover, concurrent efforts must be made to identify the (molecular) working mechanism of each strain/mixture, to establish the right doses, schedule and timing of administration and to clarify the benefits of adding prebiotics.

Other alternatives for VAP prevention could be applied, including the change of ventilator circuits with every new patient, the use of heat and moisture exchangers in absence of contraindications and weekly changes of these exchangers, and intubation via the orotracheal route ${ }^{23}$. The combined approach of the so-called (modified) Ventilator Bundle may also be beneficial ${ }^{24}$. Furthermore, educational interventions like "WHAP" are reported to reduce VAP rates ${ }^{25}$. WHAP stands for: Weaning of patients as soon as possible, Hand hygiene, Aspiration precautions and Prevention of contamination $^{25}$. In the near future, point-of-care testing will probably be introduced in the ICU. For instance, rapid, non-invasive diagnostics for VAP, like measurement of volatile organic compounds produced by bacteria in exhaled breath of the patient to identify the pathogen.

Surveillance of local resistance patterns and trends should be continued and used for the implementation of local antibiotic guidelines. Implementation of these guidelines is vital to ensure optimal antibiotic policy and to control resistance, thereby influencing patient outcome. In conclusion, infection prevention is and will be needed more than ever in the ICU, although there is still no undisputed modality available to achieve this. However, as Benjamin Franklin already said in the $18^{\text {th }}$ century: "an ounce of prevention is worth a pound of cure". 
General discussion

\section{References}

1. Fagon JY. Biological markers and diagnosis of ventilator-associated pneumonia. Crit Care 2011;15: 130.

2. Barends H, Zandstra DF, Van der Voort PHJ. Current state of affairs: SDD application in Dutch ICUs. Neth J Crit Care 2008;12:109-112.

3. Van Essen EH, De Jonge E. Selective decontamination of the digestive tract (SDD): is the game worth the candle? Semin Respir Crit Care Med 2011;32:236-242.

4. De Jonge E, Schultz MJ, Spanjaard L, Bossuyt PM, Vroom MB, Dankert J, Kesecioglu J. Effects of selective decontamination of digestive tract on mortality and acquisition of resistant bacteria in intensive care: a randomised controlled trial. Lancet 2003;362:1011-1016.

5. De Smet AM, Kluytmans JA, Cooper BS, Mascini EM, Benus RF, Van der Werf TS, Van der Hoeven JG, Pickkers P, Bogaers-Hofman D, Van der Meer NJ, Bernards AT, Kuijper EJ, Joore JC, Leverstein-van Hall MA, Bindels AJ, Jansz AR, Wesselink RM, De Jongh BM, Dennesen PJ, Van Asselt GJ, Te Velde LF, Frenay IH, Kaasjager K, Bosch FH, Van Iterson M, Thijsen SF, Kluge GH, Pauw W, De Vries JW, Kaan JA, Arends JP, Aarts LP, Sturm PD, Harinck HI, Voss A, Uijtendaal EV, Blok HE, Thieme Groen ES, Pouw ME, Kalkman CJ, Bonten MJ. Decontamination of the digestive tract and oropharynx in ICU patients. N Engl J Med 2009;360:20-31.

6. Oostdijk EA, De Smet AM, Blok HE, Thieme Groen ES, Van Asselt GJ, Benus RF, Bernards SA, Frenay IH, Jansz AR, De Jongh BM, Kaan JA, Leverstein-van Hall MA, Mascini EM, Pauw W, Sturm PD, Thijsen SF, Kluytmans JA, Bonten MJ. Ecological effects of selective decontamination on resistant Gram-negative bacterial colonization. Am J Respir Crit Care Med 2010;181:452-457.

7. SWAB. NethMap 2011 - Consumption of antimicrobial agents and antimicrobial resistance among medically important bacteria in The Netherlands. Accessed 26 August 2011. Available at http://www.swab.nl/swab/cms3.nsf/uploads/35ACD3A546C31716C12578BF002EDC4F/\$FILE/NethM ap2011.pdf.

8. Goossens H, Ferech M, Vander Stichele R, Elseviers M. Outpatient antibiotic use in Europe and association with resistance: a cross-national database study. Lancet 2005;365:579-587.

9. Stichting Werkgroep Infectiepreventie. Richtlijn MRSA, ziekenhuis. WIP 2008. Accessed 13 August 2011. Available at http://www.wip.nl/free_content/Richtlijnen/MRSA\%20ziekenhuis080310.pdf.

10. Stichting Werkgroep Infectiepreventie. Richtlijn maatregelen tegen overdracht van bijzonderresistente micro-organismen (BRMO). WIP 2010. Accessed 13 August 2011. Available at http://www.wip.nl/free_content/Richtlijnen/BRMO.pdf.

11. Rayes N, Seehofer D, Hansen S, Boucsein K, Muller AR, Serke S, Bengmark S, Neuhaus P. Early enteral supply of Lactobacillus and fiber versus selective bowel decontamination: a controlled trial in liver transplant recipients. Transplantation 2002;74:123-127.

12. Besselink MG, Van Santvoort HC, Buskens E, Boermeester MA, Van Goor H, Timmerman HM, Nieuwenhuijs VB, Bollen TL, Van Ramshorst B, Witteman BJ, Rosman C, Ploeg RJ, Brink MA, Schaapherder AF, Dejong CH, Wahab PJ, Van Laarhoven CJ, Van der Harst E, Van Eijck CH, Cuesta MA, Akkermans LM, Gooszen HG. Probiotic prophylaxis in predicted severe acute pancreatitis: a randomised, double-blind, placebo-controlled trial. Lancet 2008;371:651-659.

13. Besselink MG, Van Santvoort HC, Renooij W, De Smet MB, Boermeester MA, Fischer K, Timmerman HM, Ahmed Ali U, Cirkel GA, Bollen TL, Van Ramshorst B, Schaapherder AF, Witteman BJ, Ploeg RJ, Van Goor H, Van Laarhoven CJ, Tan AC, Brink MA, Van der Harst E, Wahab PJ, Van Eijck CH, Dejong $\mathrm{CH}$, Van Erpecum KJ, Akkermans LM, Gooszen HG. Intestinal barrier dysfunction in a randomized trial of a specific probiotic composition in acute pancreatitis. Ann Surg 2009;250:712-719.

14. Klarin B, Johansson ML, Molin G, Larsson A, Jeppsson B. Adhesion of the probiotic bacterium Lactobacillus plantarum $299 \mathrm{v}$ onto the gut mucosa in critically ill patients: a randomised open trial. Crit Care 2005;9:R285-293.

15. Barraud D, Blard C, Hein F, Marcon O, Cravoisy A, Nace L, Alla F, Bollaert PE, Gibot S. Probiotics in the critically ill patient: a double blind, randomized, placebo-controlled trial. Intensive Care Med 2010;36: 1540-1547. 
16. Kotzampassi K, Giamarellos-Bourboulis EJ, Voudouris A, Kazamias P, Eleftheriadis E. Benefits of a synbiotic formula (Synbiotic 2000Forte ${ }^{\circledR}$ ) in critically ill trauma patients: early results of a randomized controlled trial. World J Surg 2006;30:1848-1855.

17. Neuhauser MM, Weinstein RA, Rydman R, Danziger LH, Karam G, Quinn JP. Antibiotic resistance among Gram-negative bacilli in US intensive care units: implications for fluoroquinolone use. JAMA 2003;289:885-888.

18. Zandstra DF, Van Saene HK. Selective decontamination of the digestive tract as infection prevention in the critically ill. A level 1 evidence-based strategy. Minerva Anestesiol 2011;77:212-219.

19. Schultz MJ, Haas LE. Antibiotics or probiotics as preventive measures against ventilator-associated pneumonia: a literature review. Crit Care 2011;15:R18.

20. Isakow W, Morrow LE, Kollef MH. Probiotics for preventing and treating nosocomial infections: review of current evidence and recommendations. Chest 2007;132:286-294.

21. Madsen K. Probiotics in critically ill patients. J Clin Gastroentero/ 2008;42 Suppl 3 Pt 1:S116-118.

22. Rayes N, Seehofer D, Neuhaus P. Prebiotics, probiotics, synbiotics in surgery--are they only trendy, truly effective or even dangerous? Langenbecks Arch Surg 2009;394:547-555.

23. Muscedere J, Dodek P, Keenan S, Fowler R, Cook D, Heyland D. Comprehensive evidence-based clinical practice guidelines for ventilator-associated pneumonia: prevention. J Crit Care 2008;23: 126-137.

24. Wip C, Napolitano L. Bundles to prevent ventilator-associated pneumonia: how valuable are they? Curr Opin Infect Dis 2009;22:159-166.

25. Babcock HM, Zack JE, Garrison T, Trovillion E, Jones M, Fraser VJ, Kollef MH. An educational intervention to reduce ventilator-associated pneumonia in an integrated health system: a comparison of effects. Chest 2004;125:2224-2231. 
Summary 
108 


\section{Infection prevention in Intensive Care patients: probiotics compared to antibiotics}

In chapter 1 the most important modalities for prevention of nosocomial infections in Intensive Care Unit (ICU) patients are described, i.e. selective digestive tract decontamination (SDD) and probiotics.

SDD has been used ever since its first successful introduction in Intensive Care medicine in the early 1980s. Its aim is to eliminate potentially pathogenic microorganisms (PPMs) from the upper and lower gastrointestinal tract and oropharynx with antibiotics to prevent infections, while leaving the indigenous anaerobic bacteria intact. It has never been implemented worldwide as intervention, due to a lack of consensus on efficacy with regard to infectious events (e.g. ventilatorassociated pneumonia (VAP)) and mortality, and the issue of emergence and/or selection of antimicrobial resistance. However, a reduction in mortality with SDD has recently been shown. Conflicting reports are available on antibiotic resistance. SDD should probably not be used in settings with endemic levels of resistance, i.e. methicillin-resistant $S$. aureus or vancomycin-resistant enterococci. Another important parameter is the composition of the applied SDD regimen. Efforts are currently being made to elucidate these issues.

Probiotics, live microorganisms, which confer a health benefit on the host, aim at reducing colonisation and overgrowth of the intestine by PPMs, consequently reducing translocation of microbes and toxins. Probiotics are already used for treatment or prevention of antibiotic-associated diarrhoea. During the last ten years, reports have been published on application of probiotics for infection prevention in surgical patients and patients with pancreatitis. Probiotics do not carry the risk of emergence of antibiotic resistance. However, the question is whether probiotics are effective in critically ill ICU patients. Moreover, questions regarding the safety of probiotics have recently arisen.

Chapter 2 describes the trends in antimicrobial resistance among $E$. coli and $P$. aeruginosa clinical isolates from Dutch ICUs during an eight-year period. An increase in resistance to most antibiotics was shown, although resistance levels were still low compared to other countries. The lower rates are probably a consequence of the prudent use of antibiotics in The Netherlands. However, multi-drug resistance among $E$. coli has already been established. The observations made in this study emphasise the value of surveillance programmes. Knowledge of (trends in) local antibiotic resistance data is vital for an optimal antibiotic policy to control the antibiotic resistance issue.

In chapter 3 we present the retrospective analysis of the usefulness of soluble Triggering Receptor Expressed on Myeloid cells-1 (sTREM-1) in bronchoalveolar lavage 
fluid for the diagnosis microbiologically confirmed VAP. Although the mean STREM-1 concentration was significantly higher in the confirmed VAP group than in the group without confirmed VAP, this diagnostic marker turned out not to be discriminative for VAP in a mixed ICU patient population. This result was contradictory to conclusions of previous studies and could be caused by technical and diagnostic differences as well as size and composition of the study populations.

Chapter 4 shows that a clinical trial, comparing the use of SDD to that of the probiotic L. plantarum 299/299v and fibre for prevention of ICU-acquired infections, did not succeed in demonstrating non-inferiority of this probiotic. This was very likely due to the premature ending of the study as a safety precaution after a report of increased mortality risk with (multi-species) probiotic use. No increased ICU mortality risk could be demonstrated in the present study. However, with regard to infection prevention, the probiotic strain seemed inferior to SDD. Despite changes in bacterial ecology, no increase in antimicrobial resistance was found with either intervention.

Chapter 5 discusses the prevalence of antibiotic resistance among $E$. coli cultured from both rectal surveillance and clinical samples in ICU patients receiving either SDD or probiotics. Amoxicillin and co-amoxiclav resistance significantly increased after start of prophylaxis and during follow-up in the probiotics group. In the SDD group however, no significantly increased resistance of $E$. coli to the antibiotics tested was found. A possible relationship with co-amoxiclav use could be established in the probiotics group. Length of hospital stay was shown to be independently associated with emergence of co-amoxiclav resistance. The use of cefotaxime in the SDD group did not cause emergence of extended-spectrum beta-lactamase (ESBL)-producing E. coli.

A randomly amplified polymorphic DNA (RAPD) analysis was applied to establish the presence of L. plantarum 299/299v in rectal swabs from ICU patients receiving this probiotic strain (chapter 6). Probiotic carriage was only detected in a minority of patients. The acquired infection rate and mortality rates were not significantly different between the groups with and without rectal carriage. In the group with proven carriage, significantly more patients had persistent rectal colonisation with E. coli. We were therefore not able to confirm the hypothesised sequence of intestinal colonisation with L. plantarum 299/299v, subsequent change in PPM colonisation and lower nosocomial infection or mortality rates in ICU patients.

In summary, the studies described in this thesis explore the usefulness and feasibility of a rapid diagnostic test and compare the effect of two preventive interventions on infections and mortality in the ICU setting. The ICU is an environment which faces the challenges of increasing levels of antimicrobial resistance. Moreover, the 
consequences of the interventions as well as possible drawbacks were discussed (chapter 7).

The main findings were:

- An increase in resistance to most tested antibiotics was observed among E. coli and $P$. aeruginosa isolates in Dutch ICUs between 1998 and 2005

- Determination of STREM-1 in bronchoalveolar lavage fluid was not useful for diagnosing VAP in medical/surgical ICU patients

- The probiotic L. plantarum 299/299v might have been inferior to SDD with regard to preventing infectious events

- No increased risk of mortality could be demonstrated with this probiotic

- Among patients using L. plantarum 299/299v, E. coli amoxicillin and co-amoxiclav resistance significantly increased, possibly related to more co-amoxiclav use

- Among patients using SDD, neither significantly increased antibiotic resistance of E. coli was observed, nor emergence of ESBL

- Rectal colonisation with L. plantarum $299 / 299 \mathrm{v}$ could only be detected in $25 \%$ of patients

- The hypothesis that intestinal colonisation with L. plantarum 299/299v decreases PPM colonisation and thus lowers nosocomial infection or mortality rates could not be validated 

Samenvatting 
114 


\section{Infectiepreventie bij Intensive Care patiënten:}

\section{probiotica vergeleken met antibiotica}

In hoofdstuk 1 zijn de belangrijkste modaliteiten voor preventie van nosocomiale infecties bij Intensive Care (IC) patiënten beschreven, dat wil zeggen selectieve decontaminatie van het maag-darmkanaal (SDD) en probiotica.

SDD is al in gebruik sinds de eerste succesvolle toepassing op een Intensive Care in het begin van de jaren tachtig. Het doel van SDD is om met antibiotica potentieel pathogene micro-organismen (PPM's) te verwijderen uit het bovenste en onderste deel van het maag-darmkanaal en de mond-keelholte, om zo infecties te voorkomen. De van nature aanwezige anaerobe bacteriën in de darm moeten hierbij ongemoeid worden gelaten. SDD is echter nooit wereldwijd geaccepteerd als interventie, door een gebrek aan consensus over effectiviteit ten aanzien van infecties (zoals ventilatorgeassocieerde pneumonie (VAP)) en mortaliteit, alsook het probleem van ontwikkeling en/of selectie van antimicrobiële resistentie. Echter, er is wel recent aangetoond dat SDD mortaliteit reduceert. Er zijn tegenstrijdige berichten over antibioticaresistentie. Wellicht is SDD niet te gebruiken in een omgeving met endemische resistentie niveaus, zoals van methicilline-resistente $S$. aureus en vancomycine-resistente enterococcen. Een andere belangrijke parameter is de samenstelling van het toegepaste SDD regime. Momenteel worden er inspanningen geleverd om deze zaken op te helderen.

Probiotica zijn levende micro-organismen die een gezondheidsvoordeel voor de gastheer bewerkstelligen. Ze hebben als doel het reduceren van kolonisatie van en overgroei in de darm door PPM's. Hierdoor wordt translocatie van microben en toxines ook gereduceerd. Probiotica worden al gebruikt bij behandeling en preventie van antibiotica-geassocieerde diarree. In de laatste 10 jaar is er ook gepubliceerd over infectiepreventie met probiotica bij chirurgische patiënten en patiënten met pancreatitis. Probiotica hebben niet het risico van resistentie ontwikkeling. Het is echter maar de vraag of ze werkelijk effectief zijn tegen infecties bij ernstig zieke IC patiënten. Tevens is er recent het vraagstuk van veiligheid van probiotica bijgekomen.

Hoofdstuk 2 beschrijft de trends in antimicrobiële resistentie bij klinische $E$. coli en $P$. aeruginosa isolaten van Nederlandse IC's gedurende een periode van acht jaar. Een toename in resistentie tegen de meeste antibiotica werd aangetoond, hoewel resistentieniveaus nog steeds lager waren vergeleken met andere landen. De lagere cijfers zijn waarschijnlijk een gevolg van het meer beperkte antibioticagebruik in Nederland. Echter, "multi-drug" resistentie kon reeds worden vastgesteld bij $E$. coli. De waarnemingen gedaan in deze studie benadrukken de waarde van resistentie surveillance programma's. Kennis van (trends in) lokale antibioticaresistentie cijfers is van vitaal belang voor een optimaal antibioticabeleid om het antibioticaresistentie vraagstuk onder controle te houden. 
In hoofdstuk 3 presenteren we de retrospectieve analyse van de bruikbaarheid van "soluble Triggering Receptor Expressed on Myeloid cells-1" (sTREM-1) in bronchoalveolaire lavage vloeistof voor de diagnose van microbiologisch bewezen VAP. Hoewel de gemiddelde STREM-1 concentratie in de bewezen VAP groep significant hoger was dan in de groep zonder bewezen VAP, bleek deze diagnostische marker niet onderscheidend voor VAP in een gemengde IC patiëntenpopulatie. Dit resultaat was tegenstrijdig aan conclusies van eerdere studies en kan worden veroorzaakt door zowel technische en diagnostische verschillen als grootte en samenstelling van de studiepopulaties.

Hoofdstuk 4 laat zien dat een klinische studie, die SDD vergeleek met het probioticum L. plantarum 299/299v en vezels voor de preventie van op IC verkregen infecties, er niet in slaagde om non-inferioriteit van het probioticum aan te tonen. Dit werd zeer waarschijnlijk veroorzaakt door het premature einde van de studie als een veiligheidsmaatregel na een rapport over een toegenomen mortaliteitsrisico bij gebruik van (multi-species) probiotica. Er kon geen verhoogd IC mortaliteitsrisico worden aangetoond in de huidige studie. Echter, de probioticum stam leek inferieur aan SDD met betrekking tot infectiepreventie. Ondanks veranderingen in bacteriële ecologie, werd geen toename in antimicrobiële resistentie gevonden bij beide interventies.

Hoofdstuk 5 bediscussieert de prevalentie van antibioticaresistentie bij $E$. coli geïsoleerd uit zowel rectale surveillance kweken als klinische kweken van IC patiënten die SDD of probiotica kregen. Amoxicilline en co-amoxiclav resistentie namen significant toe in de probiotica groep na het starten van de prophylaxe en gedurende follow-up. In de SDD groep werd bij E. coli echter geen significant toegenomen resistentie tegen de geteste antibiotica gevonden. Een mogelijke relatie met coamoxiclav gebruik kon worden vastgesteld in de probiotica groep. Duur van ziekenhuisopname was onafhankelijk geassocieerd met het ontstaan van co-amoxiclav resistentie. Het gebruik van cefotaxime in de SDD groep veroorzaakte geen ontstaan van extended-spectrum beta-lactamase (ESBL)-producerende $E$. coli.

Een "randomly amplified polymorphic DNA" (RAPD) analyse werd toegepast om de aanwezigheid vast te stellen van L. plantarum 299/299v in rectale kweken van IC patiënten die deze probioticum stam ontvingen (hoofdstuk 6). Aanwezigheid van het probioticum kon slechts bij een minderheid van de patiënten worden vastgesteld. De infectie- en mortaliteitscijfers waren niet significant verschillend tussen de groepen met en zonder aanwezigheid in het rectum. In de groep met bewezen aanwezigheid hadden significant meer patiënten persisterende rectale kolonisatie met $E$. coli. We waren daardoor niet in staat om de hypothetische reeks te bevestigen van 
darmkolonisatie met L. plantarum 299/299v, de daaropvolgende veranderingen in kolonisatie met PPM's en lagere infectie- en mortaliteitscijfers bij IC patiënten.

Samenvattend, verkennen de studies beschreven in dit proefschrift het nut en de uitvoerbaarheid van een snelle diagnostische test en vergelijken ze het effect van twee preventieve interventies op infecties en mortaliteit in een IC omgeving. De IC is een milieu dat zich gesteld ziet voor uitdagingen van toenemende antimicrobiële resistentie. Tevens werden de consequenties alsook mogelijke keerzijdes van de interventies bediscussieerd (hoofdstuk 7).

De belangrijkste bevindingen waren:

- Een toename in resistentie tegen de meeste geteste antibiotica werd waargenomen bij $E$. coli en $P$. aeruginosa isolaten van Nederlandse IC's tussen 1998 en 2005

- Bepaling van STREM-1 in bronchoalveolaire lavage vloeistof was niet bruikbaar voor het diagnosticeren van VAP bij medische/chirurgische IC patiënten

- Het probioticum L. plantarum 299/299v zou inferieur geweest kunnen zijn aan SDD met betrekking tot preventie van infecties

- $\quad$ Er kon geen toegenomen risico op mortaliteit worden aangetoond met dit probioticum

- $\quad$ Bij patiënten die L. plantarum 299/299v gebruikten, nam de resistentie van E. coli tegen amoxicilline en co-amoxiclav significant toe, mogelijk gerelateerd aan meer co-amoxiclav gebruik

- Bij patiënten die SDD gebruikten, werd noch een significante toename van antibioticaresistentie bij $E$. coli, noch de opkomst van ESBL waargenomen

- Rectale kolonisatie met L. plantarum 299/299v kon slechts bij 25\% van de patiënten worden aangetoond

- De hypothese dat darmkolonisatie met L. plantarum 299/299v de PPM kolonisatie doet afnemen en aldus nosocomiale infecties en mortaliteit verlaagt, kon niet worden bevestigd 



\section{Dankwoord}


120 
Maastricht, 17 februari 2012

Een promotietraject is als een lantaarnpaal, lang en hard met aan het eind een lichtpuntje...Dit lichtpuntje zou niet zo groot zijn geweest als het nu is, zonder de hulp, inbreng, steun en belangstelling van een heleboel mensen. Zij krijgen hieronder dan ook de credits die ze mijns inziens verdienen. Het duurt even, het kost wat slapeloze nachten en wat lichaamsgewicht, maar dan heb je ook wat...

Mijn promotor, Prof. Bruggeman. Beste Cathrien, ik wil je bedanken voor het feit dat je altijd belangstelling had en hebt voor de voortgang van mijn onderzoek. Ook onze gesprekken over Nederlandse en Belgische politiek waardeer ik altijd zeer. Als je een Nederlands paspoort zou hebben, zou je D66 stemmen, dat weet ik zeker!

Mijn copromotor, Dr. Verbon. Beste Annelies, ook al werk je nu alweer twee jaar in Rotterdam, dank je wel dat je me altijd bent blijven aansporen om door te zetten en dat je er altijd voor me was, zeker op de momenten (24 januari 2008!) dat dat het hardst nodig was! Ik heb onze samenwerking altijd heel erg gewaardeerd en jouw soms verschillende invalshoeken zijn absoluut een meerwaarde gebleken!

Mijn copromotor, Dr. Stobberingh. Beste Ellen, ik ben je nog altijd dankbaar dat je me in 2002 tijdens de onderwijsgroep van blok 3.6 hebt gevraagd of ik als een soort student-assistent op de afdeling wilde komen werken en dat je me op die manier kennis hebt laten maken met de wereld van de microbiologie. Ook dank voor het feit dat je me altijd met beide beentjes op de grond houdt en dat je deur altijd openstaat bij vragen of problemen!

Ook de leden van de beoordelingscommissie en promotiecommissie wil ik hartelijk danken voor hun bereidheid om mijn proefschrift te beoordelen en te bediscussiëren.

Een speciaal plekje verdienen alle patiënten en/of hun naasten die toestemming hebben gegeven voor deelname aan het onderzoek. Zonder de informatie die dit opleverde, zou dit proefschrift er niet geweest zijn.

De collega's van het lab bacteriologie research. Het lab staat onder de bezielende leiding van chef Christel en souschef Jacqueline $M$, met door de jaren heen hulp van een hele batterij hulp- en leerling-koks. In volstrekt willekeurige volgorde: Miranda SN, Silvie, Siebe, Karina, Rachida, Hanne, Arrianne, Sara, Clemy, Maaike, Geert, MarieLouise, Nathalie, Elton, Resi, Jacqueline P, Bram en Mayk. Er worden, onder het motto "poep is ons beroep" of "een dag niet geswabd is een dag niet geleefd", bergen werk verzet om allerlei studies, van (heel) groot tot klein, tot een goed einde te brengen. Zo ook de mijne, waarvoor uit de grond van mijn hart duizendmaal dank! 
Een trial is niets en wordt niets zonder een goede researchnurse. Ik was zo gelukkig om de hulp van twee verpleegkundigen te hebben, één in Maastricht en één in Heerlen. Miranda H-L en Laura B-R, zonder jullie tomeloze inzet zouden we nooit zoveel patiënten hebben geïncludeerd in de PONI trial! Heel erg bedankt voor al jullie hulp, in welke vorm dan ook, om van de trial een succes te maken!

Om resultaten te verkrijgen en daaruit conclusies te kunnen trekken, heb je data nodig. Als die data verstopt zitten in een niet erg toegankelijk systeem (wat is dat toch met Philips informatiesystemen?!), heb je de hulp van een ervaren ICT'er nodig. Jerry, zonder de resultaten van jouw niet aflatende zoektocht naar gegevens van patiënten die vermeld stonden op mijn inmiddels beruchte lijstjes, zou ik hier vandaag wellicht niet staan. Ik ben je er eeuwig dankbaar voor!

In de loop van de jaren is het research gedeelte van de afdeling Medische Microbiologie ook qua bezetting dynamisch gebleken. Ik wil dan ook een hele batterij aan (ex-) collega's en stagiaires bedanken: Ruud (God), Sita, Ellen Bo, Koen, Karen, Suzanne K, Hilde, Martijn, Daisy, Dominique, Kees, Patrick, Erik, Gert, Servaas, Sander O, Frank S, John, Sander C, Judith, Wendy, Giel, Tanja, Ellen Br, Marijke, Michelle, Amita, Christel van der D, Laura de R, Raymond, Marieke, Tim, Thijs, Bart, Maarten, Geoffrey, Fahad, Casper, Margriet, Fleur, Kris.

De laatste jaren werk ik echter aan de "diagnostiek kant" van de afdeling. Ik wil dan ook mijn opleiders en overige stafleden bedanken voor hun kennis, geduld, gezelligheid en steun: Frank van Tiel, Valère Goossens, Kitty (koffie?) Linssen, Helke van Dessel, Inge van Loo, Petra Wolffs, Antoinette Brink, Selwyn "tropische verrassing" Lowe en Astrid Oude Lashof. Ook de oud-stafleden en oud-assistenten Peter Croughs, Foekje Stelma, Laura van Dommelen, Steve de Jager, Suzanne DumontLutgens en Yvonne Soethoudt mogen in dezen niet ontbreken.

Alle analisten bacteriologie (lekker hè, dubbel intens!), virologie, moleculaire diagnostiek en de ZIP collega's: bedankt voor alle leerzame en gezellige momenten.

Tegen mijn huidige collega-assistenten, de overige "ridders van de vuile kweek" Michiel, Robin en Vishal zou ik willen zeggen: ik kan me geen betere kamergenoten wensen! Misschien maar goed dat "the old boys network" binnenkort wat vrouwelijke inbreng krijgt...

Onderzoek doe je niet alleen op je eigen vertrouwde afdeling, maar ook andere collega's zijn van onschatbare waarde. Om te beginnen natuurlijk de verpleegkundigen, assistenten, fellows en staf van de IC's in Maastricht en Heerlen die geholpen hebben met de inclusies, medicatietoediening en kweekafnames.

In dit kader wil ik graag speciaal noemen Dr. Dennis Bergmans, Prof. Jan-Harm Zwaveling en Dr. Tom Dormans, die ook bij de opzet en latere fases van het onderzoek betrokken zijn geweest. 
Op het gebied van statistiek en methodologie ben ik enorm goed gesteund door Fons Kessels (binnenkort gaan we goed uit eten, beloofd!) en Prof. Martin Prins. Op de eigen afdeling kon ik hiervoor ook altijd terecht bij Peter Terporten.

De SDD drank en mondpasta werden bereid, opgeslagen en uitgegeven bij de apotheek van het azM. Francis, Ed en collega's: dank!

Probi $A B$, Gunilla and colleagues: thank you very much for providing us with the probiotic study product, performing the RAPD analyses and for your critical appraisal of the manuscripts!

Yvonne Beeuwkes en Prof. Mieke Hoogkamp zijn erg behulpzaam geweest bij het aanleveren van de landelijke resistentiedata van de IC.

Op het moment dat "de PONI" door zijn hoeven was gezakt in 2008, hebben de volgende mensen geholpen om hem weer overeind te krijgen: Els Jahae, Miem Castermans, Jos van Cann en Liz Tans, enorm bedankt voor jullie hulp en ondersteuning tijdens dit proces!

Naast mijn "dagelijkse bezigheden" ben ik ook al vele jaren met enorm veel plezier lid van de commissie Professioneel Gedrag van de geneeskundeopleiding. Ik wil de overige leden Walther, Marleen, Marij, Sophie en Niek en de oud-leden Scheltus, Erik, Ron, Marre en Karlijn dan ook danken voor de meer dan plezierige samenwerking bij het begeleiden van de studenten.

Tiny Wouters, ik vind het een eer om met mijn proefschrift tussen de minstens vijf meter aan proefschriften te staan, waarvan je eerder de lay-out hebt verzorgd. Onbegrijpelijk dat men nog geen standbeeld voor je heeft opgericht, ik had het zelf immers nooit zo gedetailleerd kunnen afwerken!

Roger Haan, super dat je me zo goed aanvoelde bij het ontwerpen van de kaft! Al bij een van de eerste ontwerpen was het raak, top! Met recht een waardige en mooi symbolische omlijsting van dit proefschrift. Ik hoop dat we samen met onze wederhelften nog veel gezellige borrelavondjes en etentjes tegemoet gaan!

Mijn paranimfen Marcel en Walther.

Marcel, poes, we hebben al heel wat mooie, hilarische, bizarre en bijzondere momenten meegemaakt de afgelopen 12 jaar. En ook al woon je tegenwoordig wat verder weg met Carolina en de kids, ik hoop dat we deze momenten zullen blijven beleven. Dank dat je ook vandaag (letterlijk) achter me staat bij weer een bijzonder moment! 
Walther, aangezien we al heel wat jaren verbazingwekkend vaak op dezelfde golflengte zitten, vind ik het dan ook niet meer dan logisch dat ik je gevraagd heb om me samen met Marcel bij te staan tijdens deze dag. Ik weet zeker dat het je gaat lukken om de spanning op de juiste momenten te breken. Alles is geoorloofd, zolang het maar professioneel blijft!

Als je onderzoek doen en schrijven wilt volhouden, is ontspanning op zijn tijd geen overbodige luxe. Hiervoor zorgden met enige regelmaat mijn vrienden, D66 collega's, schoonfamilie en familie. Dank jullie wel allemaal voor de broodnodige afleiding in de vorm van etentjes, borrels, theaterbezoek en ander vertier!

Noëlle, Benedict, Maximilian en Luca. Jammer dat we elkaar zo weinig zien omdat we zover uit elkaar wonen. Maar op de belangrijke momenten zijn we er voor elkaar. Zoals vandaag, super dat jullie er bij zijn!

Mijn ouders. Lieve pap en mam, ik ben jullie ontzettend dankbaar dat jullie mij de afgelopen 30 jaar altijd de mogelijkheid en de vrijheid hebben gegeven om me te blijven ontwikkelen. Het resultaat, dit boekje, is dan ook een beetje van jullie...De opbeurende kaartjes, telefoontjes en gesprekken hebben er mede voor gezorgd dat de grote dag eindelijk daar is.

De allerlaatste woorden wil ik richten tot de allerliefste van de hele wereld. Dionne, je weet niet half hoeveel het voor me betekent dat je er de afgelopen jaren altijd voor me geweest bent, zeker op de aller-moeilijkste momenten in 2008, en dat je er nooit een probleem van maakte als ik weer eens laat thuiskwam, moest schrijven of naar het ziekenhuis moest. Dank voor je geduld en alle last die je van mijn schouders hebt gehaald. De weekenden zijn nu weer van ons, en ik hoop dat er voor ons samen nog heel veel gaan komen! Nu eerst maar eens lekker op vakantie, we hebben het verdiend...

Zo, dan is nu het moment gekomen om er een hele dikke streep onder te zetten. 
Curriculum vitae 
126 
Guy Joseph Alphonse Pierre Marie Oudhuis werd geboren te Roosendaal op 11 april 1981. Hij groeide ook op in deze plaats en doorliep er van 1993 tot 1999 het Gymnasium van het Gertrudislyceum (vanaf 1995 Gertrudiscollege). Na zijn eindexamen in 1999 verhuisde hij naar Maastricht om er vanaf september van dat jaar aan de Universiteit Maastricht de opleiding Geneeskunde te volgen. In 2002 kwam hij voor het eerst in contact met Dr. Ellen Stobberingh, verbonden aan de afdeling Medische Microbiologie van het academisch ziekenhuis Maastricht (azM), tijdens een door haar begeleide onderwijsgroep in het kader van het toenmalige blok 3.6 infectieziekten. Door deze contacten werd in 2003 in het kader van de coschappen een wetenschapsstage gevolgd op bovengenoemde afdeling onder begeleiding van Dr. Stobberingh en Ruud Deurenberg met als onderwerp genetische achtergronden van MRSA isolaten in de Euregio. Op 27 oktober 2003 behaalde hij het doctoraal examen Geneeskunde met het predicaat Cum Laude. Nog tijdens zijn coschappen werd hij gevraagd om per 1 april 2005 te starten met een promotieonderzoek op de afdeling Medische Microbiologie, onder begeleiding van Dr. Annelies Verbon en Dr. Ellen Stobberingh. Het onderwerp was the use of selective antibiotic decontamination of the digestive tract compared to the use of live lactobacilli to prevent hospitalacquired infections in Intensive Care patients. Na een onderbreking van de opleiding van bijna 1,5 jaar werden de coschappen hervat en werd op 27 november 2006 het artsdiploma behaald met het predicaat Cum Laude. Sinds 1 april 2009 is hij in opleiding tot arts-microbioloog in het azM met als opleiders Dr. Frank van Tiel en Dr. Valère Goossens. Hij is nog steeds woonachtig in Maastricht en woont er samen met zijn lieftallige vriendin Dionne van Opbergen. 

List of publications 
130 
Deurenberg RH, Vink C, Oudhuis GJ, Mooij JE, Driessen C, Coppens G, Craeghs J, De Brauwer E, Lemmen S, Wagenvoort H, Friedrich AW, Scheres J, Stobberingh EE. Different clonal complexes of methicillin-resistant Staphylococcus aureus are disseminated in the Euregio Meuse-Rhine region. Antimicrob Agents Chemother 2005;49:4263-4271.

Van Mook WNKA, Van Luijk SJ, Oudhuis GJAPM, Gulikers MTH, Schuwirth LW, Van der Vleuten CPM. Professioneel gedrag in de opleiding geneeskunde. Tijdschrift voor Medisch Onderwijs 2007;26:174-183.

Van Mook WNKA, Van Luijk SJ, Fey-Schoenmakers MJG, Oudhuis GJAPM, Gulikers MTH, Schuwirth LW, Van der Vleuten CPM. Bespreking en beoordeling van professioneel gedrag aan de faculteit Geneeskunde te Maastricht. Tijdschrift voor Medisch Onderwijs 2007;26:237-246.

Oudhuis GJ, Verbon A, Hoogkamp-Korstanje JAA, Stobberingh EE, The Susceptibility Surveillance Study Group. Antimicrobial resistance in Escherichia coli and Pseudomonas aeruginosa from Intensive Care Units in The Netherlands, 1998-2005. Int J Antimicrob Agents 2008;31:58-63.

Oudhuis GJ, Beuving J, Bergmans D, Stobberingh EE, Ten Velde G, Linssen CF, Verbon A. Soluble Triggering Receptor Expressed on Myeloid cells-1 in bronchoalveolar lavage fluid is not predictive for ventilatorassociated pneumonia. Intensive Care Med 2009;35:1265-1270.

Oudhuis GJ, Verbon A. Reply to Gibot. Intensive Care Med 2009;35:1545-1546.

Rijnders M, Nys S, Driessen C, Hoebe C, Hopstaken R, Oudhuis GJ, Timmermans A, Stobberingh EE. Staphylococcus aureus carriage among General Practitioners in The Netherlands. Brit J Gen Pract 2010;60:902-906.

Oudhuis GJ, Bergmans DC, Dormans T, Zwaveling JH, Kessels A, Prins MH, Stobberingh EE, Verbon A. Probiotics versus antibiotic decontamination of the digestive tract: infection and mortality. Intensive Care Med 2011;37:110-117.

Oudhuis GJ, Bergmans DC, Stobberingh EE, Verbon A. Reply to Petros et al.: gut overgrowth harms the critically ill. Intensive Care Med 2011;37:1561-1562.

Oudhuis GJ, Bergmans DCJJ, Verbon A. Probiotics for prevention of nosocomial infections: efficacy and adverse effects. Curr Opin Crit Care 2011;17:487-492. 

List of abbreviations 
134 


\begin{tabular}{|c|c|}
\hline AMC & co-amoxiclav \\
\hline APACHE II & acute physiology and chronic health evaluation II \\
\hline ATC & anatomical therapeutic chemical \\
\hline BAL & bronchoalveolar lavage \\
\hline BALF & bronchoalveolar lavage fluid \\
\hline BMI & body mass index \\
\hline BSI & bloodstream infection \\
\hline CAP & community-acquired pneumonia \\
\hline $\mathrm{CDC}$ & Centers for Disease Control and Prevention \\
\hline cfu & colony forming units \\
\hline $\mathrm{Cl}$ & confidence interval \\
\hline CLSI & clinical and laboratory standards institute \\
\hline CNS & coagulase-negative staphylococci \\
\hline co-amoxiclav & amoxicillin-clavulanic acid \\
\hline COPD & chronic obstructive pulmonary disease \\
\hline DDD & defined daily doses \\
\hline ELF & epithelial lining fluid \\
\hline ELISA & enzyme-linked immunosorbent assay \\
\hline ESBL & extended-spectrum beta-lactamase \\
\hline GI & gastrointestinal \\
\hline HAl & hospital-acquired infection \\
\hline ICO & intracellular organisms \\
\hline ICU & intensive care unit \\
\hline LAB & L. plantarum $299 / 299 v$ plus fibre \\
\hline LAMVAB & Lactobacillus anaerobic MRS with vancomycin and bromocresol green \\
\hline LOS & length of stay \\
\hline MDR & multi-drug resistant \\
\hline MIC & minimal inhibitory concentration \\
\hline MRSA & methicillin-resistant S. aureus \\
\hline MV & mechanical ventilation \\
\hline NPV & negative predictive value \\
\hline NS & not significant \\
\hline OR & odds ratio \\
\hline PFGE & pulsed field gel electrophoresis \\
\hline PPI & proton pump inhibitor \\
\hline PPM & potentially pathogenic microorganism \\
\hline PPV & positive predictive value \\
\hline PTA & polymyxin $\mathrm{E}$, tobramycin, amphotericin $\mathrm{B}$ \\
\hline RAPD & randomly amplified polymorphic DNA \\
\hline RCT & randomised controlled trial \\
\hline ROC & receiver operating characteristic \\
\hline $\mathrm{RR}$ & relative risk \\
\hline
\end{tabular}


RT respiratory tract

RTI respiratory tract infection

SDD selective digestive tract decontamination

SOD selective oropharyngeal decontamination

STREM-1 soluble Triggering Receptor Expressed on Myeloid cells-1

UTI urinary tract infection

VAP ventilator-associated pneumonia

VRE vancomycin-resistant enterococci 
The house is rockin', don't bother knockin', come on in.

Stevie Ray Vaughan (1954-1990) 